TRABALHO DE GRADUAÇÃO

\title{
AVALIAÇÃO COMPARATIVA ENTRE DOIS INSTRUMENTOS DE MEDIÇÃO PARA ANÁLISE DA QUALIDADE DA ENERGIA ELÉTRICA
}

MARCOS DIEGO DE CASTRO SILVA

Publicação: ENE - 1/2010

Brasília, setembro de 2010

\section{UNIVERSIDADE DE BRASÍLIA}




\author{
UNIVERSIDADE DE BRASÍLIA \\ FACULDADE DE TECNOLOGIA \\ DEPARTAMENTO DE ENGENHARIA ELÉTRICA
}

\title{
AVALIAÇÃO COMPARATIVA ENTRE DOIS INSTRUMENTOS DE MEDIÇÃO PARA ANÁLISE DA QUALIDADE DA ENERGIA \\ ELÉTRICA
}

MARCOS DIEGO DE CASTRO SILVA

RELATÓRIO DE PROJETO FINAL SUBMETIDO AO DEPARTAMENTO DE ENGENHARIA ELÉTRICA DA FACULDADE DE TECNOLOGIA DA UNIVERSIDADE DE BRASÍLIA COMO PARTE DOS REQUISITOS NECESSÁRIOS PARA A OBTENÇÃO DO GRAU DE ENGENHEIRO ELETRICISTA.

APROVADO POR:

Prof. Anésio de Leles Ferreira Filho, (ENE-UnB)

(Orientador)

Prof. Rafael Amaral Shayani, (ENE-UnB)

(Examinador Interno)

Prof. Marcus Vinícius Borges Mendonça, (ENE-UnB)

(Examinador Interno)

BRASÍLIA/DF, 10 DE SETEMBRO DE 2010. 


\section{FICHA CATALOGRÁFICA}

\section{SILVA, MARCOS DIEGO DE CASTRO}

Avaliação Comparativa Entre Dois Instrumentos de Medição Para Análise da Qualidade da Energia Elétrica [Distrito Federal] 2010.

xi, 72p., 210 x 297 mm (ENE/FT/UnB, Engenheiro, Engenharia Elétrica, 2010).

Projeto Final de Graduação - Universidade de Brasília. Faculdade de Tecnologia.

Departamento de Engenharia Elétrica.
1. Instrumentos de Medição
2. Avaliação Comparativa

3. Qualidade da Energia Elétrica

I. ENE/FT/UnB

II. Título (série)

\section{REFERÊNCIA BIBLIOGRÁFICA}

SILVA, M. D. C. (2010). Avaliação Comparativa Entre Dois Instrumentos de Medição Para Análise da Qualidade da Energia Elétrica. Projeto Final de Graduação em Engenharia Elétrica, Publicação ENE - 1/10, Departamento de Engenharia Elétrica, Universidade de Brasília, Brasília, DF, 72p.

\section{CESSÃO DE DIREITOS}

AUTOR: Marcos Diego de Castro Silva ORIENTADOR: Anésio de Leles Ferreira Filho TíTULO: Avaliação Comparativa Entre Dois Instrumentos de Medição Para Análise da Qualidade da Energia Elétrica

GRAU: Engenheiro ANO: 2010

É concedida à Universidade de Brasília permissão para reproduzir cópias deste relatório de projeto final de graduação e para emprestar ou vender tais cópias somente para propósitos acadêmicos e científicos. $O$ autor e o orientador reservam outros direitos de publicação e nenhuma parte desse relatório de projeto final de graduação pode ser reproduzida sem autorização por escrito do autor e do orientador.

Marcos Diego de Castro Silva (AUTOR)

Anésio de Leles Ferreira Filho (ORIENTADOR) 


\section{AGRADECIMENTOS}

Primeiramente e acima de tudo a Deus, por sua graça e por ter me capacitado a chegar onde estou.

Aos meus pais, que me deram todo o suporte e condições necessárias à minha formação. A eles que sempre estiveram ao meu lado e dedicam suas vidas para oferecer o melhor a seus filhos.

Aos meus irmãos, que prezo tanto e os tenho como exemplo de vida. Por todo incentivo e ajuda na superação das dificuldades.

Ao Professor Anésio de Leles, cuja orientação foi fundamental para meu crescimento e interação com a área de qualidade da energia elétrica. Pela sua dedicação ao projeto e solicitude em ajudar sempre que necessário.

Aos professores e amigos Marcus Borges e Sandoval Menezes, integrantes do grupo de trabalho sobre qualidade da energia elétrica criado em 2009.

Aos professores Kleber Melo e Jorge Cormane, pelo auxílio no projeto.

Ao Clovis Simões e ao Wellington Guedes, em nome da empresa Spin Engenharia de Automação Ltda., pelo suporte oferecido e intermediação no empréstimo do medidor SEL-734, o qual foi utilizado no projeto.

Ao Renan Bernardes e Levi Santos, em nome da empresa Schweitzer Engineering Laboratories, Comercial Ltda., pela assistência prestada e pelo empréstimo do medidor SEL-734.

Ao Leandro Alves e ao Augusto dos Santos, em nome da empresa Metrum Equipamentos de Medição e Testes Ltda., por toda assistência prestada, de grande valia para a utilização do outro equipamento de medição utilizado no projeto, o ION 7600.

Aos demais professores do Departamento de Engenharia Elétrica da Universidade de Brasília, pela inestimável contribuição em minha formação acadêmica. 
Dedico este trabalho a Deus, a meus pais, Wilmondes e Narcisa e ao meus irmãos, Henrique e Tiago. 


\section{SUMÁRIO}

1 - INTRODUÇÃO

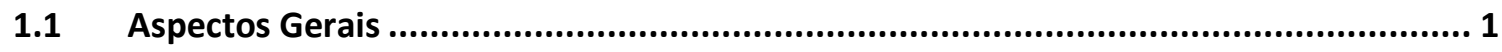

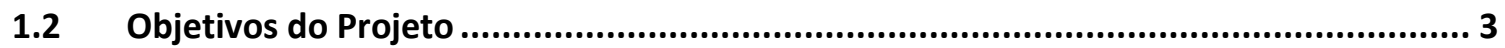

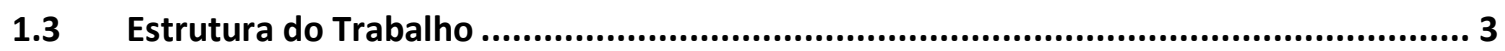

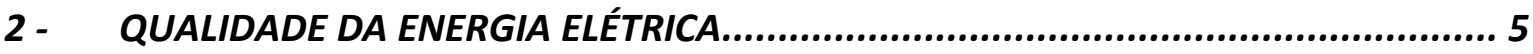

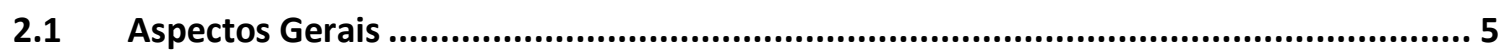

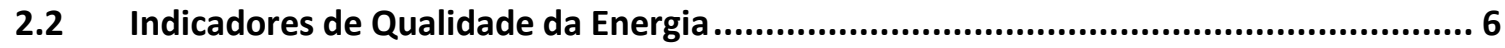

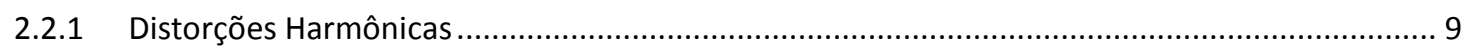

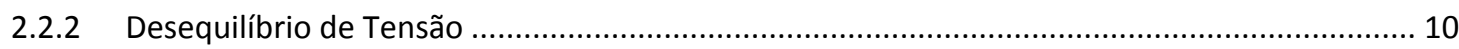

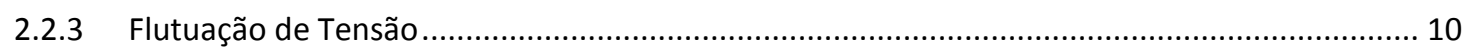

2.2.4 Variação de Tensão de Curta Duração (VTCD) ................................................................ 11

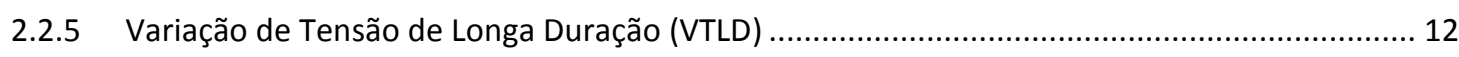

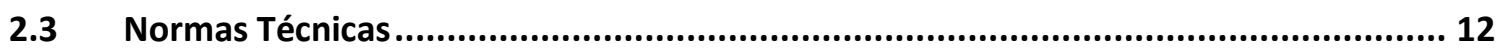

2.3.1 Normatizações e Legislações Brasileiras.............................................................................. 12

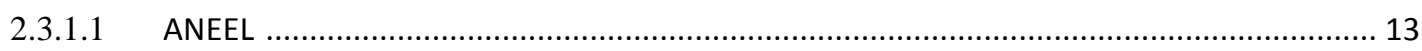

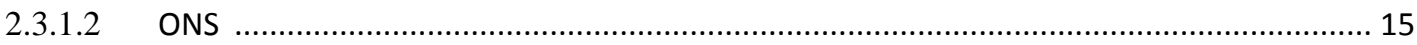

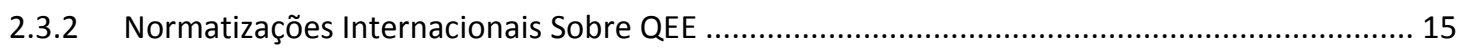

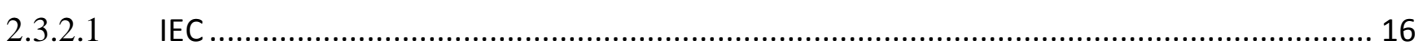

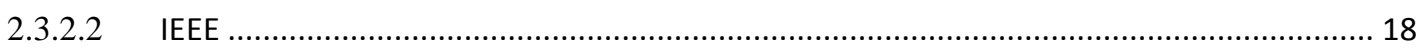

2.4 Monitoração da QEE e Protocolos de Medições ..................................................... 19

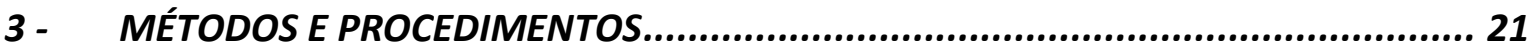

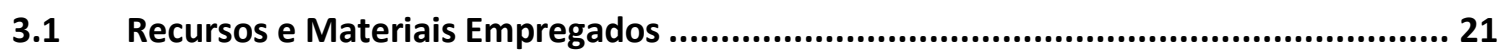

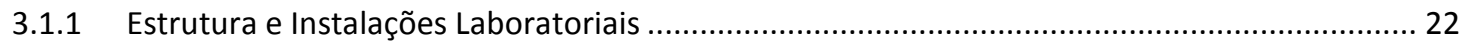

3.1.2 Características Gerais da Fonte de Distúrbios ............................................................... 23

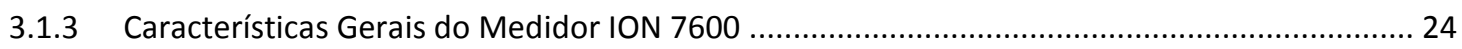

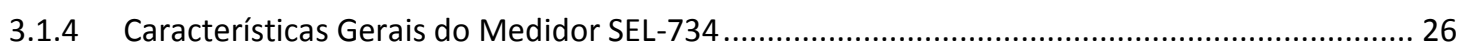

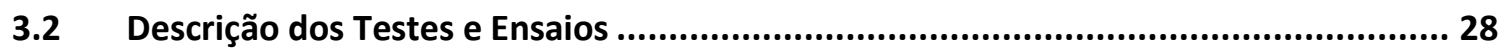

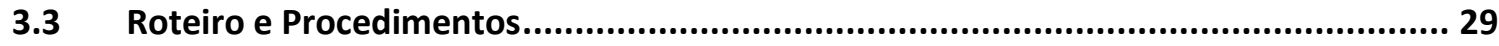

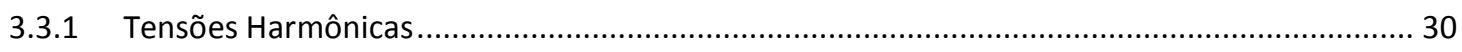

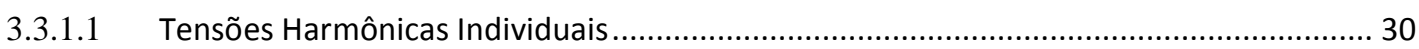

3.3.1.2 Composição de Harmônicas ..................................................................................... 30

3.3.1.3 Tensões Harmônicas com Diferentes Frequências ...................................................... 31

3.3.1.4 Tensões Harmônicas Individuais Variáveis ............................................................. 31

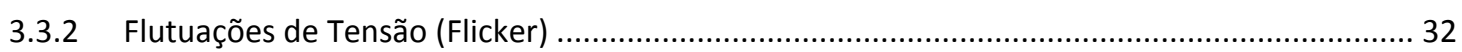




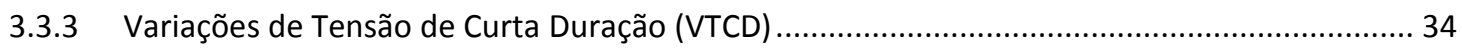

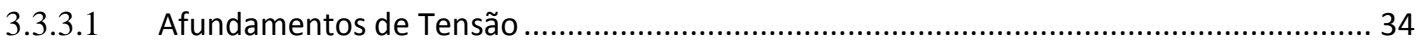

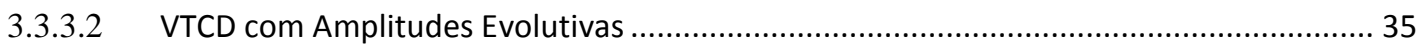

3.3.4 Variações de Tensão em Regime Permanente ................................................................... 35

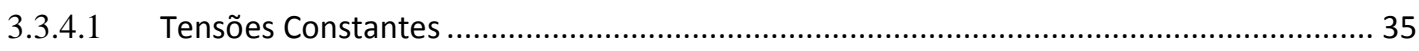

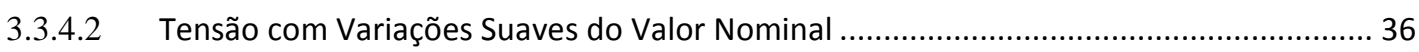

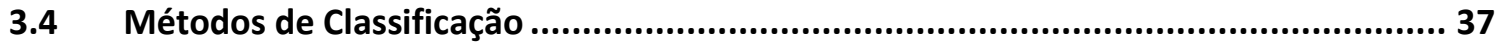

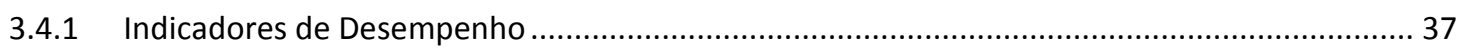

3.4.1.1 Capacidade de Medição das Grandezas .................................................................. 37

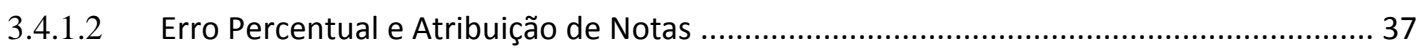

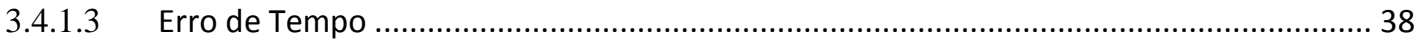

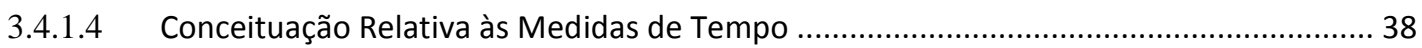

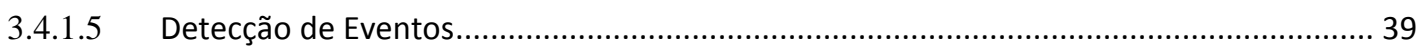

3.4.2 Tratamento Estatístico dos Indicadores de Desempenho ................................................... 39

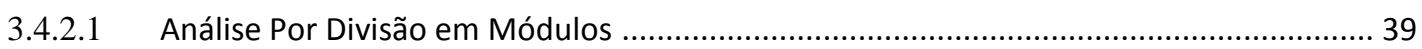

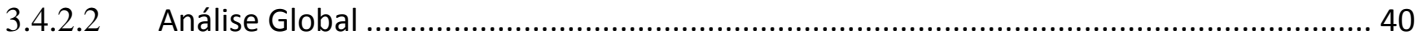

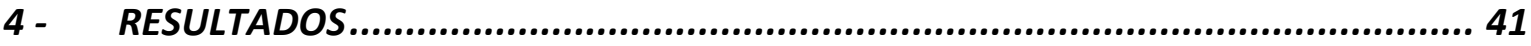

4.1 Avaliação e Resultados Individuais dos Ensaios........................................... 41

4.1.1 Tensões Harmônicas Individuais...................................................................................... 41

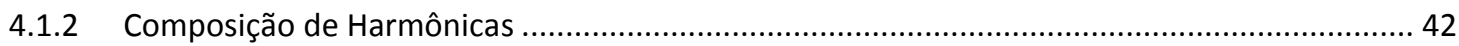

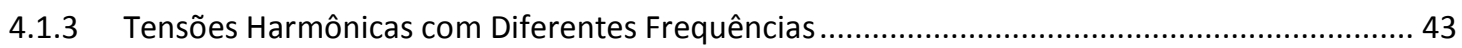

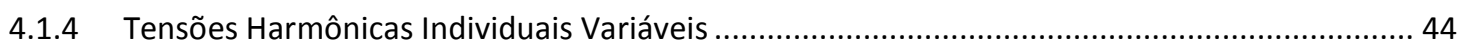

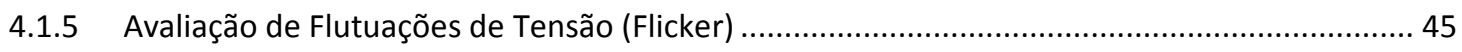

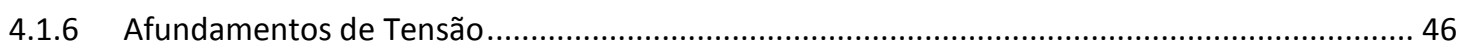

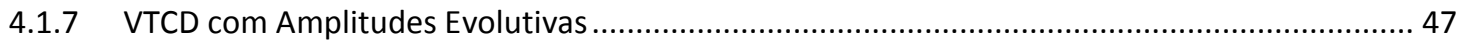

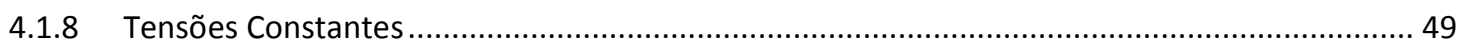

4.1.9 Tensão com Variações Suaves do Valor Nominal ................................................................. 49

4.2 Avaliação Por Divisão em Módulos ............................................................... 50

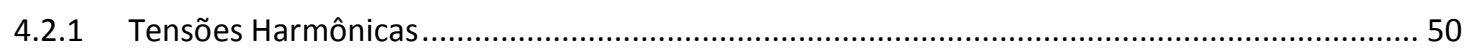

4.2.2 Flutuações De Tensão (Flicker) ................................................................................. 51

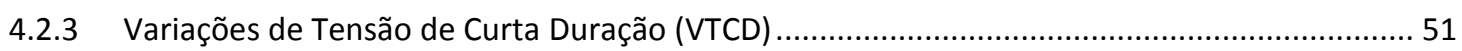

4.2.4 Variações de Tensão em Regime Permanente ................................................................ 52

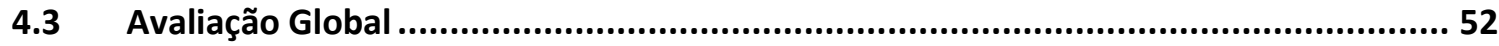

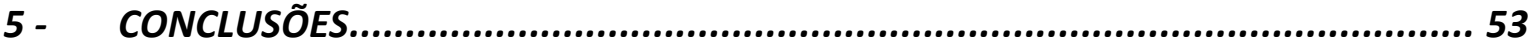

5.1 Conclusões e Observações Gerais ............................................................. 53

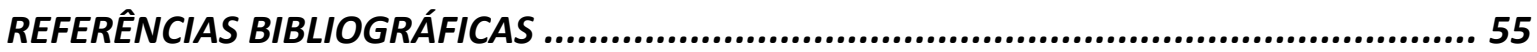


APÊNDICE.

A.1 Software e Manuseamento da Fonte de Distúrbios ................................................. 58

A.2 Programação e Recolhimento dos Dados com o ION 7600 ........................................6 63

A.3 Programação e Recolhimento dos Dados com o SEL-734 ..........................................69 


\section{LISTA DE TABELAS}

Tabela 2.1 - Classificação dos indicadores da QEE.................................................... 7

Tabela 2.2 - Resumo: causas, efeitos e propostas de soluções........................................ 8

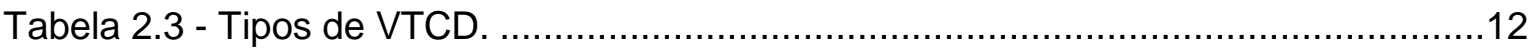

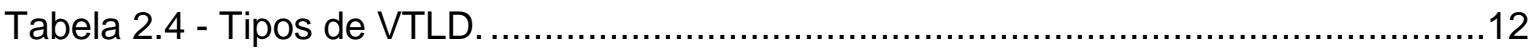

Tabela 3.1 - Relação Dispositivos e Softwares Empregados. .......................................21

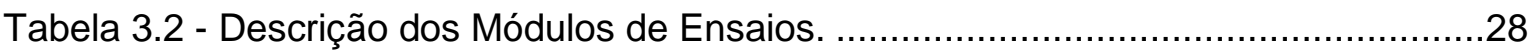

Tabela 3.3 - Ensaios de Harmônicas Individuais.............................................................30

Tabela 3.4 - Ensaio de Composição de Harmônicas.........................................................30

Tabela 3.5 - Ensaios de Harmônicas com Frequências Diferentes. ................................31

Tabela 3.6 - Ensaios com Harmônicas Variáveis. ...........................................................32

Tabela 3.7 - Especificação Para Teste de um Medidor de Flicker.....................................33

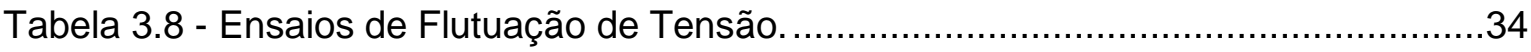

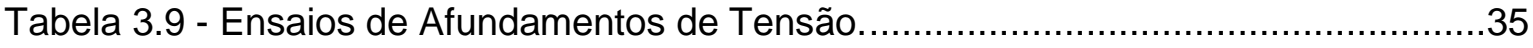

Tabela 3.10 - Ensaios de VTCD Com Amplitudes Evolutivas...........................................35

Tabela 3.11 - Ensaios com Tensões Constantes. ...........................................................36

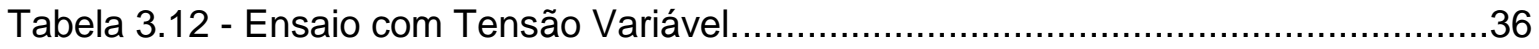

Tabela 3.13 - Correlação Erro Percentual e Nota de Desempenho..................................38

Tabela 3.14 - Conceito de Desempenho Para Medidas de Tempo. .................................38

Tabela 4.1 - Resultados de Harmônicas Individuais. ....................................................41

Tabela 4.2 - Notas de Harmônicas Individuais. ................................................................42

Tabela 4.3 - Características do Ensaio de Composição de Harmônicas. ..........................42

Tabela 4.4 - Resultados de Composição de Harmônicas................................................43

Tabela 4.5 - Notas de Composição de Harmônica. .......................................................43

Tabela 4.6 - Resultados de Tensões Harmônicas com Diferentes Frequências................43

Tabela 4.7 - Notas de Tensões Harmônicas com Diferentes Frequências.......................44

Tabela 4.8 - Resultados de Tensões Harmônicas Individuais Variáveis.............................44

Tabela 4.9 - Notas de Tensões Harmônicas Individuais Variáveis..................................45

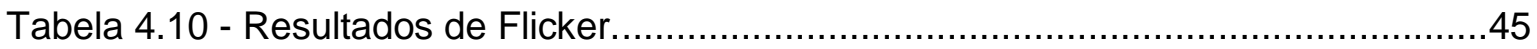

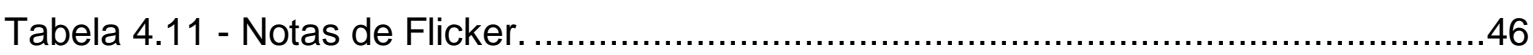

Tabela 4.12 - Resultados de Afundamentos de Tensão...............................................46 
Tabela 4.13 - Notas e Conceitos de Afundamentos de Tensão. .......................................47

Tabela 4.14 - Características dos Ensaios de VTCD com Amplitudes Evolutivas. ...........48

Tabela 4.15 - Resultados de VTCD com Amplitudes Evolutivas. ..................................48

Tabela 4.16 - Notas e Conceitos de VTCD com Amplitudes Evolutivas. ..........................48

Tabela 4.17 - Resultados de Tensões Constantes....................................................49

Tabela 4.18 - Notas de Tensões Constantes. ..................................................................49

Tabela 4.19 - Resultados de Variações Suaves de Tensão...........................................50

Tabela 4.20 - Notas de Variações Suaves de Tensão. ..................................................50

Tabela 4.21 - Módulo de Harmônicas. ............................................................................. 50

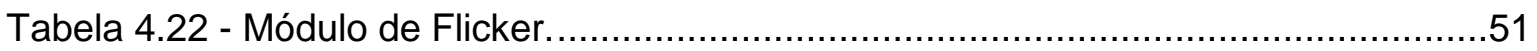

Tabela 4.23 - Módulo de Variações de Tensão de Curta Duração....................................51

Tabela 4.24 - Módulo de Variações de Tensão em Regime Permanente..........................52

Tabela 4.25 - Resultado Final Por Modelo. .................................................................. 


\section{LISTA DE FIGURAS}

Figura 2.1 - Forma de Onda com Harmônica............................................................ 9

Figura 2.2 - Desequilíbrio de Tensão (Fonte: Xavier, 2005).......................................10

Figura 3.1 - Organização da Bancada de Trabalho................................................23

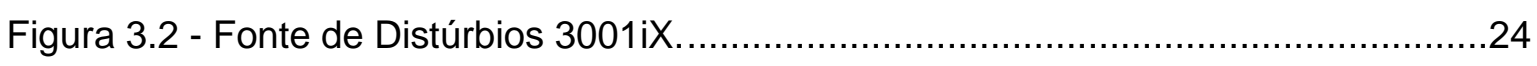

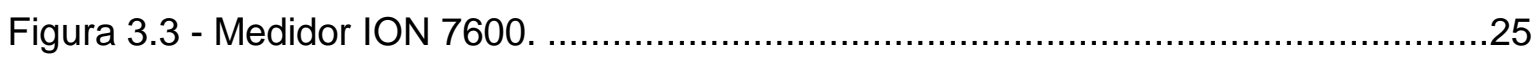

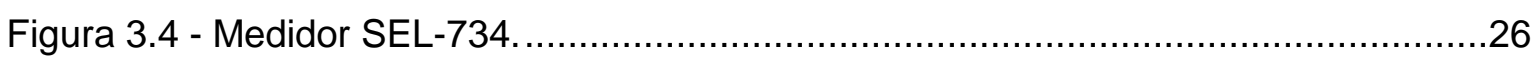

Figura 3.5 - Variação da Harmônica de Ordem 5 (Ensaio 13)........................................31

Figura 3.6 - Variação da Harmônica de Ordem 5 (Ensaio 14) ......................................32

Figura 3.7 - Forma de Onda Sujeita à Variações Retangulares (Fonte: IEC 61000-4-15) 33

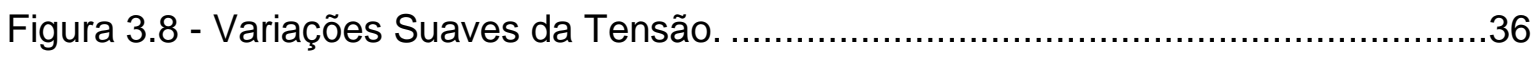

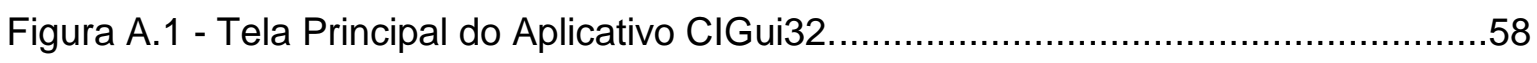

Figura A.2 - Janela Para Configuração de Formas de Onda com Harmônicas. ................59

Figura A.3 - Janela do Analisador de Harmônicas. .........................................................60

Figura A.4 - Janela de Visualização da Forma de Onda. ............................................61

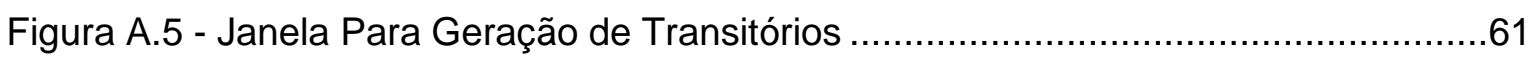

Figura A.6 - Tela principal do Management Console .....................................................63

Figura A.7 - Cadastramento de Dispositivos. .......................................................64

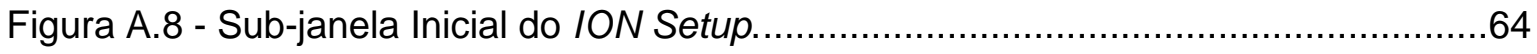

Figura A.9 - Árvore Apresentada na Tela Inicial do ION Setup. ....................................65

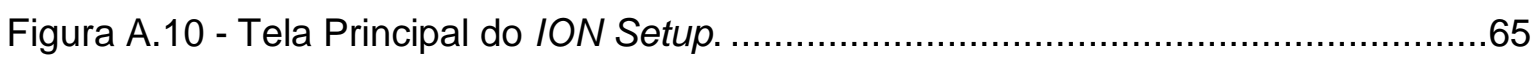

Figura A.11 - Janela Para Configuração dos Registros..............................................66

Figura A.12 - Janela Para a Escolha das 'Sources' .....................................................66

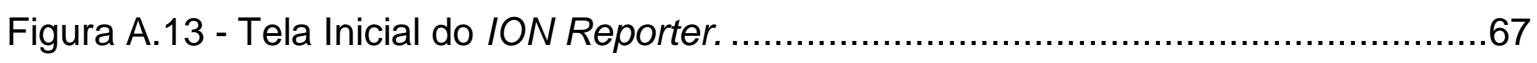

Figura A.14 - Janela Para Edição de Relatórios do ION Reporter...................................67

Figura A.15 - Janela Para Escolha de Datas de Geração dos Relatórios........................68

Figura A.16 - Janela Inicial do 'AcSELerator Quick Set'.............................................69

Figura A.17 - Janela de Configurações (Settings Editor).............................................70

Figura A.18 - Janela Para Configuração do 'Part Number'...........................................71

Figura A.19 - Janela do 'Load Profile Data'. .......................................................... 72 


\section{CAPÍTULO 1}

\section{1 - INTRODUÇÃO}

\subsection{Aspectos GeRAIS}

Diferentemente da atualidade, nos primeiros anos de existência dos sistemas de distribuição da energia elétrica, eram utilizadas tensões contínuas. Todavia, esta opção de uso não se sustentou por muito tempo, pois logo se percebeu que o sistema de corrente alternada é mais viável e vantajoso.

Entretanto, a adoção do sistema de corrente alternada como padrão trouxe algumas implicações inerentes a problemas relacionados com a Qualidade da Energia Elétrica (QEE). Como será visto mais adiante, um sistema de corrente alternada tem algumas peculiaridades referentes à correta geração do sinal, que, em contrapartida, não é observado em sistemas de correntes contínuas. Frisa-se que em sistemas trifásicos essas peculiaridades são ainda mais evidentes.

Apesar do processo de geração, transmissão e distribuição da energia elétrica necessitar de cuidados relativos à QEE, em sua fase inicial, ainda não era dada a devida atenção a esta questão, pelo menos não com o mesmo rigor e parâmetros que são impostos atualmente. A prioridade para aquele momento era a expansão da rede elétrica e a continuidade dos serviços. Preocupações concernentes à sua qualidade eram deixadas para segundo plano.

À época já existiam equipamentos como motores elétricos e rádios, mas a maior parte da carga elétrica era constituída de lâmpadas incandescentes e outros tipos de resistências. A aparelhagem utilizada pelos consumidores tinha um alto grau de imunidade contra os distúrbios possíveis de serem acometidos no sistema.

No entanto, com o passar do tempo a abrangência do suprimento energético se disseminou e, concomitantemente, evoluíram os perfis de carga dos novos aparelhos, o que veio a contribuir para uma maior atenção dos consumidores e agentes do setor. Então, iniciou-se uma nova geração de dispositivos que fazem uso de eletrônica de potência, os quais infelizmente são mais susceptíveis a problemas com a QEE e tem a desvantagem de deteriorar a forma de onda da tensão nas unidades consumidoras.

As indústrias, assim como os setores residenciais e comerciais, passaram por renovações. Padrões mais rigorosos e exigências do mercado globalizado foram impostos. Demandas por produção e qualidade dos produtos e serviços vêm crescendo a uma taxa exponencial à medida que novas tecnologias são descobertas. Nesta nova ordem mundial, os sistemas de controle e os processos automatizados destacam-se como a pedra angular da economia industrial, contribuindo para aumentar o uso de 
aparelhos microprocessados, retificadores de tensão CA-CC e cargas controladas eletronicamente.

Contudo, os tais dispositivos citados, tem carga com característica não-linear, ou seja, a resposta de suas correntes frente às tensões aplicadas se dá de maneira bem complexa, provocando uma distorção do sinal da rede elétrica e interferindo diretamente na qualidade da energia elétrica do sistema em questão. Asseverando ainda mais essa conjuntura, estes mesmos equipamentos eletrônicos que deterioram a forma de onda de tensão são os que demandam uma energia com melhor qualidade.

A tendência mundial continua sendo o crescimento vertiginoso desses tipos especiais de cargas que, além de deteriorar o sinal, requerem uma forma de onda livre de imperfeições. A necessidade de pesquisas nesta área também vem crescendo. Já existem tecnologias de eletrônica de potência modernas que anulam ou reduzem significativamente os efeitos indesejáveis causados no sistema elétrico, porém, esses equipamentos ainda apresentam altos custos, tornando-os economicamente inviáveis.

Vale ressaltar que o mercado na área de QEE ainda se encontra muito aberto e passível de mais investimentos, sendo bastante receptível a novos estudos, quer seja para avaliação, aprimoramento dos serviços, controle do sistema elétrico, quantificação do problema ou manutenção da boa qualidade do produto. Contudo, qualquer que seja a aplicação do profissional que trabalha na investigação da qualidade da energia, é necessário que ele lide, em maior ou menor grau, com aspectos peculiares ao seu monitoramento.

Por definição, a monitoração da qualidade da energia é o processo de recolhimento, análise e interpretação dos dados de medições brutas em informações úteis (Dugan, 2002). Para isto, a principal ferramenta de trabalho utilizada são os equipamentos medidores das grandezas elétricas, cada qual com suas limitações e diferenciais intrínsecos, o que pesa diretamente na decisão de compra do consumidor.

Evidentemente, um produto com recursos extras e que atenda às necessidades do cliente da forma mais prática possível, terá uma enorme vantagem sobre aquele que não possua essas características, ainda mais com os altos níveis de exigência que são impostos pelo contexto atual, onde a excelência é veementemente impetrada.

É muito importante que os agentes do setor elétrico e consumidores tenham informações claras a respeito dos produtos disponíveis, e este por sua vez, apresente as funcionalidades para qual foi criado, de acordo com as normas e padrões vigentes, quer sejam padrões legais ou exigidos pelo competitivo mercado tecnológico atual. Portanto, é nesses moldes, que o presente estudo vem contribuir para uma avaliação entre dois instrumentos medidores das grandezas da energia elétrica. 


\subsection{Objetivos do Projeto}

O projeto tem por finalidade fazer uma análise comparativa entre dois instrumentos capazes de medir grandezas relacionadas à qualidade da energia elétrica, a saber, o ION 7600 da Power Measurement e o SEL-734 da Schweitzer. É feita uma avaliação quanto à capacidade dos dispositivos em aferir corretamente cada um dos principais indicadores da QEE. O método proposto visa à obtenção de resultados organizados em forma de tabelas que sintetizem as características de cada medidor posto a prova.

Para que tais propósitos sejam atingidos com critérios, consistência, precisão e clareza dos resultados, é relevante o prévio conhecimento do desempenho dos diversos produtos disponibilizados no mercado. Dois pontos fundamentais se fazem imprescindíveis para a identificação e conhecimento do padrão dos instrumentos a serem utilizados: um relacionado com a precisão das amostragens no seu sentido mais amplo, e outro, vinculado à questão do tratamento das informações coletadas (Relatório Técnico UFU/ONS, 2004).

Além disso, é requerido adquirir o domínio necessário para se trabalhar com cada equipamento medidor e com a fonte programável de tensão. Como será visto no Capítulo 3 e no Apêndice, os medidores tem suas características intrínsecas, tanto quanto à parte física (hardware), quanto aos softwares. Assim como eles, a fonte de distúrbios também requer algum conhecimento para programação das formas de ondas, permitindo a geração e visualização do sinal para certificar-se de que a saída é realmente a correta.

\subsection{ESTRUTURA DO TRABALHO}

A sequência de exposição dos assuntos é organizada para facilitar a compreensão, bem como enfatizar pontos importantes referentes à metodologia e resultados dos ensaios propostos, os quais trazem consigo algumas implicações inerentes à familiarização com a aparelhagem. $O$ trabalho (excluindo-se o capítulo em questão) é dividido da seguinte maneira:

- Capítulo 2: apresenta os conceitos e definições da qualidade da energia elétrica juntamente com seus itens indicadores além de destacar suas causas e efeitos, frisando a importância do tema na atualidade. É dado um destaque às principais normas referentes ao assunto, assim como um detalhamento da sua monitoração e dos protocolos de medições concernentes a QEE.

- Capítulo 3: constitui-se da apresentação dos métodos e procedimentos, tanto para a realização dos ensaios quanto para obtenção de indicadores que possam oferecer informações a respeito da qualidade dos medidores, permitindo-se concretizar a avaliação comparativa entre ambos os medidores no Capítulo 4.

- Capítulo 4: destina-se exclusivamente a apresentar os resultados obtidos e fazer a avaliação comparativa entre os dois equipamentos postos à prova. 
- Capítulo 5: traz as conclusões finais concernentes ao desenvolvimento deste projeto, mencionando-se as contribuições, resultados alcançados e trabalhos futuros. 


\section{CAPÍTULO 2}

\section{2 - QUALIDADE DA ENERGIA ELÉTRICA}

\subsection{Aspectos GeRAIS}

Distúrbios nas redes elétricas também aconteciam no passado, mas apesar disso, o conceito de qualidade da energia elétrica foi difundido somente a partir da década de 80 . Segundo definição da ANEEL o termo está relacionado com os desvios que possam ocorrer na magnitude, forma de onda e/ou frequência da tensão/corrente elétrica, que podem ser tanto de natureza permanente como transitória e afetam diretamente todo o desempenho do sistema de geração, transmissão e distribuição de energia.

A maior parte das normas e padronizações, no entanto, definem limites somente para as características da tensão. Isso porque, em sistemas elétricos, é possível controlar apenas a qualidade da tensão. Nenhum controle pode ser exercido sobre a corrente, uma vez que ela é determinada pela solicitação das cargas. (Rola; Júnior, 2006 apud Oliveira, 2005).

Idealmente a tensão da rede elétrica deve satisfazer quatro exigências: ser uma senóide pura; de amplitude constante igual à nominal; com uma frequência de $60 \mathrm{~Hz}$ (para o caso do Brasil); e com ângulos de $120^{\circ}$ de defasagem entre as fases. Mas na realidade é aceitável que tais requisitos sofram algumas variações em torno de seu valor ideal, principalmente quando se trata do módulo da tensão, já que na prática é impossível gerar o sinal de forma perfeita durante todo o tempo, além de não se ter o controle de possíveis eventos aleatórios ou de difícil previsão que possam ocorrer na rede.

Devido à evolução tecnológica dos dispositivos utilizados pelos consumidores, bem como as mudanças ocorridas na estrutura do setor elétrico, tornou-se fundamental ter um serviço de boa qualidade (confiável) e um sinal isento de anormalidades, com a penalidade de provocar ineficiências técnicas e econômicas com significativas perdas para os setores industrial, comercial, e residencial. Logo, a abordagem sobre a qualidade da energia elétrica veio à tona porque o provimento do serviço já era confiável, ou seja, fornecimento ininterrupto, as cargas se tornaram mais sensíveis e novos equipamentos permitiram a medição e avaliação das anormalidades (Filho; Sousa; Vasconcelos, 2009 apud Dugan, 2002; Bollen, 2000).

Pesquisas mostram que os custos resultantes de problema de QEE são muito elevados, e de acordo com a EPRI (Electric Power Research Institute) estes prejuízos chegam a mais de 120 bilhões de euros por ano, só nos Estados Unidos (Junior; Prado, 2006 apud AFONSO, 2004). Fica evidente que a questão da QEE entregue aos consumidores é um assunto de primordial importância, e com um maior grau de esclarecimento e cobrança por parte dos consumidores entram em cena as agências regulamentadoras com a 
imposição de normas e estudos sobre o tema, pressionando as empresas de energia elétrica a adequarem seus serviços aos moldes vigentes. Contudo, ainda faltam legislações claras com respeito às responsabilidades das concessionárias quanto à entrega de energia elétrica com boa qualidade e eventuais prejuízos, sendo este comumente um motivo de disputa entre os consumidores e concessionárias.

Com as reformas setoriais ocorrendo juntamente com a privatização dos ativos federais e estaduais, e com a criação da Agência Nacional de Energia Elétrica (ANEEL), começouse a desenhar o novo quadro de políticas regulatórias nacionais. As mesmas se apoiaram, dentre outros, na introdução da competição nos setores de geração e comercialização de energia elétrica, com incentivo de redução de custos e aumento dos lucros das concessionárias, tornando possível a prática de tarifas módicas. Nascia um mercado altamente competitivo, onde a qualidade no fornecimento da energia passou a exprimir lucratividade e garantia de clientes (Pinto, 2006 apud GBIRARD et al., 2002).

\subsection{INDICADORES DE QUALIDADE DA ENERGIA}

Os distúrbios plausíveis de acontecer numa rede elétrica são vários e dividem-se em diversas categorias, com a possibilidade de ocorrerem individualmente ou serem relacionados entre si, ou seja, um primeiro evento no sistema elétrico pode ser o causador direto de um segundo.

Como já foi dito, qualquer alteração da forma de onda que difere da ideal é considerado como um distúrbio da QEE. Contudo, a natureza dessa perturbação tem características diferentes uma das outras, e em geral, são classificadas quanto à sua duração, intensidade e conteúdo espectral.

Os prejuízos advindos de problemas relacionados à QEE são motivo de preocupação pelos consumidores. Ninguém deseja que haja anomalias no sinal elétrico no ponto de entrega da concessionária, já que isto acarreta perdas, mau funcionamento e/ou redução da vida útil de equipamentos. Entre os principais agentes causadores de distúrbios se destacam: partida, falha ou utilização imprópria de grandes equipamentos, descargas atmosféricas, uso de cargas não-lineares, manobras do sistema, curto-circuito, sobrecargas e redes mal dimensionadas.

Nas seções posteriores serão definidos com mais rigor os seguintes itens indicadores da QEE:

- Distorções Harmônicas;

- Desequilíbrio de Tensão;

- Flutuações de Tensão (Flicker);

- Variações de Tensão de Curta Duração (VTCD);

- Variações de Tensão em Regime Permanente. 
A seguir, a Tabela 2.1 classifica os principais distúrbios quanto a sua duração e amplitude e a Tabela 2.2 descreve suas causas, efeitos e soluções.

Tabela 2.1 - Classificação dos indicadores da QEE.

\begin{tabular}{|c|c|c|c|}
\hline CATEGORIA & ESPECTRO TÍPICO & DURAÇÃO TÍPICA & AMPLITUDE \\
\hline \multicolumn{4}{|l|}{ 1.0 Transientes } \\
\hline \multicolumn{4}{|l|}{1.1 Impulsivo } \\
\hline 1.1.1 Nanossegundos & $5 \mathrm{~ns}$ & $<50$ ns & \\
\hline 1.1.2 Microssegundos & $1 \mu \mathrm{s}$ & $50 \mathrm{~ns}-1 \mathrm{~ms}$ & \\
\hline 1.1.3 Milissegundos & $0,1 \mathrm{~ms}$ & $>1 \mathrm{~ms}$ & \\
\hline \multicolumn{4}{|l|}{1.2 Oscilatórios } \\
\hline 1.2.1 Menor frequencia & $<5 \mathrm{kHz}$ & $0,3-50 \mathrm{~ms}$ & $0-4 p u$ \\
\hline 1.2.2 Frequencia média & $5-500 \mathrm{kHz}$ & $20 \mu \mathrm{s}$ & $0-8 \mathrm{pu}$ \\
\hline 1.2.3 Maior frequência & $0,0-5 \mathrm{MHz}$ & $5 \mu \mathrm{s}$ & $0-4 \mathrm{pu}$ \\
\hline \multicolumn{4}{|l|}{ 2.0 Variações de curta duração } \\
\hline \multicolumn{4}{|l|}{2.1 Instantânea } \\
\hline 2.1.1 Interrupção & & 0,5-30 ciclos & $<0,1 \mathrm{pu}$ \\
\hline 2.1.2 Afundamentos & & 0,5-30 ciclos & $0,1-0,9 \mathrm{pu}$ \\
\hline 2.1.3 Elevação & & 0,5-30 ciclos & $1,1-1,8 \mathrm{pu}$ \\
\hline \multicolumn{4}{|l|}{ 2.2 Momentânea } \\
\hline 2.2.1 Interrupção & & 30 ciclos $-3 s$ & $<0,1 \mathrm{pu}$ \\
\hline 2.2.2 Afundamentos & & 30 ciclos $-3 s$ & $0,1-0,9 \mathrm{pu}$ \\
\hline 2.2.3 Elevação & & 30 ciclos $-3 \mathrm{~s}$ & $1,1-1,4 \mathrm{pu}$ \\
\hline \multicolumn{4}{|l|}{ 2.3 Temporária } \\
\hline 2.3.1 Interrupção & & $3 \mathrm{~s}-1 \mathrm{mim}$ & $<0,1 \mathrm{pu}$ \\
\hline 2.3.2 Afundamentos & & $3 \mathrm{~s}-1 \mathrm{mim}$ & $0,1-0,9 \mathrm{pu}$ \\
\hline 2.3.3 Elevação & & $3 \mathrm{~s}-1 \mathrm{mim}$ & $1,1-1,2 \mathrm{pu}$ \\
\hline \multicolumn{4}{|l|}{ 3.0 Variações de longa duração } \\
\hline 3.1 Interrupções sustentadas & & $>1 \min$ & $0,0 \mathrm{pu}$ \\
\hline 3.2 Subtensões & & $>1 \min$ & $0,8-0,9 \mathrm{pu}$ \\
\hline 3.3 Sobretensões & & $>1 \min$ & $1,1-1,2 \mathrm{pu}$ \\
\hline 4.0 Desequilíbrio de tensão & & Reg. Permanente & $0,5-2 \%$ \\
\hline \multicolumn{4}{|l|}{ 5.0 Distorção da forma de onda } \\
\hline 5.1 Tensão de offset & & Reg. Permanente & $0-0,1 \%$ \\
\hline 5.2 Harmônicas & 0-100 Harmônica & Reg. Permanente & $0-20 \%$ \\
\hline 5.3 Inter-harmônicas & $0-6 \mathrm{KHz}$ & Reg. Permanente & $0-2 \%$ \\
\hline
\end{tabular}




\section{(Continuação da Tabela 2.1)}

\begin{tabular}{|l|l|l|l|}
\hline 5.4 Notching & Reg. Permanente & \\
\hline 5.5 Ruídos & $\begin{array}{l}\text { Ampla banda de } \\
\text { frequência }\end{array}$ & Reg. Permanente & $0-1 \%$ \\
\hline 6.0 Flutuação de tensão & $<25 \mathrm{~Hz}$ & Intermitente & $\begin{array}{l}0,1-7 \% \\
0,2-2 \text { Pst }\end{array}$ \\
\hline 7.0 Variação de frequência & & $<10 \mathrm{~s}$ &
\end{tabular}

Fonte: Dugan (2002).

Tabela 2.2 - Resumo: causas, efeitos e propostas de soluções.

\begin{tabular}{|c|c|c|c|c|}
\hline DISTÚRBIO & DESCRIÇÃO & CAUSAS & EFEITOS & SOLUÇÕES \\
\hline Transientes & $\begin{array}{l}\text { Distúrbio na curva } \\
\text { senoidal, resultando } \\
\text { em rápido e agudo } \\
\text { aumento de tensão. }\end{array}$ & $\begin{array}{l}\text { Descargas } \\
\text { atmosféricas, } \\
\text { manobras da } \\
\text { concessionária, } \\
\text { manobras de grandes } \\
\text { cargas e bancos de } \\
\text { capacitores. }\end{array}$ & $\begin{array}{l}\text { Travamento, perda de } \\
\text { memória e erros de } \\
\text { processamento, queima } \\
\text { de placas eletrônicas, } \\
\text { danificação de materiais } \\
\text { de isolação e de } \\
\text { equipamentos. }\end{array}$ & $\begin{array}{l}\text { Supressores de } \\
\text { transientes; } \\
\text { UPS com } \\
\text { supressores de } \\
\text { transientes; } \\
\text { Transformadores } \\
\text { de isolação. }\end{array}$ \\
\hline Interrupções & $\begin{array}{l}\text { Interrupção total da } \\
\text { alimentação elétrica. }\end{array}$ & $\begin{array}{l}\text { Curto-circuito, } \\
\text { descargas } \\
\text { atmosféricas, outros } \\
\text { acidentes que exijam } \\
\text { manobras precisas } \\
\text { de fusíveis, } \\
\text { disjuntores, etc. }\end{array}$ & $\begin{array}{l}\text { Queda do sistema, } \\
\text { danificação de } \\
\text { componentes e perda } \\
\text { de produção. }\end{array}$ & $\begin{array}{l}\text { UPS; } \\
\text { Geradores de } \\
\text { emergência } \\
\text { (interrupções de } \\
\text { longa duração). }\end{array}$ \\
\hline $\begin{array}{l}\text { Afundamentos/ } \\
\text { Elevações de } \\
\text { Tensão }\end{array}$ & $\begin{array}{l}\text { Afundamentos (sags) } \\
\text { e elevações (swells) } \\
\text { são variações } \\
\text { momentâneas, não } \\
\text { superiores a } 1 \text { min e } \\
\text { dentro de certos } \\
\text { limites, na amplitude } \\
\text { da tensão. }\end{array}$ & $\begin{array}{l}\text { Queda/Partida de } \\
\text { grandes } \\
\text { equipamentos, curto- } \\
\text { circuito, falha em } \\
\text { equipamentos ou } \\
\text { manobras da } \\
\text { concessionária. }\end{array}$ & $\begin{array}{l}\text { Perda de dados e erros } \\
\text { de processamento, } \\
\text { desligamento de } \\
\text { equipamentos, } \\
\text { oscilações em motores } \\
\text { e redução de sua vida } \\
\text { útil. }\end{array}$ & $\begin{array}{l}\text { UPS; } \\
\text { Reguladores de } \\
\text { tensão. }\end{array}$ \\
\hline $\begin{array}{l}\text { Variações de } \\
\text { Tensões de } \\
\text { Longa Duração }\end{array}$ & $\begin{array}{l}\text { Variações na } \\
\text { amplitude da tensão } \\
\text { dentro de certos } \\
\text { limites e com duração } \\
\text { acima de } 1 \text { min. }\end{array}$ & $\begin{array}{l}\text { Sobrecarga de } \\
\text { equipamentos e da } \\
\text { fiação, utilização } \\
\text { imprópria de } \\
\text { transformadores, } \\
\text { fiação sub- } \\
\text { dimensionada ou } \\
\text { conexões mal feitas. }\end{array}$ & $\begin{array}{l}\text { Desligamento de } \\
\text { equipamentos, } \\
\text { sobreaquecimento de } \\
\text { motores e lâmpadas, } \\
\text { redução de vida útil ou } \\
\text { de eficiência dos } \\
\text { equipamentos. }\end{array}$ & $\begin{array}{l}\text { UPS; } \\
\text { Verificar } \\
\text { conexões, } \\
\text { topologia e fiações } \\
\text { elétricas. }\end{array}$ \\
\hline Harmônicos & $\begin{array}{l}\text { Alteração do padrão } \\
\text { normal de tensão } \\
\text { (onda senoidal) por } \\
\text { frequências múltiplas } \\
\text { da fundamental ( } 60 \mathrm{~Hz} \\
\text { no Brasil). }\end{array}$ & $\begin{array}{l}\text { UPS, Reatores } \\
\text { eletrônicos, } \\
\text { inversores de } \\
\text { frequência, } \\
\text { retificadores e outras } \\
\text { cargas não-lineares. }\end{array}$ & $\begin{array}{l}\text { Sobreaquecimento de } \\
\text { cabos e equipamentos, } \\
\text { diminuição do } \\
\text { desempenho de } \\
\text { motores, operação } \\
\text { errônea de disjuntores, } \\
\text { relés e fusíveis. }\end{array}$ & $\begin{array}{l}\text { Filtros de } \\
\text { harmônicas; } \\
\text { Reatores de linha; } \\
\text { Melhorias na } \\
\text { fiação e no } \\
\text { aterramento; } \\
\text { Transformadores } \\
\text { de isolação. }\end{array}$ \\
\hline
\end{tabular}

Fonte: Filho; Sousa; Vasconcelos, 2009 apud Franco, 2009. 
A Tabela 2.1 comprova que os distúrbios tem características bem diversificadas no que se refere ao seu espectro de frequência, duração e amplitude.

Já a Tabela 2.2 permite identificar os diversos fatores que causam perturbações no sinal da rede elétrica. Observa-se que existem soluções para todos os distúrbios, o que é muito importante quando se leva em consideração os aspectos econômicos.

\subsubsection{DISTORÇÕES HARMÔNICAS}

Os harmônicos são tensões ou correntes senoidais que possuem frequências múltiplas da frequência fundamental de operação do sistema. Redes elétricas onde este tipo distorção da forma de onda é encontrado são consideradas redes com energia suja ou poluída. O fenômeno ocorre devido à queda de tensão provocada pela circulação das correntes harmônicas no sistema, como consequência direta do uso de cargas não lineares, tais como: fornos a arco, fornos de indução, conversores estáticos, máquinas de solda, lâmpadas fluorescentes entre outros.

Preocupações a respeito dos efeitos causados pelas distorções harmônicas são recentes, pois os equipamentos elétricos do passado eram mais robustos ao fenômeno. De acordo com Dugan (2002), para fins práticos, as ordens de harmônicas mais

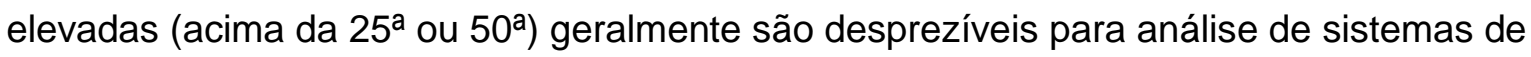
potência, apesar de poderem causar interferências em dispositivos eletrônicos de baixa potência.

A Figura 2.1 abaixo mostra a aparência da forma de onda quando se verifica na mesma presença de harmônicos:
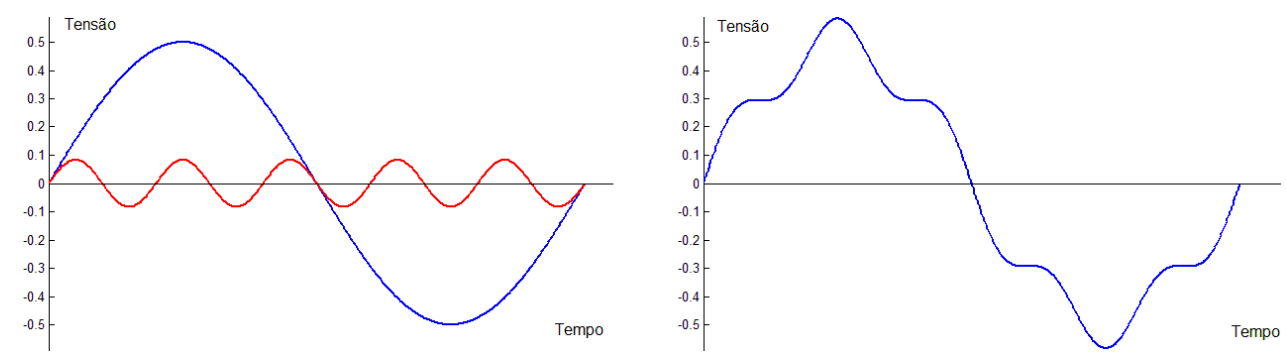

Figura 2.1 - Forma de Onda com Harmônica.

Outro objeto de avaliação concernente ao assunto é a Distorção Harmônica Total de Tensão (DHTV). Este índice mede o valor efetivo, ponderando todas as componentes harmônicas da forma de onda. Por definição, a DHTV é dada pela equação 2.1:

$$
D H T V=\frac{\sqrt{\sum_{h=2}^{h m a ́ x} V_{h}{ }^{2}}}{V_{1}} \times 100
$$

Onde $V_{1}$ é a tensão fundamental e $V_{h}$ é a tensão harmônica de ordem h. 


\subsubsection{DESEQUILÍBRIO de TENSÃo}

Um sistema trifásico equilibrado tem a magnitude das três fases iguais e um ângulo de $120^{\circ}$ graus de defasagem entre elas, ou seja, na representação fasorial tem-se:

$$
\bar{V}_{a}=V_{m} \angle 0^{\circ} ; \bar{V}_{b}=V_{m} \angle-120^{\circ} ; \bar{V}_{c}=V_{m} \angle 120^{\circ}
$$

Assim, o desequilíbrio de tensão é definido como qualquer diferença entre fases do módulo ou ângulo das tensões fasoriais.

A grandeza que mede a severidade do desequilíbrio de tensão é denominada fator $\mathrm{K}$. Existem vários métodos para o seu cálculo, o principal deles (método das componentes simétricas) é alicerçado nos estudos de C. L. FORTESCUE, o fator K é definido pela relação entre os módulos de tensão de sequência negativa pela positiva.

A forma de onda mostrada na Figura 2.2 retrata dois desequilíbrios de tensão, o primeiro no módulo da tensão da fase $A$ e o segundo uma defasagem angular na fase $B$.

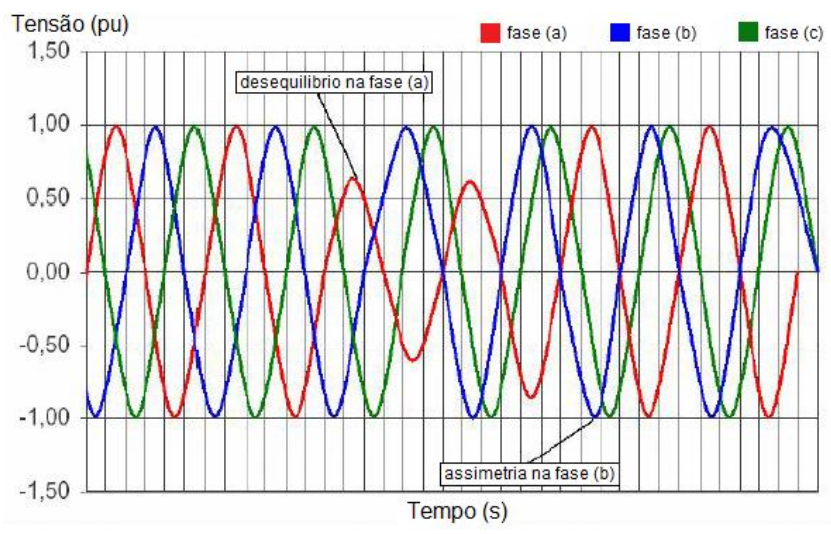

Figura 2.2 - Desequilíbrio de Tensão (Fonte: Xavier, 2005).

\subsubsection{FLUTUAÇÃo de TenSÃo}

Flutuação de tensão é caracterizada por variações sistemáticas do valor eficaz de tensão dentro da faixa de 0,95 a 1,05 pu, essas variações podem ser aleatórias, repetitivas ou esporádicas. O principal agente causador do distúrbio são as cargas industriais com solicitação variável da magnitude da corrente ao longo do tempo.

O efeito mais comum deste distúrbio é o fenômeno da cintilação luminosa ou flicker, que é a variação do fluxo luminoso emitido por uma lâmpada quando sujeita a essas condições. Na faixa de frequência de 0 a $30 \mathrm{~Hz}$ (na pior situação $10 \mathrm{~Hz}$ ) o olho humano é extremamente sensível às variações da emissão luminosa das lâmpadas, causando na maioria das vezes desconforto ou irritação visual as pessoas que se encontram em ambientes onde exista flicker. 
A cintilação luminosa esta diretamente relacionada com a sensibilidade e reação de cada pessoa. Este fenômeno é um estudo fundamentado em resultados experimentais baseados na fisiologia humana, os quais tratam o conjunto lâmpada/olho/cérebro como um sistema neurofisiológico complexo e não-linear. A intensidade da perturbação causada pela cintilação luminosa depende principalmente da amplitude, da frequência e do tempo de exposição às flutuações (Junior; Prado, 2006 apud PONTES, 2000).

O método padrão ou internacional para se mensurar a cintilação luminosa é o "UIE Flickermeter - functional and design specifications" proposto pela União Internacional de Eletrotermia o qual é recomendado internacionalmente pela International Electrotechnical Commission (IEC) (Junior; Prado, 2006).

O medidor de cintilação luminosa baseia-se em modelos estatísticos da percepção humana frente a flutuações de tensão. É composto por cinco estágios, a saber:

- Estágio 1 - adaptação da tensão de entrada;

- Estágio 2 - demodulação do sinal adaptado;

- Estágio 3 - ponderação em frequência;

- Estágio 4 - média quadrática;

- Estágio 5 - tratamento estatístico.

Existem dois indicadores de severidade do fenômeno flicker. O primeiro é o Pst (shortterm probability) que é quantificado numa base de tempo de 10 minutos. Já o segundo é o PIt (long-term probability), é uma média cúbica de 12 valores consecutivos de Pst, somando ao todo uma janela de tempo de 2 horas.

\subsubsection{VARIAÇÃo de Tensão de CURTA DuRAÇÃo (VTCD)}

Este distúrbio engloba a categoria de afundamentos, elevações e interrupções momentâneas de tensão da IEC. Como pode ser visto na Tabela 2.1, dependendo da sua duração, as VTCD se dividem em três grupos: instantânea, momentânea ou temporária. (Dugan, 2002).

Variações de tensão de curta duração são causadas por condições de falta, como a energização de grandes cargas que requerem altas correntes de partida, ou maus contatos em conexões da fiação de sistemas de potência. Dependendo da localização e das condições do sistema, o distúrbio tem a capacidade de causar temporariamente: afundamentos de tensão (sags), elevações de tensão (swells) ou uma completa perda de tensão (interrupções). A falta em questão pode ocorrer perto ou remotamente do ponto de interesse. Em ambos os casos, o impacto causado na tensão durante essa condição irá se perpetuar até que os dispositivos de proteção operem para sanar o problema (Dugan, 2002). 
A Tabela 2.3 elucida os três tipos de VTCD existentes:

Tabela 2.3 - Tipos de VTCD.

\begin{tabular}{|l|c|c|}
\multicolumn{1}{c|}{ TIPO } & TENSÃO [pu] & TEMPO \\
\hline Afundamentos & 0,1 a 0,9 & $<1$ min \\
\hline Elevações & 1,1 a 1,8 & 0,5 ciclo a $1 \mathrm{~min}$ \\
\hline Interrupções & $<0,1$ & 0,5 ciclo a $1 \mathrm{~min}$ \\
\hline
\end{tabular}

\subsubsection{VARIAÇÃo de TeNSÃo de LoNGa DURAÇÃo (VTLD)}

Variação de tensão de longa duração é aquela que tem duração maior ou igual a um minuto, sendo considerado um distúrbio de regime permanente. Geralmente causado por variações de carga e operações de chaveamento no sistema. A Tabela 2.4 mostra a divisão do fenômeno sobre o aspecto da amplitude da tensão e do tempo.

Tabela 2.4 - Tipos de VTLD.

\begin{tabular}{|l|c|c|}
\hline \multicolumn{1}{|c|}{ TIPO } & TENSÃO [pu] & TEMPO \\
\hline Subtensão & $<0,9$ & $>1 \mathrm{~min}$ \\
\hline Sobretensão & $>1,1$ & $>1 \mathrm{~min}$ \\
\hline Interrupções Sustentadas & 0 & $>1 \mathrm{~min}$ \\
\hline
\end{tabular}

Pelos valores supracitados, nota-se que as variações de tensão de longa duração são subdivididas de forma semelhante às de curta duração.

\subsection{NORMAS TÉCNICAS}

\subsubsection{NORMATIZAÇÕES E LEGISLAÇÕES BRASILEIRAS}

Num contexto mais recente do setor energético brasileiro ocorreu o desmembramento de várias empresas vinculadas ao setor elétrico, onde foi reduzida a força do Estado nas funções empresariais. Então surgiram constantes privatizações das empresas existentes e apresentou-se um novo modelo de instituições especializadas em executar e fiscalizar as funções de regulação, planejamento da expansão, operação e financiamento do setor. (Matana, 2008).

Uma entidade que merece um destaque pelo trabalho que vem desenvolvendo na área da QEE, é a Associação Brasileira de Normas Técnicas (ABNT), responsável por elaborar a norma NBR IEC 61000-4-30 Compatibilidade Eletromagnética (CEM) Parte 430 "Técnicas de Medição - Métodos de Medição da Qualidade da Energia Elétrica", 
baseada na IEC 61000-4-30 ${ }^{1}$ - Testing and Measurement Techniques - Power quality measurement methods (Belchior et al., 2009 apud NBR/IEC; Newman, 2009).

A norma orienta quanto aos procedimentos para se fazer a avaliação e integração no tempo dos valores medidos. O objetivo é tornar idênticos os resultados obtidos por diferentes equipamentos quando o mesmo fenômeno eletromagnético é medido. Para tanto, entra-se num nível de detalhamento que abrange: os métodos, desempenho requerido, incertezas e faixas de valores dos diversos parâmetros (Belchior et al., 2009).

Entretanto, pode-se afirmar que o papel atual desempenhado pelo setor energético brasileiro é de responsabilidade principal da Agência Nacional de Energia Elétrica (ANEEL) e do Operador Nacional do Sistema (ONS). Além terem o encargo com praticamente tudo o que se refere à energia elétrica no país, esses dois órgãos não deixaria de abordar questões específicas como a qualidade e os aspectos de medições da energia, assuntos que serão tratados nas seções 2.3.1.1 e 2.3.1.2.

\subsubsection{ANEEL ${ }^{2}$}

Foi criada no final de 1996, porém regulamentada em outubro de 1997. Sua missão é proporcionar condições favoráveis para que o mercado de energia elétrica se desenvolva com equilíbrio entre os agentes e em benefício da sociedade.

Até o final de 2009, a QEE no país estava subordinada a duas normas principais:

1 - Resolução 024/2000 da ANEEL: De 27 de fevereiro de 2000, a qual define os padrões de continuidade do fornecimento de energia elétrica para consumidores abaixo de $230 \mathrm{kV}$.

2 - Resolução 505/2001 da ANEEL: De 26 de novembro de 2001, que estabelece os padrões relativos à conformidade dos níveis de tensão em regime permanente para sistemas de energia elétrica.

Porém a resolução normativa no 395 , de 15 de dezembro de 2009, revoga entre outras, as resoluções $024 / 2000$ e a 505/2001. A partir de então passa a valer as normas de Procedimentos de Distribuição de Energia Elétrica no Sistema Elétrico Nacional (PRODIST). Estas normas disciplinam o relacionamento entre as distribuidoras de energia elétrica e demais agentes (unidades consumidoras e centrais geradores) conectados aos sistemas de distribuição, que incluem redes e linhas em tensão inferior a 230 quilovolts $(\mathrm{kV})$. Tratam, também, do relacionamento entre as distribuidoras e a Agência, no que diz respeito ao intercâmbio de informações.

\footnotetext{
${ }_{1}^{1}$ Norma discutida mais detalhadamente na seção 2.3.2.2

${ }^{2}$ As resoluções e normas referidas a esta seção podem ser encontradas no sítio da ANEEL: $<$ http://www.aneel.gov.br/>.
} 
O PRODIST contém 8 Módulos. A versão vigente (após primeira revisão) está listada a seguir:

Módulo 1 - Introdução

Módulo 2 - Planejamento da Expansão do Sistema de Distribuição

Módulo 3 - Acesso ao Sistema de Distribuição

Módulo 4 - Procedimentos Operativos do Sistema de Distribuição

Módulo 5 - Sistemas de Medição

Módulo 6 - Informações Requeridas e Obrigações

Módulo 7 - Cálculo de Perdas na Distribuição

Módulo 8 - Qualidade da Energia Elétrica

Com respeito à $Q E E$, destaca-se o módulo 8, o qual:

- Define as suas terminologias e caracteriza os fenômenos, parâmetros e valores de referência relativos à conformidade de tensão em regime permanente e às perturbações na forma de onda de tensão, estabelecendo mecanismos que possibilitem à ANEEL fixar padrões para os indicadores de QEE (seção de qualidade do produto);

- Estabelece a metodologia para apuração dos indicadores de continuidade e dos tempos de atendimento (seção de qualidade dos serviços prestados);

- Trata do planejamento do processo de implantação dos indicadores de qualidade do produto da energia elétrica (seção de disposições transitórias).

Para tanto, são definidos os índices, critérios de amostragem e padrões de qualidade do produto para os seguintes aspectos considerados (em regime permanente ou transitório):
a) Tensão em regime permanente;
b) Fator de potência;
c) Harmônicos;
d) Desequilíbrio de tensão;
e) Flutuação de tensão;
f) Variações de tensão de curta duração;
g) Variação de frequência. 


\subsubsection{ONS $^{3}$}

Foi criado em 26 de agosto de 1998, é responsável pela coordenação e controle da operação das instalações de geração e transmissão de energia elétrica no Sistema Interligado Nacional (SIN), sob a fiscalização e regulação da ANEEL.

Atinentes ao ONS destacam-se os documentos normativos de Procedimentos de Rede, elaborados com a participação dos agentes, e aprovados pela ANEEL. Definem os procedimentos e os requisitos necessários à realização das atividades de planejamento da operação eletroenergética, administração da transmissão, programação e operação em tempo real no âmbito do SIN.

Os principais objetivos dos Procedimentos de Rede são:

- Legitimar, garantir e demonstrar a transparência, integridade, equanimidade, reprodutibilidade e excelência da operação do Sistema Interligado Nacional (SIN);

- Estabelecer, com base legal e contratual, as responsabilidades do ONS e dos agentes de operação, no que se refere a atividades, insumos, produtos e prazos dos processos de operação do sistema elétrico;

- Especificar os requisitos técnicos contratuais exigidos nos Contratos de Prestação de Serviços de Transmissão - CPST, dos Contratos de Conexão ao Sistema de Transmissão - CCT e dos Contratos de Uso do Sistema de Transmissão - CUST.

Ao todo, os Procedimentos de Rede são divididos em 26 módulos, sendo suas versões aprovadas em caráter definitivo pela ANEEL através da resolução REN no 372/2009. Dentre os módulos, destaca-se o submódulo 25.6 que fala sobre os indicadores de qualidade de energia elétrica (frequência e tensão).

\subsubsection{NORMATIZAÇõES INTERNACIONAIS SOBRE QEE}

Nos últimos anos, diversos organismos vem trabalhando para o desenvolvimento de parâmetros, características, conceituação, metas, índices e objetivos para a qualidade da energia nos mais variados setores desta atividade. As exigências e o cumprimento destes padrões descritos nas normas são, mais do que nunca, requeridos comercialmente nos contratos de fabricação de produtos ou prestações de serviço (Matana, 2008).

Alguns exemplos de organizações de normatização, que atuam em seus campos específicos e uma breve descrição sobre as mesmas, são elucidados abaixo:

- European Committee for Electrotechnical Standardization (CENELEC): prepara as normas relativas à área de engenharia elétrica para os países que pertencem a União Européia (CENELEC).

\footnotetext{
${ }^{3}$ Referências dos documentos normativos de Procedimentos de Rede podem ser encontradas no próprio sítio do ONS: <http://www.ons.org.br/procedimentos/index.aspx>.
} 
- National Electrical Manufacturers Association (NEMA): associação americana que define padrões para diversos campos da engenharia elétrica, normalmente com aplicações mais voltadas ao uso industrial (NEMA).

- Information Technology Industry Council (ITIC): é uma organização de intermediação para a indústria de tecnologia da informação nos Estados Unidos. Quando ainda possuía outro nome, (Computer and Business Equipment Manufacturers Association, CBEMA) elaborou uma curva de suportabilidade de equipamentos elétricos (ligados a tecnologia da informação) frente a distúrbio na rede. Por sua vez, vale ressaltar que mais recentemente esta curva foi atualizada pela própria organização (ITIC).

- American National Standards Institute (ANSI): é uma organização americana privada e sem fins lucrativos que supervisiona o desenvolvimento de normas para produtos, serviços e processos (ANSI).

- International Organization for Standardization (ISO): é uma entidade de padronização e normalização que atualmente conta com um grupo de 170 países (ISO).

No que se refere à qualidade da energia, no âmbito mundial, a Electrotechnical Commission (IEC) e o Institute of Electrical and Electronics Engineers (IEEE) são duas organizações de importante destaque que vem realizando um excelente trabalho ao longo do tempo e contribuindo em muitos aspectos para a área. As seções 2.3.2.1 e 2.3.2.2 explicam mais detalhadamente o papel desempenhado por essas duas instituições.

\subsubsection{IEC}

A IEC foi criada em Londres no ano de 1906. É uma organização internacional de padronização de tecnologias elétricas, eletrônicas e afins. Serve como base para normalizações em diversos países, sendo referência na elaboração de propostas e contratos pelo mundo todo. Também lida com avaliações de conformidade, certificando se equipamentos e outros componentes do sistema estão em conformidade com os padrões (IEC: Missão).

A comissão tem por objetivo (IEC: Missão):

- Atender eficientemente as exigências do mercado global;

- Assegurar a utilização a nível mundial das normas e sistemas de avaliação de conformidade;

- Avaliar e melhorar a qualidade dos produtos e serviços abrangidos pelas suas normas;

- Estabelecer as condições para a interoperabilidade de sistemas complexos; 
- Aumentar a eficiência dos processos industriais;

- Contribuir para a melhoria da saúde e segurança humana;

- Contribuir para a proteção do ambiente.

Vale frisar que o conjunto de normas da família IEC 61000, referentes à compatibilidade eletromagnética (Electromagnetic compatibility, EMC) se caracterizam de fundamental importância. Estas normas são aceitas internacionalmente e também abrangem assuntos concernentes à QEE.

Em termos simples, a EMC descreve a capacidade dos sistemas elétricos e eletrônicos de funcionar corretamente quando próximos um do outro, ou seja, avalia-se a emissão de distúrbios e quão imune a este um equipamento deve ser. Na prática, isso significa que as perturbações eletromagnéticas de cada dispositivo devem ser limitadas e ter um nível adequado de imunidade às perturbações em seu ambiente (IEC: EMC).

A estrutura da série de normas IEC 61000 (excluindo-se os itens 7 e 8) ${ }^{4}$ é dividida da seguinte maneira (IEC: Estrutura):

- Parte 1: Geral

- Considerações gerais (introdução, princípios, fundamentos e segurança).

- Definições e terminologias.

- Parte 2: Ambiente

○ Descrição do ambiente

○ Classificação do ambiente

○ Níveis de compatibilidade

- Parte 3: Limites

○ Limites de emissão

- Limites de imunidade (na medida em que não se enquadram sob a responsabilidade das comissões do produto)

- Parte 4: Técnicas de teste e medições

○ Técnicas de Medição

- Técnicas de teste

- Parte 5: Orientações de instalação e mitigação

○ Orientações de instalação

- Métodos de mitigação e dispositivos

- Parte 6: Normas genéricas

- Parte 9: Diversos

\footnotetext{
${ }^{4}$ Os itens 7 e 8 ainda estão em aberto.
} 
A família de normas da Parte 4 (IEC 61000-4) especifica, entre outros, os procedimentos de ensaios e as características necessárias de um medidor, como a aquisição das leituras, o tratamento dos dados e a classificação dos resultados para análise dos distúrbios englobados pela QEE (Matana, 2008).

Muitas normas internacionais utilizam estes conceitos de medidores da IEC como requisitos para obtenção dos valores das medidas dos fenômenos eletromagnéticos envolvidos e suas análises. Baseado nisto pode-se afirmar que as normas da IEC são mais utilizadas para equipamentos de medição sobre QEE que as outras normas vigentes (Matana, 2008).

\subsubsection{IEEE}

O IEEE tem sua sede localizada nos Estados Unidos. Deixa sua marca pelo desenvolvimento de importantes normas e estudos em praticamente todos os campos da engenharia elétrica. Com relação à qualidade da energia, não podia ser diferente, o tema é abordado com um nível de aprofundamento bem elevado.

As recomendações do IEEE são focadas no comportamento do sistema elétrico ou na instalação industrial como um todo. Suas normas limitam os níveis de distúrbios sobre a QEE no Ponto de Acoplamento Comum (PAC) ${ }^{5}$ a todos os equipamentos. Com isto, não são os equipamentos específicos que são avaliados, mas as instalações em geral (Matana, 2008 apud Serni, 2006).

A seguir, estão listadas as principais normas e padronização referentes à qualidade da energia (IEEE):

- IEEE SCC-22: Comitê de Coordenação de Padrões da Qualidade de Energia;

- IEEE 1159: Monitoração da Qualidade de Energia Elétrica;

- IEEE 1159,1: Guia Para Registradores e Requisitos de Aquisição de Dados.

- IEEE 1159,2: Caracterização dos Eventos de Qualidade de Energia.

- IEEE 1159,3: Formato Para Troca dos Dados da Qualidade de Energia.

- IEEE P1564: Índices de Afundamentos de Tensão;

- IEEE 1346: Compatibilidade do Sistema Elétrico com Equipamentos Eletrônicos;

- IEEE P1100: Alimentação e Aterramento de Equipamentos Eletrônicos;

- IEEE 1433: Definições de Qualidade de Energia;

- IEEE P1453: Flutuação de Tensão;

- IEEE 519: Controle de Harmônica em Sistemas Elétricos de Potência;

\footnotetext{
${ }^{5}$ Ponto de Acoplamento Comum é o ponto mais próximo do lado da rede de serviço ao cliente onde outro cliente pode ser abastecido.
} 
- IEEE Grupo de Trabalho de Harmônicos;

- Comitê de Dispositivos de Proteção Contra Surtos (Surge Protective Devices, SPD);

- IEEE P446: Sistemas Auxiliares de Emergência;

- IEEE P1409: Sistemas de Distribuição de Energia;

- IEEE P1547: Geração Distribuída e Interconexão de Sistemas Elétricos;

\subsection{MonitoraÇÃo da QEE E PROtocolos de MEdições}

Monitoração da qualidade da energia é o processo de recolhimento, análise e interpretação dos dados de medições brutas em informações úteis. O processo de recolhimento de dados é normalmente realizado através de medições da tensão e da corrente ao longo de um período de tempo. Tradicionalmente, o processo de análise e interpretação dos dados era realizado manualmente, mas avanços recentes no processamento de sinais e na área de inteligência artificial tornaram possível a concepção e implementação de sistemas inteligentes para a análise e interpretação automática dos dados brutos em informação útil, necessitando de uma mínima intervenção humana (Dugan, 2002).

Os objetivos da monitoração da energia elétrica geralmente determinam a escolha do equipamento a ser adquirido, para tanto, atenta-se às características como os limites de operação e os métodos de aquisição, análise, interpretação e armazenamento de dados. A saber, os motivos para a monitoração de um sistema podem ser divididos em quatro (Dugan, 2002):

- Monitoramento para caracterizar o desempenho do sistema.

- Monitoramento para caracterizar problemas específicos.

- Monitoramento para o aprimoramento dos serviços de qualidade de energia.

- Monitoramento para manutenção preventiva ou manutenção just-in-time.

No mercado atual existe uma enorme variedade de instrumentos de medição, com diferentes marcas, modelos e recursos. Na maioria das vezes é percebida uma falta de padronização entre eles, e a decisão de compra do consumidor pelo produto A ou B fica bastante prejudicada, portanto é requerido que todos os envolvidos, quer sejam as concessionárias, distribuidoras, agências reguladoras ou o próprio consumidor tenham conhecimento das funcionalidades e informações claras sobre o produto.

Assim como a comercialização de grande variedade de equipamentos, a quantidade de medições de parâmetros da QEE tem sido incrementada significativamente nos últimos anos. Entretanto, não há procedimentos legais que garantam a qualidade integral destas medições, havendo uma escassez de protocolos oficiais padronizados, além da ausência 
de metrologia oficial ou mesmo mão-de-obra capacitada para a medição. (Belchior et al., 2009).

Discute-se muito sobre quais os limites aceitáveis para os protocolos de medição que são utilizados nos equipamentos. Nesta realidade, observa-se que um mesmo fenômeno, quando medido por dois equipamentos diferentes, pode apresentar valores muito distintos, tornando-se imprescindível o estabelecimento de um protocolo com o qual seja possível, homogeneizar as medições dos parâmetros indicadores dos níveis da qualidade da energia elétrica em um sistema (Belchior et al., 2009).

No que tange a padronização dos métodos e técnicas de medição da energia elétrica, o Brasil ainda deixa a desejar, não há uma definição clara dos protocolos de medições para os cálculos de cada um dos parâmetros referentes à qualidade do produto. Todavia, a elaboração da norma NBR IEC 61000-4-30 pode trazer alguma melhora de modo a formalizar os métodos de medição da QEE. 


\section{CAPÍTULO 3}

\section{3 - MÉTODOS E PROCEDIMENTOS}

Este capítulo propõe uma sistematização dos métodos e procedimentos para a realização dos ensaios, pormenorizando seus aspectos práticos e estabelecendo padrões de forma a proporcionar parâmetros de comparação. Num primeiro momento é apresentada a estrutura laboratorial, além de se abordar as peculiaridades de cada dispositivo empregado nos testes. Em seguida, apresenta-se toda a sistemática necessária à obtenção dos indicadores para qualificar e mensurar a precisão de cada medidor, incluindo o tratamento estatístico dos dados, permitindo-se fazer uma avaliação mais direcionada à determinada categoria de ensaios.

\subsection{Recursos e MAteriais EMpregados}

Ao todo são utilizadas três ferramentas de trabalho, a saber:

- Fonte de tensão monofásica programável ${ }^{6}$ (modelo 3001iX da California Instruments): possibilita a geração de sinais com precisão;

- Medidor ION 7600 da Power Measurement;

- Medidor SEL-734 da Schweitzer.

Além do mais, como pode ser visto na Tabela 3.1, cada um dos equipamentos listados acima possui programas próprios. Explicações sobre seus aspectos computacionais são encontradas no apêndice, respectivamente nas seções A.1, A.2 e A.3.

Tabela 3.1 - Relação Dispositivos e Softwares Empregados.

\begin{tabular}{|c|c|c|}
\hline MODELO & $\begin{array}{l}\text { SOFTWARE } \\
\text { EMPREGADO }\end{array}$ & DESCRIÇÃO DO SOFTWARE \\
\hline Fonte 3001iX & $\begin{array}{l}\text { AC Source } \\
\text { CIGui32 }\end{array}$ & $\begin{array}{l}\text { Permite a geração de sinal monofásico programado pelo } \\
\text { usuário, sendo possível gerar quase todo o tipo de forma } \\
\text { de onda desejado. }\end{array}$ \\
\hline \multirow[b]{2}{*}{ ION 7600} & $\begin{array}{c}\text { Management } \\
\text { Console }\end{array}$ & $\begin{array}{l}\text { Ferramenta do ION Enterprise destinada à criação da } \\
\text { rede de comunicação dos dispositivos, dividida em } \\
\text { servidores, sítios, dispositivos e modems. }\end{array}$ \\
\hline & Vista & $\begin{array}{l}\text { Ferramenta do ION Enterprise que permite a interface } \\
\text { gráfica com o usuário e visualizar os dados em tempo } \\
\text { real, além de oferecer históricos, formas de onda e } \\
\text { registros dos dispositivos da rede. }\end{array}$ \\
\hline
\end{tabular}

\footnotetext{
${ }^{6}$ Por motivos técnicos não foi possível utilizar uma fonte de tensão trifásica.
} 


\section{(Continuação da Tabela 3.1)}

\begin{tabular}{|l|l|}
\hline Designer & $\begin{array}{l}\text { Ferramenta do ION Enterprise destinada à configuração } \\
\text { do medidor por meio de programação orientada ao } \\
\text { objeto. Tal processo é realizado por meio da } \\
\text { interconexão de módulos, os quais podem ser de } \\
\text { medição, integração, aritméticos, etc. }\end{array}$ \\
\hline ION 7600 & $\begin{array}{l}\text { Ferramenta do ION Enterprise responsável pela geração } \\
\text { dos relatórios pré-configurados pelo usuário, geralmente } \\
\text { em forma de planilha ou em alguns casos na forma } \\
\text { gráfica. }\end{array}$ \\
\hline Reporter & $\begin{array}{l}\text { Ferramenta que possibilita configurações básicas para } \\
\text { os dispositivos de monitoramento, permitindo exibir } \\
\text { diagnósticos da rede e dados em tempo real. }\end{array}$ \\
\hline ION Setup & $\begin{array}{l}\text { Software destinado à instalação e atualização de outros } \\
\text { softwares da Schweitzer, além de oferecer algumas } \\
\text { literaturas e guias práticos. }\end{array}$ \\
\hline SEL Compass
\end{tabular}

Fazendo a leitura da tabela anterior, percebe-se que é requerido o manejo de várias ferramentas computacionais. Nenhum dos dispositivos supracitados funciona de forma autônoma com todos os seus recursos disponíveis, sendo requerida a instalação e o uso de um ou mais software para cada equipamento. Além do mais, como pode ser visto na seção A.2 do apêndice, para o ION 7600 serão utilizados apenas três dos cinco softwares empregados.

\subsubsection{ESTRUTURA E INSTALAÇÕES LABORATORIAIS}

A bancada preparada para a realização dos ensaios foi composta pelos seguintes itens:

- Fonte de Distúrbios 3001iX: destinada à geração dos sinais de tensão requeridos para os testes;

- Medidores modelos ION 7600 e SEL-734: equipamentos ligados no mesmo barramento dos terminais de saída da fonte de distúrbios. Possibilitando fazer as leituras dos valores predeterminados;

- Computador tipo Desktop: requerido para se comunicar com a fonte de distúrbios e fazer as configurações pertinentes;

- Computador tipo Laptop: necessário para a comunicação com os dois medidores, permitindo fazer configurações e leituras das medições. 
Complementando o que foi mencionado anteriormente, a Figura 3.1 apresenta a disposição física da bancada de trabalho.

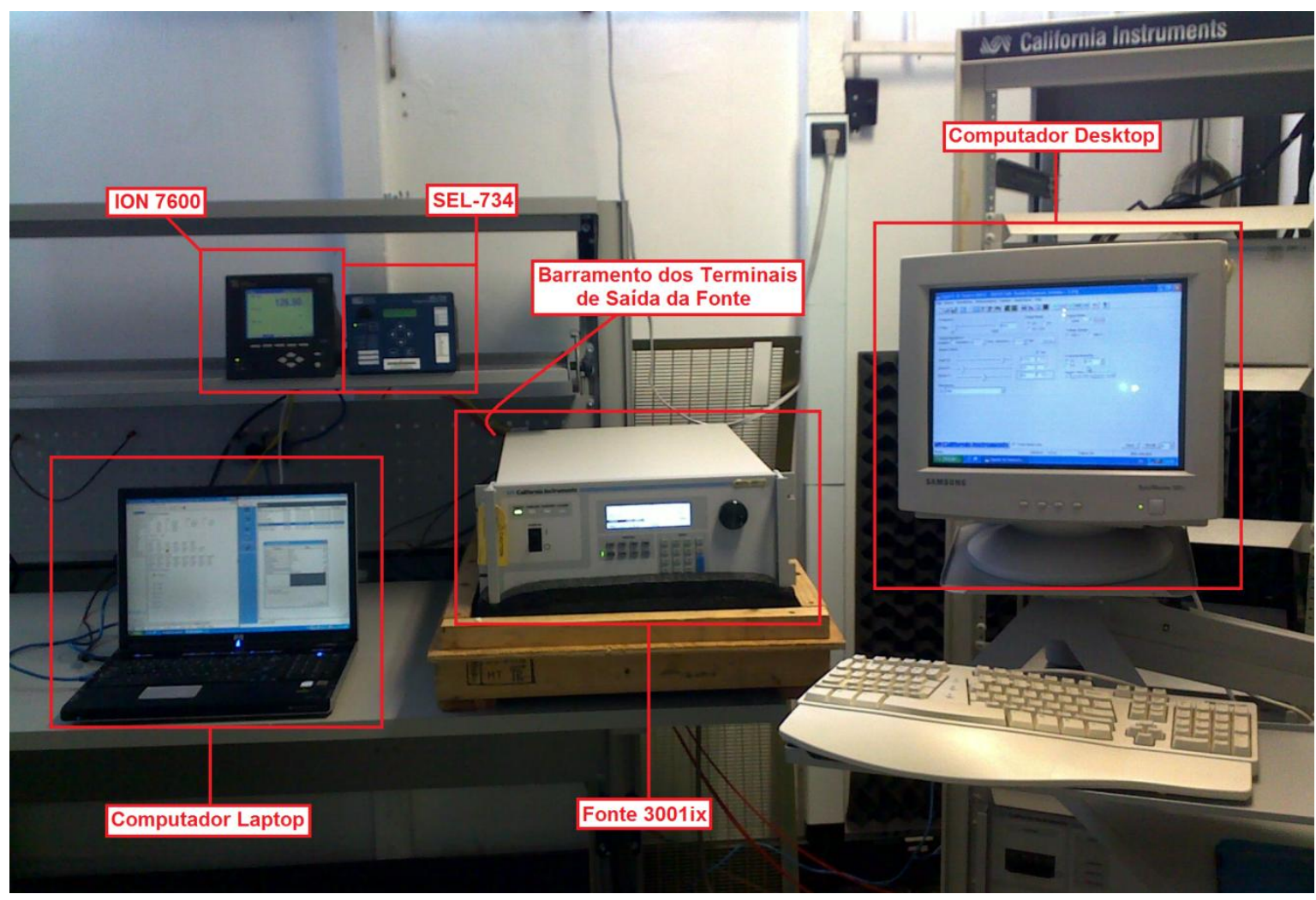

Figura 3.1 - Organização da Bancada de Trabalho.

\subsubsection{CARACTERÍsticas Gerais da FonTE DE Distúrbios}

Segundo descrições do fabricante, a série de fontes iX da California Instruments atende a uma ampla variedade de aplicações, como:

- Gerar sinais AC, DC ou uma combinação de ambos;

- Gerar sinais com harmônicas até a 50ª ordem, com o ajuste da amplitude e do ângulo de fase;

- Gerar transitórios, permitindo-se gravar até 100 formas de ondas para esse propósito;

- Gerar formas de onda senoidais, quadradas, ou definidas pelo usuário;

- Regular precisamente a frequência e a amplitude da tensão;

- Simular os mais variados tipos de distúrbios;

- Comunicação com o computador por meio de interface IEEE-488 ou RS232C.

Além disso, uma característica muito importante é que o equipamento atende às exigências da série de normas EN 61000 sobre testes de conformidades. 
A fim de qualificar melhor o produto, a Figura 3.2 mostra a foto do módulo principal do modelo 3001iX:

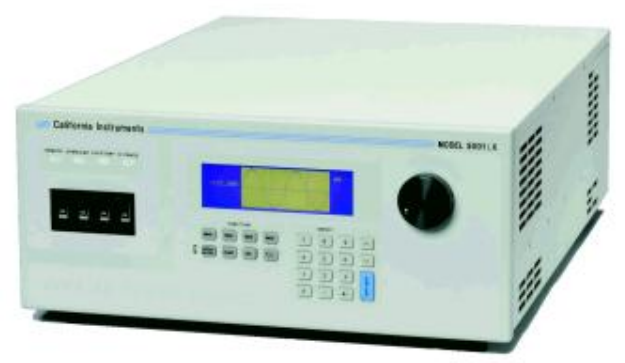

Figura 3.2 - Fonte de Distúrbios 3001iX.

Nota-se que o dispositivo possui um painel frontal de LCD, este permite fazer as configurações do mesmo e exibir seus valores de forma independente do software. As medições disponíveis são de: harmônicas, frequência, tensão, corrente, corrente de pico, fator de crista, potência real, potência aparente e fator de potência.

Com o auxílio do software, facilmente se tem o controle do dispositivo, o que inclui as funcionalidades de:

- Controlar de todos os parâmetros da saída em regime permanente;

- Criar, executar, salvar, carregar e imprimir programações de transitórios;

- Gerar e salvar formas de ondas com harmônicas;

- Gerar e salvar formas de ondas arbitrárias;

- Fazer o download de dados de um osciloscópio digital;

- Capturar e exibir as formas de ondas da tensão e da corrente de saída;

- Medir, exibir, imprimir e registrar medições das harmônicas de tensão e corrente;

- Executar programas de testes relativos à: IEC 61000-4-11, IEC 61000-4-14 e IEC 61000-4-28;

\subsubsection{CARACTERÍsticas Gerais do MEdidor ION 7600}

Segundo descrições do fabricante o ION 7600 é um dispositivo de controle e medição inteligente, desenvolvido para uma grande gama de aplicações. Usado tanto de maneira isolada ou dentro de uma rede de gerenciamento de energia, sendo capaz de associar de forma transparente com sistemas já existentes. Eficaz para soluções integradas no gerenciamento de novas estruturas de faturamento, geração distribuída, compra de energia, controle de custo da energia, eficiência operacional, qualidade e confiabilidade da energia.

Uma foto do medidor é mostrada na Figura 3.3. 


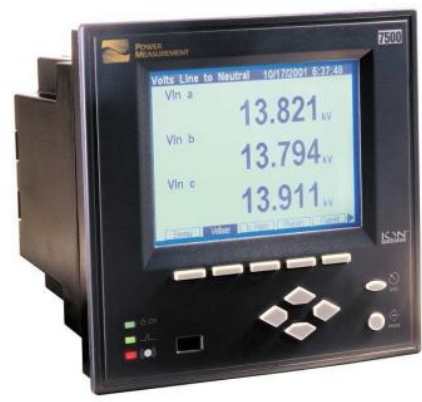

Figura 3.3 - Medidor ION 7600.

A seguir, listam-se as principais características do equipamento:

- Medição true RMS de tensão, corrente, potência e energia.

- O painel frontal de cristal líquido: usado para exibição de dados, configuração do medidor e acesso rápido e fácil às funções básicas.

- Entradas e saídas digitais e analógicas.

- Portas múltiplas de comunicação:

○ Conexão RS-232

○ Conexões RS-485

○ Conexões Ethernet

○ Conexões do Modem Interno (Opcional)

○ Conexões da Porta Infravermelha (Opcional)

- Conectividade à Internet possibiliatando receber e-mails, visualizar dados instantâneos e configurar o sistema através de um navegador Web de qualquer lugar.

- Protocolos industriais padronizados.

- Precisão no sincronismo de tempo: permite uma vasta capacidade de integração com sistemas de gerenciamento de energia já existentes.

- Extensas capacidades de entrada e saída, registros de eventos e medições avançadas para a monitoração da qualidade de energia.

- Grande variedade de telas de exibição pré-configuradas, sendo possível personalizá-las de forma que o medidor atenda às exigências particulares do usuário.

- Em muitos casos, podem substituir numerosos medidores tradicionais, transdutores e circuitos de controle.

- Possibilidade de integração dos medidores com o software ION ou qualquer outro sistema de gerenciamento de energia. 
O dispositivo pode ser efetivamente usado tanto no lado do fornecimento de energia, quanto nas aplicações do lado da demanda. Algumas das suas aplicações mais comuns são:

- Medição de faturamento;

- Automação de subestação;

- Monitoração da qualidade de energia;

- Medição de operações comerciais e industriais;

- Controle de demanda e fator de potência;

- SCADA (controle supervisório e aquisição de dados);

- Controle e monitoramento de geração distribuída.

\subsubsection{Características Gerais do MEdidor SEL-734}

Segundo descrições do fabricante o SEL-734 tem um avançado sistema de monitoração e automação, possibilitando fornecer (de forma amigável) relatórios completos da qualidade da energia, diagramas fasoriais e análise precisa das medições. É adequado tanto para usinas geradoras, subestações de transmissão, subestações de distribuição, bem como para aplicações industriais diversas. O usuário pode fazer medições da energia consumida ou gerada, registrar o perfil de carga, controlar bancos de capacitores e gerenciar o consumo da energia pelo período do dia, semana ou como for conveniente, segundo o conceito de Time-of-Use.

Vale frisar que além deste, existe um modelo de equipamento que pertence a essa mesma família de medidores, o SEL-734P, o qual tem alguns recursos extras e é capaz de medir o fenômeno de cintilação luminosa. Entretanto é possível instalar uma versão revisada do firmware que permite os dispositivos básicos medirem as grandezas relativas a flicker. No caso do presente projeto será utilizada a versão 133 lançada em novembro de 2009.

Uma foto do medidor é mostrada na Figura 3.4:

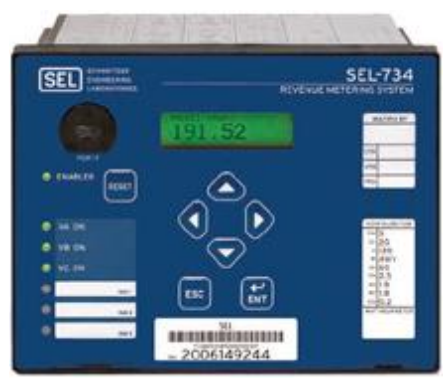

Figura 3.4 - Medidor SEL-734. 
O dispositivo tem conformidade com os padrões de medição ANSI e IEC, assegurando a compatibilidade com qualquer sistema de medição. O SEL-734 também realiza medição de faturamento classe de precisão $0,2 \%$. Algumas de suas características básicas são (SEL-734):

- Funções de Medição:

○ Instantânea;

- Qualidade da Energia;

- Registros de Valores Máximos e Mínimos.

- Funções de Monitoramento:

- Curva ITIC / CBEMA para análise de variações de tensão de curta duração;

- Resumo das ocorrências dos distúrbios de tensão de curta duração;

- Oscilografia de alta resolução;

- Armazena os últimos 682 eventos;

- Perfil de Carga: armazena em memória de massa até 192 grandezas configuráveis por períodos de até 115 dias (considerando intervalos de aquisição de 5 minutos);

- Frequência de atualização a cada 3 segundos;

- Medição sincronizada de fasores.

- Funções de Controle:

- 02 entradas e 03 saídas binárias com a opção de uma placa adicional perfazendo 06 entradas e 07 saídas.

- Programação através de equações lógicas, SELOGIC.

- Integração:

- 1 porta óptica frontal (tipo 2 ANSI) e 2 portas seriais EIA-232 traseiras;

○ IRIG-B;

- 1 porta EIA-485 e 1 porta EIA-232 adicional (opcional);

○ 1 porta Ethernet (opcional);

- 1 modem (opcional);

- Protocolos Seriais: DNP3.0 (opcional), ASCII, LMD, Modbus RTU, MV-90, SEL Fast Operate, SEL Fast Meter, Mirrored Bits;

- Protocolos Ethernet: Modbus TCP (opcional), Telnet (opcional) e DNP3 LAN/ WAN (opcional). 


\subsection{DesCriçÃo dos TeStes E EnSAIOS}

Com vistas a fazer a avaliação comparativa entre os dois instrumentos de medição, é imperativo que a análise de desempenho seja feita focada nos seguintes indicadores da qualidade da energia elétrica ${ }^{7}$ :

- Distorções harmônicas;

- Flutuações de tensão (flicker);

- Variações de tensão de curta duração (VTCD);

- Variações de tensão em regime permanente.

A sequência de testes dos quatro itens supracitados foi baseada no trabalho desenvolvido pela Universidade Federal de Uberlândia para o ONS (Relatório Técnico UFU/ONS, 2004). A Tabela 3.2 divide os ensaios em quatro módulos e descreve o conteúdo de cada um deles.

Tabela 3.2 - Descrição dos Módulos de Ensaios.

\begin{tabular}{|c|c|c|c|}
\hline MÓDULO & OBJETIVO & DESCRIÇÃO & $\begin{array}{c}\text { № DOS } \\
\text { ENSAIOS }\end{array}$ \\
\hline I & $\begin{array}{l}\text { Medição de } \\
\text { tensões } \\
\text { harmônicas }\end{array}$ & $\begin{array}{l}\text { Esta etapa consiste na realização de testes com } \\
\text { tensões distorcidas, superpondo à fundamental com } \\
\text { componentes individuais e várias distorções } \\
\text { simultâneas equilibradas. Além de formas de onda } \\
\text { estáveis no tempo, são também produzidas situações } \\
\text { em que as distorções são variadas ao longo do } \\
\text { período de teste. Ainda, análise de desempenho para } \\
\text { frequência fundamental de } 60 \mathrm{~Hz} \text { e outras, nas } \\
\text { imediações desta, devem ser também incorporadas } \\
\text { nesta fase. }\end{array}$ & $01-14$ \\
\hline II & $\begin{array}{c}\text { Medição de } \\
\text { flutuações de } \\
\text { tensão } \\
\text { (“Flicker) }\end{array}$ & $\begin{array}{l}\text { Os testes voltados para a análise dos equipamentos } \\
\text { sob o ponto de vista de "Flicker" compreendem a } \\
\text { geração de sinais de tensões fundamentais } \\
\text { moduladas através de função quadrada. Assim } \\
\text { procedendo, através do controle da amplitude da } \\
\text { oscilação e sua correspondente frequência reproduz- } \\
\text { se distintos valores para o indicador Pst. }\end{array}$ & $15-24$ \\
\hline
\end{tabular}

\footnotetext{
${ }^{7}$ Por motivos técnicos não foi possível utilizar uma fonte de tensão trifásica. Consequentemente a realização de ensaios referentes a desequilíbrios de tensão foi suprimida.
} 


\section{(Continuação da Tabela 3.2)}

\begin{tabular}{|c|c|c|c|}
\hline III & $\begin{array}{c}\text { Medição de } \\
\text { VTCD's }\end{array}$ & $\begin{array}{l}\text { Primeiramente são analisados os fenômenos } \\
\text { relacionados com o afundamento de curta duração, } \\
\text { com a ocorrência de vários eventos sequenciais. } \\
\mathrm{Na} \text { outra parte, com condições semelhantes às } \\
\text { mencionadas anteriormente, devem ser acrescentados } \\
\text { os fenômenos relacionados com elevações da tensão. }\end{array}$ & $25-35$ \\
\hline IV & $\begin{array}{c}\text { Medição de } \\
\text { variações de } \\
\text { tensão em } \\
\text { regime } \\
\text { permanente }\end{array}$ & $\begin{array}{l}\text { Nesta categoria são investigadas as variações de } \\
\text { tensão de longa duração, considerando afundamentos } \\
\text { e elevações de tensão ocorrendo uma única vez. As } \\
\text { variações consideradas se apresentam de forma } \\
\text { contínua para todos os ensaios, a exceção do } 38 \text {, o } \\
\text { qual tem sua variação de tensão submetida à } \\
\text { alternâncias de valores. }\end{array}$ & $36-38$ \\
\hline
\end{tabular}

\subsection{Roteiro e Procedimentos}

Antes de dar seguimento aos testes, é preciso estabelecer uma sistematização coerente para a geração do sinal e futura obtenção dos indicadores de desempenho de cada ensaio. Desse modo, quando não for especificado o contrário, deve-se ter:

- Tensões fundamentais eficazes de 127 Volts;

- Frequências fundamentais de $60 \mathrm{~Hz}$;

- Período de 10 minutos para a integralização dos valores lidos;

- Sincronização dos medidores com a maior precisão possível: dessa forma os instantes das leituras serão bem próximos, diminuindo o erro ao máximo. $\mathrm{Na}$ prática, essa diferença de tempo pode ser ajustada para valores menores que 100 milissegundos.

Agora, falta estipular os valores dos parâmetros a serem gerados pela fonte programável. Designadas para este propósito, as próximas subseções propõem um roteiro de testes que devem ser realizados de forma sequencial. 


\subsubsection{TENSÕES HARMÔNICAS}

\subsubsection{TENSÕES HARMÔNICAS INDIVIDUAIS}

Nestes ensaios, as harmônicas aplicadas terão amplitudes constantes e ângulos de fase de zero grau.

A Tabela 3.3 expõe os valores dos parâmetros referentes aos ensaios de 1 a 9 .

Tabela 3.3 - Ensaios de Harmônicas Individuais.

\begin{tabular}{|c|c|c|}
\hline \multirow{2}{*}{ Ensaio } & \multicolumn{2}{|c|}{ Características do Ensaio } \\
\cline { 2 - 3 } & $\begin{array}{c}\text { Ordem da } \\
\text { Harmônica }\end{array}$ & $\begin{array}{c}\text { Valor Aplicado } \\
{[\%]}\end{array}$ \\
\hline 01 & 02 & 1,0 \\
\hline 02 & 03 & 2,0 \\
\hline 03 & 04 & 1,0 \\
\hline 04 & 05 & 2,0 \\
\hline 05 & 07 & 2,0 \\
\hline 06 & 11 & 1,5 \\
\hline 07 & 13 & 1,5 \\
\hline 08 & 17 & 1,0 \\
\hline 09 & 25 & 1,0 \\
\hline
\end{tabular}

\subsubsection{COMPOSIÇÃO DE HARMÔNICAS}

No ensaio de número 10 serão aplicadas simultaneamente as nove ordens de componentes harmônicas dos ensaios de 01 a 09, perfazendo-se uma distorção Harmônica Total da Tensão (DHTV) de 4,5\%.

A Tabela 3.4 expõe os valores dos parâmetros referentes ao ensaio 10.

Tabela 3.4 - Ensaio de Composição de Harmônicas.

\begin{tabular}{|c|c|c|c|c|c|c|c|c|c|c|}
\hline \multirow[b]{2}{*}{ Ensaio } & \multicolumn{10}{|c|}{ Características do Ensaio } \\
\hline & V2 [\%] & V3 [\%] & $V_{4}[\%]$ & V5 [\%] & V7 [\%] & V11 [\%] & $\mathrm{V}_{13}[\%]$ & V17 [\%] & $V_{25}[\%]$ & $\begin{array}{c}\text { DHTV } \\
{[\%]}\end{array}$ \\
\hline 10 & 1,0 & 2,0 & 1,0 & 2,0 & 2,0 & 1,5 & 1,5 & 1,0 & 1,5 & 4,5 \\
\hline
\end{tabular}




\subsubsection{TENSÕES HARMÔNICAS COM DIFERENTES FREQUÊNCIAS}

Nos ensaios 11 e 12 as harmônicas aplicadas terão amplitudes constantes e ângulos de fase de zero grau, porém a frequência será diferente de $60 \mathrm{~Hz}$.

A Tabela 3.5 mostra como serão os ensaios 11 e 12 .

Tabela 3.5 - Ensaios de Harmônicas com Frequências Diferentes.

\begin{tabular}{|c|c|c|c|}
\hline \multirow{2}{*}{ Ensaio } & \multicolumn{3}{|c|}{ Características do Ensaio } \\
\cline { 2 - 4 } & $\begin{array}{c}\text { Frequência } \\
\text { Fundamental }\end{array}$ & $\begin{array}{c}\text { Ordem da } \\
\text { Harmônica }\end{array}$ & $\begin{array}{c}\text { Valor Aplicado } \\
{[\%]}\end{array}$ \\
\hline 11 & $59,9 \mathrm{~Hz}$ & 05 & 2,0 \\
\hline 12 & $60,1 \mathrm{~Hz}$ & 13 & 1,5 \\
\hline
\end{tabular}

\subsubsection{TENSÕES HARMÔNICAS INDIVIDUAIS VARIÁVEIS}

Nos ensaios 13 e 14 as harmônicas aplicadas terão ângulos de fase de zero grau, porém a harmônica de $5^{\underline{a}}$ ordem sofrerá variações controladas da amplitude, de forma que durante o período de tempo da leitura o seu valor médio seja conhecido.

Como pode ser observado na Figura 3.5, as variações do ensaio 13 serão suaves (de 0,02\%), com degraus de 250 milissegundos, em média a amplitude do sinal será de $5,29 \%$ da fundamental, cada degrau significa uma variação de $0,02 \%$, portanto o valor máximo atinge $5,77 \%$ e o mínimo 4,81\%. Na figura está representado apenas um ciclo. Ao todo, este processo deve ser programado para se repetir 16 vezes, somando um total de 560 segundos. No intervalo de tempo restante, a amplitude da componente de ordem 5 deve se manter em $5,29 \%$, não contribuindo para aumentar nem diminuir o seu valor médio.

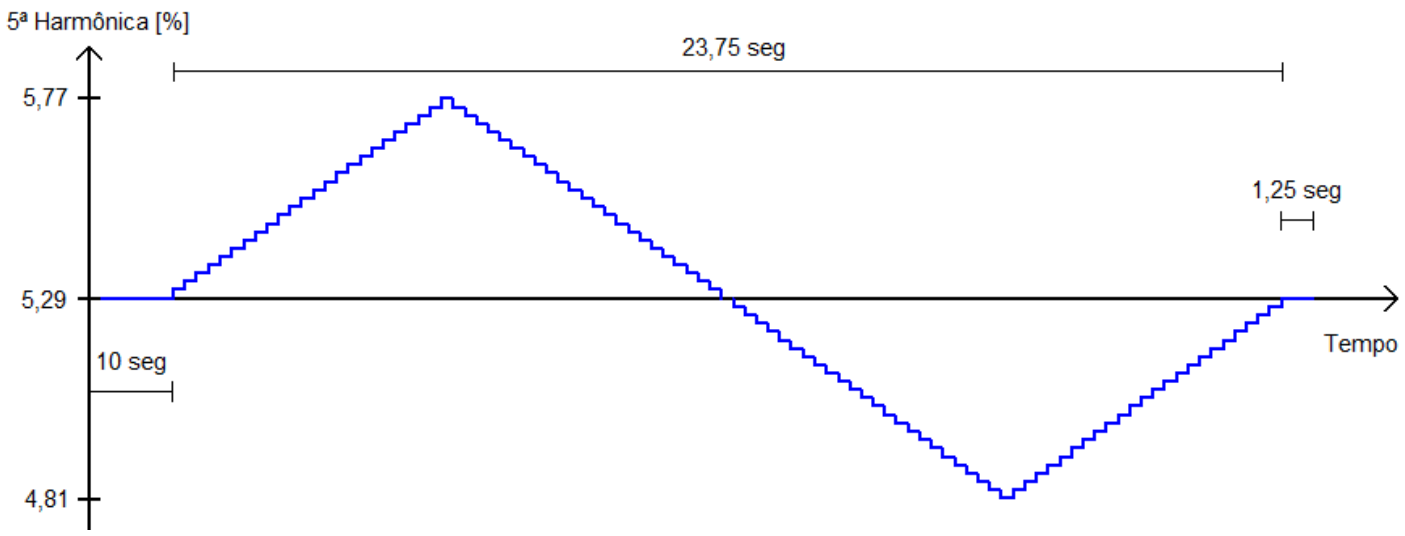

Figura 3.5 - Variação da Harmônica de Ordem 5 (Ensaio 13). 
Já as variações do ensaio 14 serão mais abruptas e com degraus de 600 milissegundos. Como pode ser observado na Figura 3.6, o meio ciclo abaixo dos 6,0\% é o espelhado da parte de cima, portanto, o valor da amplitude harmônica média dessa ordem será de $6,0 \%$. Ao todo, este ciclo de onda deve ser programando para se repetir 37 vezes, somando um total de 555 segundos. No intervalo de tempo restante, a amplitude da componente de ordem 5 deve se manter em $6,0 \%$, não contribuindo para aumentar nem diminuir o valor médio da componente.

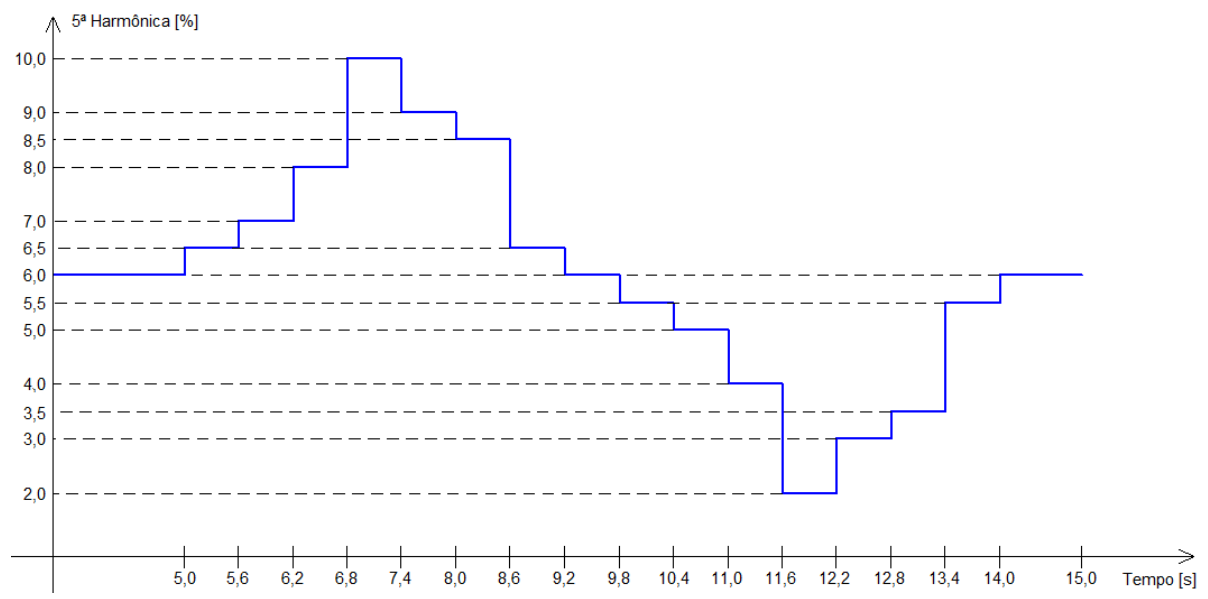

Figura 3.6 - Variação da Harmônica de Ordem 5 (Ensaio 14).

A Tabela 3.6 mostra como serão os ensaios de 13 e 14 .

Tabela 3.6 - Ensaios com Harmônicas Variáveis.

\begin{tabular}{|c|c|c|c|c|c|c|}
\hline \multirow{2}{*}{ Ensaio } & \multicolumn{6}{|c|}{ Características Do Ensaio } \\
\hline & Descrição & $\begin{array}{c}\text { V5 média } \\
{[\%]}\end{array}$ & V3 [\%] & V7 [\%] & $V_{11}[\%]$ & DHTV [\%] \\
\hline 13 & $\begin{array}{l}\text { - Variações suaves da } \\
\text { harmônica de ordem 5; } \\
\text { - Degraus de } 250 \text { ms; }\end{array}$ & 5,29 & 2,00 & 2,00 & - & 6,00 \\
\hline 14 & $\begin{array}{l}\text { - Variações abruptas da } \\
\text { harmônica de ordem 5; } \\
\text { - Degraus de } 600 \text { ms; }\end{array}$ & 6,00 & 2,00 & 2,00 & 1,50 & 6,80 \\
\hline
\end{tabular}

\subsubsection{FLUtUAÇões de TENSÃo (FLICKER)}

Nesta série de ensaios relativos ao fenômeno flicker, a grandeza a ser medida será seu indicador de severidade de curta duração (Pst). Para tanto, será utilizada a metodologia proposta pela norma IEC 61000-4-15 sobre especificações e aspectos funcionais de um medidor de flicker (Flickermeter functional and design specifications). 
A tensão fundamental utilizada será de 120 Volts e $60 \mathrm{~Hz}$, o modelo será baseado numa lâmpada incandescente de $60 \mathrm{~W}$, e suas variações serão retangulares, como mostrado na Figura 3.7, a qual também apresenta um conceito importante: a relação $\Delta V / V$, que neste caso específico é de $40 \%$.

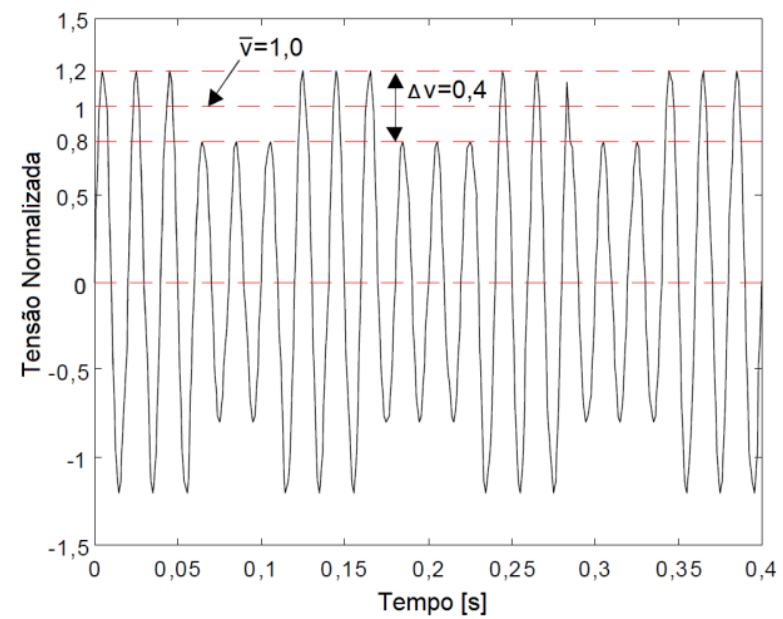

Figura 3.7 - Forma de Onda Sujeita à Variações Retangulares (Fonte: IEC 61000-4-15).

O próximo passo é saber como gerar o sinal para obter um determinado valor de Pst. Para isto, recorre-se à Tabela 3.7 onde é estabelecido uma combinação entre o número de variações retangulares por minuto e a relação $\Delta \mathrm{V} / \mathrm{V}$ que constitui um Pst unitário. Portanto, para uma determinada frequência fixa, basta fazer a normalização, aumentando ou diminuindo proporcionalmente a relação $\Delta V / V$, de forma que o sinal gerado apresente o índice Pst desejado.

Tabela 3.7 - Especificação Para Teste de um Medidor de Flicker.

\begin{tabular}{|c|c|c|}
\hline \multirow{2}{*}{$\begin{array}{c}\text { VARIAÇÕES RETANGULARES } \\
\text { POR MINUTO }\end{array}$} & \multicolumn{2}{|c|}{ RELAÇÃO PERCENTUAL AVIN } \\
\hline $\begin{array}{c}\text { Nota: } 1620 \text { variaçōes retangulares } \\
\text { por minuto equivalem a } 13,5 \mathrm{~Hz}\end{array}$ & $\begin{array}{c}\text { LÂMPADA } 120 \mathrm{~V} \\
\text { LA HZ }\end{array}$ & $50 \mathrm{HZ}$ \\
\hline 1 & 3,166 & 2,724 \\
\hline 2 & 2,568 & 2,211 \\
\hline 7 & 1,695 & 1,459 \\
\hline 39 & 1,044 & 0,906 \\
\hline 110 & 0,841 & 0,725 \\
\hline 1620 & 0,547 & 0,402 \\
\hline 4000 & Teste não Requerido & 2,40 \\
\hline 4800 & 4,834 & Teste não Requerido \\
\hline
\end{tabular}

Fonte: IEC 61000-4-15. 
A título de esclarecimento, supõe-se que seja requerido um Pst de 3 unidades e uma oscilação de 39 variações retangulares por minuto. Então a relação $\Delta V / V$ será de $3,132 \%$ $(1,044 \times 3)$, o que equivale a variações de 1,88 Volts em torno dos 120 Volts, ou seja, $1,88=(3,132 / 100) \times 120 / 2$.

Agora que se tem o domínio necessário para a geração de sinais com flutuações de tensão, os valores de referência para a realização dos ensaios são mostrados na Tabela 3.8.

Tabela 3.8 - Ensaios de Flutuação de Tensão.

\begin{tabular}{|c|c|c|}
\hline \multirow{2}{*}{ Ensaio } & \multicolumn{2}{|c|}{ Características do Ensaio } \\
\cline { 2 - 3 } & Pst Aplicado & $\begin{array}{c}\text { Variações Retangulares } \\
\text { por Minuto }\end{array}$ \\
\hline 15 & 5,428 & 39 \\
\hline 16 & 5,506 & 07 \\
\hline 17 & 3,033 & 39 \\
\hline 18 & 3,048 & 07 \\
\hline 19 & 2,394 & 39 \\
\hline 20 & 2,360 & 07 \\
\hline 21 & 1,437 & 39 \\
\hline 22 & 1,475 & 07 \\
\hline 23 & 0,958 & 39 \\
\hline 24 & 0,983 & 07 \\
\hline
\end{tabular}

\subsubsection{VARIAções de Tensão de CuRTA DuRAÇÃo (VTCD)}

\subsubsection{Afundamentos de Tensão}

Nesta etapa de ensaios será gerada uma sequência de vários afundamentos de tensão, com um intervalo de 15 segundos entre cada um. A Tabela 3.9 mostra a tensão, a duração, e o número de eventos do ensaio 25. 
Tabela 3.9 - Ensaios de Afundamentos de Tensão.

\begin{tabular}{|c|c|c|c|}
\hline \multirow{2}{*}{ Ensaio } & \multicolumn{3}{|c|}{ Características do Ensaio } \\
\cline { 2 - 4 } & $\begin{array}{c}\text { Tensão } \\
{[\%]}\end{array}$ & $\begin{array}{c}\text { Duração dos } \\
\text { Eventos [ms] }\end{array}$ & $\begin{array}{c}\text { No de } \\
\text { Eventos }\end{array}$ \\
\hline 25 & 85 & 33,33 & 20 \\
\hline 26 & 85 & 333,33 & 20 \\
\hline 27 & 70 & 33,33 & 20 \\
\hline 28 & 70 & 333,33 & 20 \\
\hline 29 & 40 & 33,33 & 20 \\
\hline 30 & 40 & 333,33 & 20 \\
\hline 31 & 10 & 33,33 & 20 \\
\hline 32 & 10 & 333,33 & 20 \\
\hline
\end{tabular}

\subsubsection{VTCD COM AMPLITUDES EVOLUTIVAS}

Os três ensaios seguintes são bem semelhantes aos da seção anterior, porém, as elevações de tensões serão incluídas, haverá apenas dois eventos por teste, e também se monitorará o intervalo entre os eventos. A Tabela 3.10 mostra os valores requeridos na execução dos testes.

Tabela 3.10 - Ensaios de VTCD Com Amplitudes Evolutivas.

\begin{tabular}{|c|c|c|c|c|c|}
\hline \multirow{3}{*}{ Ensaio } & \multicolumn{5}{|c|}{ Características do Ensaio } \\
\hline & \multicolumn{2}{|c|}{$1^{\circ}$ Evento } & \multicolumn{2}{|c|}{$2^{\circ}$ Evento } & \multirow{2}{*}{$\begin{array}{l}\text { Intervalo Entre os } \\
\text { Eventos [ms] }\end{array}$} \\
\hline & Tensão [\%] & Duração [ms] & Tensão [\%] & Duração [ms] & \\
\hline 33 & 85 & 300 & 70 & 300 & 100 \\
\hline 34 & 85 & 300 & 110 & 300 & 100 \\
\hline 35 & 110 & 300 & 117 & 300 & 100 \\
\hline
\end{tabular}

\subsubsection{Variações de Tensão em Regime Permanente}

\subsubsection{Tensões CONSTANTES}

Nos ensaios 36 e 37 serão gerados sinais constantes com amplitude de $90 \%$ e $110 \%$ da tensão fundamental. As leituras serão realizadas na unidade de Volts, e em seguida 
convertidas manualmente para porcentagem. Os respectivos valores dos ensaios são mostrados na Tabela 3.11.

Tabela 3.11 - Ensaios com Tensões Constantes.

\begin{tabular}{|c|c|c|}
\hline \multirow{2}{*}{ Ensaio } & \multicolumn{2}{|c|}{ Características do Ensaio } \\
\cline { 2 - 3 } & Tensão [V] & Tensão [\%] \\
\hline 36 & 114,30 & 90 \\
\hline 37 & 139,70 & 110 \\
\hline
\end{tabular}

\subsubsection{TENSÃo COM VARIAÇões SUAVES do VALOR NOMINAL}

Este último ensaio testará a capacidade dos equipamentos em apurar as medições de tensão com variações suaves ao longo do tempo. A amplitude do sinal deve ter seu comportamento determinado pela envoltória da forma de onda mostrada na Figura 3.8.

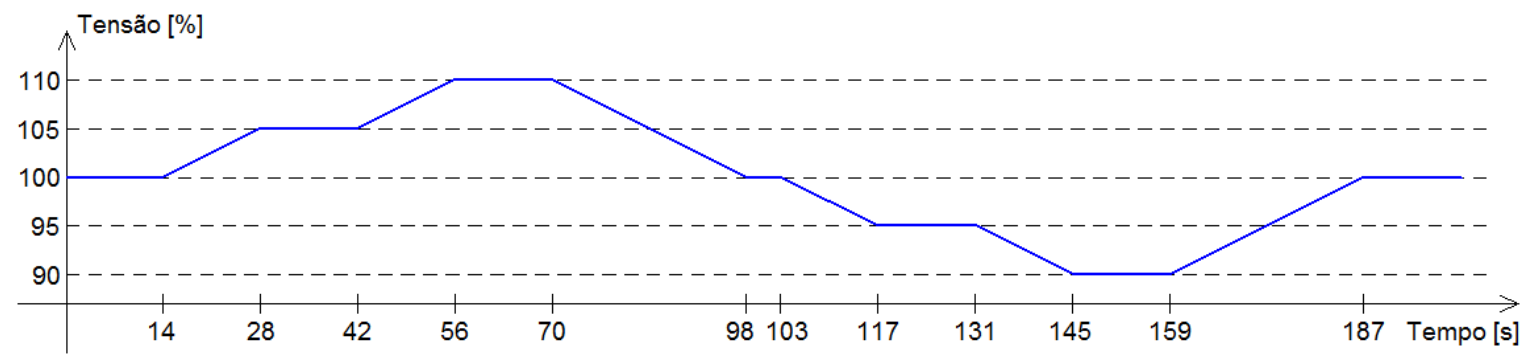

Figura 3.8 - Variações Suaves da Tensão.

Como o intervalo de integralização é de 10 minutos, este ciclo deve se repetir por três vezes, totalizando um tempo de 9 minutos e 21 segundos. Já nos 39 segundos restantes a tensão deverá permanecer em 100\% da fundamental (127 Volts), não contribuindo para alterar seu valor médio.

A Tabela 3.12 ilustra as características do referido ensaio:

Tabela 3.12 - Ensaio com Tensão Variável.

\begin{tabular}{|c|c|c|c|}
\multirow{2}{*}{ Ensaio } & \multicolumn{3}{|c|}{ Características do Ensaio } \\
\cline { 2 - 4 } & Tensão Mínima [V] & Tensão Máxima [V] & Tensão Média [V] \\
\hline 38 & 114,30 & 139,70 & 127,00 \\
\hline
\end{tabular}




\subsection{MÉtodos de Classificação}

Esta seção tem a finalidade de elaborar uma metodologia de classificação de ambos os equipamentos postos a prova. Essencialmente, após a coleta dos dados, os métodos utilizados para classificar os equipamentos podem ser divididos em dois:

- Na obtenção dos indicadores de desempenho: onde se faz a análise individual de cada ensaio;

- No tratamento estatístico desses indicadores: disponibilizando informações úteis sobre aspectos intrínsecos à determinada categoria de ensaios, além de uma avaliação geral para cada modelo de medidores.

\subsubsection{INDICADORES DE DESEMPENHO}

Basicamente, os indicadores de desempenho são formados por índices ou conceitos que permitem mensurar a precisão dos equipamentos para se medir determinada grandeza. A seguir, listam-se os cinco indicadores de desempenho que serão pormenorizados nas subseções sequentes:

1. Capacidade de medição das grandezas;

2. Erro percentual e atribuição de notas;

3. Erro de tempo;

4. Conceituação relativa às medidas de tempo;

5. Detecção de eventos.

\subsubsection{CAPACIDADE DE MEDIÇÃo dAs GRANDEZAS}

Como seu próprio título dá a entender, este indicador avalia a capacidade dos equipamentos em realizar as medições de todas as grandezas relativas à qualidade da energia.

\subsubsection{ERro Percentual e Atribuição de Notas}

O erro percentual será calculado usando a expressão 3.1:

$$
\text { Erro }(\%)=\frac{\mid \text { ValorMedido }- \text { ValorDeReferência } \mid}{\text { ValorDeReferência }} \times 100
$$

Por sua vez, para uma dada medição, será atribuída uma nota condizente com a faixa de valor que o erro percentual se enquadrar, essa relação é indicada pela Tabela 3.13. 
Tabela 3.13 - Correlação Erro Percentual e Nota de Desempenho.

\begin{tabular}{|c|c|}
\hline FAIXA DE ERROS [\%] & NOTA \\
\hline $0 \leq$ Erro $\leq 3$ & 10 \\
\hline $3<$ Erro $\leq 5$ & 09 \\
\hline $5<$ Erro $\leq 7,5$ & 07 \\
\hline $7,5<$ Erro $\leq 10$ & 05 \\
\hline $10<$ Erro $\leq 15$ & 03 \\
\hline $15<$ Erro $\leq 20$ & 01 \\
\hline Erro $>20$ & 0 \\
\hline
\end{tabular}

\subsubsection{ERRO DE TEMPO}

Para ensaios que envolvem grandezas de tempo, a avaliação se torna um pouco diferente. Nesses casos não teria sentido fazer a mensuração do erro em unidades percentuais, pois a escala de tempo de ocorrência dos eventos é da ordem de milissegundos.

Portanto, o erro é calculado pela diferença entre o tempo medido e o tempo de referência, conforme mostra a expressão 3.2:

$$
\text { Erro(ms) }=\mid \text { ValorMedido }- \text { ValorDeReferência } \mid
$$

\subsubsection{Conceituação Relativa Às Medidas de Tempo}

Apesar de ser útil para algumas aplicações, a estratégia de avaliação do indicador anterior não estabelece um parâmetro para a qualificação das grandezas medidas. Portanto, para sanar esse problema, foi estipulado um tempo limite de 1/2 ciclo de onda. Conforme é exposto na Tabela 3.14, se num determinado teste a discrepância entre o valor medido e o valor de referência for maior do que 1/2 ciclo, haverá uma reprovação, caso contrário, haverá uma aprovação.

Tabela 3.14 - Conceito de Desempenho Para Medidas de Tempo.

\begin{tabular}{|c|c|c|}
\hline $\begin{array}{c}\text { FAIXA DE ERRO } \\
{[\text { CICLOS] }}\end{array}$ & $\begin{array}{c}\text { FAIXA DE ERRO } \\
{[\mathrm{ms}]}\end{array}$ & CONCEITO \\
\hline $0 \leq$ Erro $\leq 1 / 2$ & $0 \leq$ Erro $\leq 8,33$ & APROVADO \\
\hline Erro $>1 / 2$ & Erro $>8,33$ & REPROVADO \\
\hline
\end{tabular}




\subsubsection{DETECÇÃo de Eventos}

Como seu próprio título dá a entender, este indicador permite avaliar a capacidade dos medidores em detectar a ocorrência de certo evento, como por exemplo, uma elevação ou afundamento momentâneo de tensão.

\subsubsection{TRATAMENTO ESTAtístico dos IndicAdoRES DE DESEMPENHO}

Todos os métodos, utilizados para obtenção dos indicadores de desempenho, que foram abordados até o momento se aplicam à avaliação das grandezas de forma individual a cada teste. Porém, também é importante fazer uma análise de cunho mais abrangente, agrupando os ensaios em suas respectivas classes de módulos, ou dividindo-os em dois grupos, de acordo com o modelo do equipamento.

Portanto, a avaliação dos resultados será dividida em três partes, a saber:

- Análise individual: caracterizada pela obtenção dos indicadores de desempenho explicados na seção 3.4.1. Os resultados de cada teste serão tratados de maneira particular;

- Análise por divisão em módulos: os resultados obtidos serão divididos em quatro módulos de acordo com o arranjo dos indicadores da qualidade da energia proposto pela Tabela 3.2;

- Análise global: os resultados obtidos serão condensados numa avaliação geral de cada modelo de equipamentos.

\subsubsection{ANÁLISE POR DIVISÃo EM MódULOS}

Nesta parte, o método para a avaliação consiste na obtenção dos valores médios para os indicadores de erros percentuais e de tempo, além de se fazer um apanhado geral dos demais indicadores.

Os valores dos erros percentuais e de tempo médio são obtidos seguindo respectivamente as expressões 3.3 e 3.4 :

$$
\begin{aligned}
& \operatorname{ErroMédio}(\%)=\frac{\sum_{n=1}^{T} \operatorname{Erro}_{n}(\%)}{T} \\
& \operatorname{ErroMédio~}(\mathrm{ms})=\frac{\sum_{n=1}^{T} \operatorname{Erro}_{n}(\mathrm{~ms})}{T}
\end{aligned}
$$

Onde $\mathrm{n}$ representa o índice atribuído ao erro e a variável T representa o número total de erros computados. 


\subsubsection{ANÁlise Global}

Como a análise global consiste no agrupamento dos resultados por modelo de medidor, é natural pensar que esta avaliação poderia ser realizada aos moldes daquela feita pela divisão em módulos. Porém, isto acarretaria numa distorção dos valores, pois os módulos de ensaios com maior número de testes também teriam maior peso na obtenção dos valores médios.

Para contornar essa situação, deve-se igualar o peso de cada um dos módulos de ensaio, bastando fazer a média dos resultados obtidos por módulos, e não dos indicadores de desempenho de maneira individual. A expressão 3.5 mostra como calcular o erro global médio.

$$
\text { ErroGlobalMédio }=\frac{\sum_{n=1}^{M} \text { ErroMédio }_{n}}{M}
$$

Onde, $\mathrm{n}$ representa o índice atribuído ao módulo e a variável $\mathrm{M}$ representa o número total de módulos, ou seja, M é igual a quatro. 


\section{CAPÍTULO 4}

\section{4 - RESULTADOS}

O presente capítulo tem o objetivo de apresentar os resultados alcançados por ambos os equipamentos de medição, segundo a metodologia de classificação proposta pela seção 3.4 do capítulo passado.

\subsection{Avaliação e RESULTAdos IndividuAIS dos ENSAIOS}

$\mathrm{Na}$ avaliação individual dos ensaios, o processo de obtenção dos dados consiste no que foi explicado na seção 3.4.1 sobre os indicadores de desempenho. Os resultados obtidos, devidamente organizados, são indicados pelas Tabelas 4.1 a 4.19.

\subsubsection{TENSÕES HARMÔNICAS INDIVIDUAIS}

Como pode ser observado pela Tabela 4.1, nesta série de ensaios, tanto o ION 7660 quanto o SEL-734 apresentaram resultados muito consistentes. A maior discrepância em relação ao valor de referência foi de 1,0\% para o ION 7600 e 2,0\% para o SEL-734.

Tabela 4.1 - Resultados de Harmônicas Individuais.

\begin{tabular}{|c|c|c|c|c|}
\hline \multirow{2}{*}{ Ensaio } & \multicolumn{2}{|c|}{ Características do Ensaio } & \multicolumn{2}{|c|}{ Resultados } \\
\hline & $\begin{array}{l}\text { Ordem da } \\
\text { Harmônica }\end{array}$ & $\begin{array}{c}\text { Valor Aplicado } \\
{[\%]}\end{array}$ & Eq. & $\begin{array}{c}\text { Amplitude } \\
{[\%]}\end{array}$ \\
\hline \multirow{2}{*}{01} & \multirow{2}{*}{02} & \multirow{2}{*}{1,00} & ION & 1,00 \\
\hline & & & SEL & 0,99 \\
\hline \multirow{2}{*}{02} & \multirow{2}{*}{03} & \multirow{2}{*}{2,00} & ION & 2,01 \\
\hline & & & SEL & 2,02 \\
\hline \multirow{2}{*}{03} & \multirow{2}{*}{04} & \multirow{2}{*}{1,00} & ION & 1,00 \\
\hline & & & SEL & 0,99 \\
\hline \multirow{2}{*}{04} & \multirow{2}{*}{05} & \multirow{2}{*}{2,00} & ION & 2,01 \\
\hline & & & SEL & 2,01 \\
\hline \multirow{2}{*}{05} & \multirow{2}{*}{07} & \multirow{2}{*}{2,00} & ION & 1,99 \\
\hline & & & SEL & 2,00 \\
\hline \multirow{2}{*}{06} & \multirow{2}{*}{11} & \multirow{2}{*}{1,50} & ION & 1,49 \\
\hline & & & SEL & 1,50 \\
\hline
\end{tabular}


(Continuação Tabela 4.1)

\begin{tabular}{|l|l|l|l|l|}
\hline 07 & 13 & 1,50 & ION & 1,50 \\
\hline \multirow{2}{*}{08} & 17 & 1,00 & SEL & 1,49 \\
\hline \multirow{2}{*}{09} & 25 & 1,00 & ION & 1,00 \\
\hline & & & SEL & 0,99 \\
\hline
\end{tabular}

Por sua vez, aplicando a metodologia da seção 3.4.1.2, obtem-se as notas individuais de cada ensaio, as quais são mostradas na Tabela 4.2.

Tabela 4.2 - Notas de Harmônicas Individuais.

\begin{tabular}{|c|c|c|}
\hline \multirow{2}{*}{ Ensaio } & Nota: ION 7600 & Nota: SEL-734 \\
\cline { 2 - 3 } & Amplitude & Amplitude \\
\hline 01 & 10 & 10 \\
\hline$\vdots$ & $\vdots$ & $\vdots$ \\
\hline 09 & 10 & 10 \\
\hline
\end{tabular}

\subsubsection{COMPOSIÇÃO DE HARMÔNICAS}

No ensaio de composição de harmônicas houve uma diferença entre o valor do índice DHTV medido e o de referência. Entretanto, pela análise das Tabelas 4.3 e 4.4, respectivamente sobre os valores de referência e os resultados da medição, percebe-se que algumas ordens de harmônicas apresentaram discrepâncias mais acentuadas do que as outras. Além disso, mesmo para esses casos onde os erros foram maiores, a leitura das grandezas foi muito semelhante para os dois equipamentos medidores. Portanto, neste ensaio em específico, admite-se a hipótese de parte dos erros serem inerentes ao próprio sinal gerado, mas ainda assim vale ressaltar que em nenhum dos casos a discrepância se mostrou tão alta a nível de se fazer uma mitigação mais detalhada do ensaio.

Tabela 4.3 - Características do Ensaio de Composição de Harmônicas.

\begin{tabular}{|c|c|c|c|c|c|c|c|c|c|c|}
\hline & \multicolumn{7}{|c|}{ Caracteristicas do Ensaio } \\
\hline Ensaio & $V_{2}[\%]$ & $V_{3}[\%]$ & $V_{4}[\%]$ & $V_{5}[\%]$ & $V_{7}[\%]$ & $V_{11}[\%]$ & $V_{13}[\%]$ & $V_{17}[\%]$ & $V_{25}[\%]$ & $\begin{array}{c}\text { DHTV } \\
{[\%]}\end{array}$ \\
\hline 10 & 1,0 & 2,0 & 1,0 & 2,0 & 2,0 & 1,5 & 1,5 & 1,0 & 1,5 & 4,5 \\
\hline
\end{tabular}


Tabela 4.4 - Resultados de Composição de Harmônicas.

\begin{tabular}{|c|c|c|c|c|c|c|c|c|c|c|c|}
\hline \multirow{2}{*}{ Ensaio } & \multicolumn{10}{|c|}{ Resultados } \\
\cline { 2 - 13 } & Eq. & V2 [\%] & V3 [\%] & V4 [\%] & V5 [\%] & V7 [\%] & V11 [\%] & V13 [\%] & V17 [\%] & V25 [\%] & $\begin{array}{c}\text { DHTV } \\
{[\%]}\end{array}$ \\
\hline \multirow{2}{*}{10} & ION & 1,02 & 2,00 & 0,95 & 2,02 & 1,97 & 1,56 & 1,53 & 1,08 & 1,38 & 4,67 \\
\hline & SEL & 1,01 & 2,01 & 0,94 & 2,03 & 1,95 & 1,55 & 1,54 & 1,08 & 1,35 & 4,66 \\
\hline
\end{tabular}

Neste ensaio, como se pode notar pela Tabela 4.5, as notas apenas serão atribuídas para o índice de distorção harmônica total, visto que na seção 4.1.1 as componentes harmônicas individuais já foram avaliadas separadamente.

Tabela 4.5 - Notas de Composição de Harmônica.

\begin{tabular}{|c|c|c|}
\hline \multirow{2}{*}{ Ensaio } & Nota: ION 7600 & Nota: SEL-734 \\
\cline { 2 - 3 } & DHTV & DHTV \\
\hline 10 & 09 & 09 \\
\hline
\end{tabular}

\subsubsection{TENSÕES HARMÔNICAS COM DIFERENTES FREQUÊNCIAS}

Para os ensaios envolvendo tensões harmônicas com frequências diferentes da nominal, ambos os modelos apresentaram resultados bem coerentes, contudo, houve uma discrepância razoável da amplitude da harmônica para o ensaio de número 12 (os dois dispositivos ficaram bem no limiar entre nota 09 e 10). Já para parte de medição da frequência, o SEL-734 apresentou um pequeno erro de $0.01 \mathrm{~Hz}$ no primeiro teste. De modo a comprovar o que foi dito, a Tabela 4.6 mostra as leituras realizadas pelos dois equipamentos.

Tabela 4.6 - Resultados de Tensões Harmônicas com Diferentes Frequências.

\begin{tabular}{|c|c|c|c|c|c|c|}
\hline \multirow{2}{*}{ Ensaio } & \multicolumn{3}{|c|}{ Características do Ensaio } & \multicolumn{3}{|c|}{ Resultados } \\
\hline & $\begin{array}{l}\text { Freq. Fund. } \\
\text { [Hz] }\end{array}$ & $\begin{array}{l}\text { Ordem da } \\
\text { Harmônica }\end{array}$ & $\begin{array}{c}\text { Amplitude } \\
\text { [\%] }\end{array}$ & Eq. & $\begin{array}{l}\text { Freq. Fund. } \\
\text { [Hz] }\end{array}$ & $\begin{array}{c}\text { Amplitude } \\
{[\%]}\end{array}$ \\
\hline \multirow{2}{*}{11} & \multirow{2}{*}{$59,9 \mathrm{~Hz}$} & \multirow{2}{*}{05} & \multirow{2}{*}{2,0} & ION & 59,90 & 2,02 \\
\hline & & & & SEL & 59,89 & 2,01 \\
\hline \multirow{2}{*}{12} & \multirow{2}{*}{$60,1 \mathrm{~Hz}$} & \multirow{2}{*}{13} & \multirow{2}{*}{1,5} & ION & 60,10 & 1,54 \\
\hline & & & & SEL & 60,10 & 1,55 \\
\hline
\end{tabular}


As notas obtidas para essa seção de ensaios são expostas na Tabela 4.7. Com relação à amplitude da componente harmônica do ensaio número 12, os dois dispositivos tiveram um erro percentual que correspondeu a um limiar entre nota 09 e 10, contudo, o medidor ION 7600 recebeu nota máxima, enquanto o SEL-734 recebeu nota 09.

Tabela 4.7 - Notas de Tensões Harmônicas com Diferentes Frequências.

\begin{tabular}{|c|c|c|c|c|}
\hline \multirow{2}{*}{ Ensaio } & \multicolumn{2}{|c|}{ Nota: ION 7600} & \multicolumn{2}{|c|}{ Nota: SEL-734 } \\
\cline { 2 - 5 } & Freq. Fund. & Amplitude & Freq. Fund. & Amplitude \\
\hline 11 & 10 & 10 & 10 & 10 \\
\hline 12 & 10 & 10 & 10 & 09 \\
\hline
\end{tabular}

\subsubsection{TENSÕES HARMÔNICAS INDIVIDUAIS VARIÁVEIS}

Os ensaios 13 e 14, referentes a tensões harmônicas individuais variáveis, tem seus resultados e notas exibidos pelas Tabelas 4.8 e 4.9. Fazendo uma análise dos resultados, observa-se que apesar de todos os quesitos terem recebido nota 10 , 0 SEL-734 tem certa dificuldade para monitorar variações bruscas das componentes harmônicas, pois, em valores absolutos, sua discrepância foi relativamente alta, o que não aconteceu com o ION 7600, o qual apresentou resultados bem próximos do esperado.

Tabela 4.8 - Resultados de Tensões Harmônicas Individuais Variáveis.

\begin{tabular}{|c|c|c|c|c|c|c|}
\hline \multirow[b]{2}{*}{ Ensaio } & \multicolumn{3}{|c|}{ Características do Ensaio } & \multicolumn{3}{|c|}{ Resultados } \\
\hline & Descrição & $\begin{array}{l}\text { V5 média } \\
{[\%]}\end{array}$ & $\begin{array}{l}\text { DHTV } \\
{[\%]}\end{array}$ & Eq. & $\begin{array}{l}\text { V5 média } \\
{[\%]}\end{array}$ & $\begin{array}{l}\text { DHTV } \\
{[\%]}\end{array}$ \\
\hline \multirow{2}{*}{13} & $\begin{array}{l}\text { - Variações suaves do } \\
\text { harmônico de ordem } 5 ;\end{array}$ & \multirow{2}{*}{5,29} & \multirow{2}{*}{6,00} & ION & 5,32 & 6,04 \\
\hline & $\begin{array}{l}\text { Degraus de } 250 \mathrm{~ms} \\
\qquad \mathrm{~V}_{3}=2,00 \% ; \mathrm{V} 7=2,00 \%\end{array}$ & & & SEL & 5,31 & 6,03 \\
\hline \multirow[b]{2}{*}{14} & $\begin{array}{l}\text { - Variações abruptas do } \\
\text { harmônico de ordem 5; }\end{array}$ & \multirow[b]{2}{*}{6,00} & \multirow[b]{2}{*}{6,80} & ION & 6,00 & 6,83 \\
\hline & $\begin{array}{l}\text { - Degraus de } 600 \mathrm{~ms} \\
\qquad \begin{array}{c}\mathrm{V} 3=2,00 \% ; \mathrm{V} 7=2,00 \% \\
\mathrm{~V}_{11}=1,50 \%\end{array}\end{array}$ & & & SEL & 5,84 & 6,72 \\
\hline
\end{tabular}


Tabela 4.9 - Notas de Tensões Harmônicas Individuais Variáveis.

\begin{tabular}{|c|c|c|c|c|c|}
\multirow{2}{*}{ Ensaio } & \multicolumn{2}{|c|}{ Nota: ION 7600} & \multicolumn{2}{|c|}{ Nota: SEL-734 } \\
\cline { 2 - 6 } & V5 média & DHTV & V5 média & DHTV \\
\hline 13 & 10 & 10 & 10 & 10 \\
\hline 14 & 10 & 10 & 10 & 10 \\
\hline
\end{tabular}

\subsubsection{Avaliação de Flutuações de Tensão (Flicker)}

No geral, como pode ser visto na Tabela 4.10, os resultados dos testes do fenômeno de cintilação luminosa foram satisfatórios, à exceção do ensaio 16 para o medidor ION 7600 o qual perfez um erro de $5,70 \%$

Tabela 4.10 - Resultados de Flicker.

\begin{tabular}{|c|c|c|c|c|}
\hline \multirow{2}{*}{ Ensaio } & \multicolumn{2}{|c|}{ Características do Ensaio } & \multicolumn{2}{|c|}{ Resultados } \\
\hline & $\begin{array}{l}\text { Variações Retangulares } \\
\text { por Minuto }\end{array}$ & Pst Aplicado & Eq. & Pst Medido \\
\hline \multirow{2}{*}{15} & \multirow{2}{*}{39} & \multirow{2}{*}{5,428} & ION & 5,42 \\
\hline & & & SEL & 5,53 \\
\hline \multirow{2}{*}{16} & \multirow{2}{*}{07} & \multirow{2}{*}{5,506} & ION & 5,82 \\
\hline & & & SEL & 5,52 \\
\hline \multirow{2}{*}{17} & \multirow{2}{*}{39} & \multirow{2}{*}{3,033} & ION & 3,04 \\
\hline & & & SEL & 3,10 \\
\hline \multirow{2}{*}{18} & \multirow{2}{*}{07} & \multirow{2}{*}{3,048} & ION & 3,11 \\
\hline & & & SEL & 3,06 \\
\hline \multirow{2}{*}{19} & \multirow{2}{*}{39} & \multirow{2}{*}{2,394} & ION & 2,40 \\
\hline & & & SEL & 2,45 \\
\hline \multirow{2}{*}{20} & \multirow{2}{*}{07} & \multirow{2}{*}{2,360} & ION & 2,40 \\
\hline & & & SEL & 2,43 \\
\hline \multirow{2}{*}{21} & \multirow{2}{*}{39} & \multirow{2}{*}{1,437} & ION & 1,44 \\
\hline & & & SEL & 1,43 \\
\hline \multirow{2}{*}{22} & \multirow{2}{*}{07} & \multirow{2}{*}{1,475} & ION & 1,51 \\
\hline & & & SEL & 1,47 \\
\hline \multirow{2}{*}{23} & \multirow{2}{*}{39} & \multirow{2}{*}{0,958} & ION & 0,96 \\
\hline & & & SEL & 0,96 \\
\hline \multirow{2}{*}{24} & \multirow{2}{*}{07} & \multirow{2}{*}{0,983} & ION & 1,00 \\
\hline & & & SEL & 0,99 \\
\hline
\end{tabular}


O único ensaio que não recebeu nota máxima foi propriamente o de número 16 . Sua nota 07 foi a mais baixa entre todas as outras. A Tabela 4.11 mostra a relação das notas desta sequência de testes.

Tabela 4.11 - Notas de Flicker.

\begin{tabular}{|c|c|c|}
\hline \multirow{2}{*}{ Ensaio } & Nota: ION 7600 & Nota: SEL-734 \\
\cline { 2 - 3 } & Pst Medido & Pst Medido \\
\hline 15 & 10 & 10 \\
\hline 16 & 07 & 10 \\
\hline 18 & 10 & 10 \\
\hline$\vdots$ & $\vdots$ & $\vdots$ \\
\hline 24 & 10 & 10 \\
\hline
\end{tabular}

\subsubsection{Afundamentos de Tensão}

Os resultados obtidos, concernentes a seção de ensaios de afundamentos de tensão, são exibidos pela Tabela 4.12. Observa-se que as medições da amplitude dos eventos foram bem próximas do valor de referência para ambos os modelos. Contudo, as medições de duração dos eventos foram bem piores para o dispositivo ION 7600: em muitos casos o erro foi maior do que 1/2 ciclo de onda, e em vários outros testes houve aprovação com diferenças de tempo no limiar dos 8,33 ms.

Tabela 4.12 - Resultados de Afundamentos de Tensão.

\begin{tabular}{|c|c|c|c|c|c|c|c|}
\hline \multirow[b]{2}{*}{ Ensaio } & \multicolumn{3}{|c|}{ Características do Ensaio } & \multicolumn{4}{|c|}{ Resultados } \\
\hline & $\begin{array}{c}\text { Tensão } \\
{[\%]}\end{array}$ & $\begin{array}{l}\text { Duração dos } \\
\text { Eventos [ms] }\end{array}$ & $\begin{array}{l}\text { № de } \\
\text { Eventos }\end{array}$ & Eq. & $\begin{array}{l}\text { Amplitude } \\
\text { Média [\%] }\end{array}$ & $\begin{array}{l}\text { Duração } \\
\text { Média [ms] }\end{array}$ & $\begin{array}{l}\text { № de } \\
\text { Eventos }\end{array}$ \\
\hline \multirow{2}{*}{25} & \multirow{2}{*}{85} & \multirow{2}{*}{33,33} & \multirow{2}{*}{20} & ION & 85,00 & 27,10 & 20 \\
\hline & & & & SEL & 84,70 & 32,95 & 20 \\
\hline \multirow{2}{*}{26} & \multirow{2}{*}{85} & \multirow{2}{*}{333,33} & \multirow{2}{*}{20} & ION & 85,00 & 326,00 & 20 \\
\hline & & & & SEL & 84,64 & 333,10 & 20 \\
\hline \multirow{2}{*}{27} & \multirow{2}{*}{70} & \multirow{2}{*}{33,33} & \multirow{2}{*}{20} & ION & 70,00 & 39,00 & 20 \\
\hline & & & & SEL & 69,70 & 33,55 & 20 \\
\hline \multirow{2}{*}{28} & \multirow{2}{*}{70} & \multirow{2}{*}{333,33} & \multirow{2}{*}{20} & ION & 70,00 & 340,90 & 20 \\
\hline & & & & SEL & 69,65 & 333,55 & 20 \\
\hline
\end{tabular}


(Continuação Tabela 4.12)

\begin{tabular}{|c|c|c|c|c|c|c|c|}
\hline \multirow{2}{*}{29} & \multirow{2}{*}{40} & \multirow{2}{*}{33,33} & \multirow{2}{*}{20} & ION & 40,10 & 41,95 & 20 \\
\hline & & & & SEL & 39,83 & 34,55 & 20 \\
\hline \multirow{2}{*}{30} & \multirow{2}{*}{40} & \multirow{2}{*}{333,33} & \multirow{2}{*}{20} & ION & 40,10 & 341,85 & 20 \\
\hline & & & & SEL & 39,77 & 333,85 & 20 \\
\hline \multirow{2}{*}{31} & \multirow{2}{*}{10} & \multirow{2}{*}{333,33} & \multirow{2}{*}{20} & ION & 10,20 & 42,35 & 20 \\
\hline & & & & SEL & 09,82 & 34,70 & 20 \\
\hline \multirow{2}{*}{32} & \multirow{2}{*}{10} & \multirow{2}{*}{333,33} & \multirow{2}{*}{20} & ION & 10,20 & 342,35 & 20 \\
\hline & & & & SEL & 09,84 & 334,55 & 20 \\
\hline
\end{tabular}

Como pode ser visto na Tabela 4.13, para o quesito de amplitude média não houve nenhuma nota inferior a 10 e, além disso, ambos os equipamentos foram capazes de captar a totalidade dos afundamentos. Observando-se a coluna de número de reprovações é possível saber a quantidade de medições errôneas (lembrando que em cada ensaio foram gerados 20 eventos). Portanto, nota-se que o ION 7600 errou na leitura da duração de 40 eventos, de um total de 160, enquanto o SEL-734 não errou nenhuma.

Tabela 4.13 - Notas e Conceitos de Afundamentos de Tensão.

\begin{tabular}{|c|c|c|c|c|c|c|c|c|}
\hline \multirow{2}{*}{ Ensaio } & \multicolumn{4}{|c|}{ Nota e Avaliação: ION 7600} & \multicolumn{4}{|c|}{ Nota e Avaliação: SEL-734 } \\
\hline & $\begin{array}{l}\text { Amplitude } \\
\text { Média }\end{array}$ & $\begin{array}{l}\text { Duração } \\
\text { Média }\end{array}$ & $\begin{array}{l}\quad № \text { de } \\
\text { Eventos }\end{array}$ & $\begin{array}{c}\text { № de } \\
\text { Reprovações }\end{array}$ & $\begin{array}{l}\text { Amplitude } \\
\text { Média }\end{array}$ & $\begin{array}{l}\text { Duração } \\
\text { Média }\end{array}$ & $\begin{array}{l}\text { № de } \\
\text { Eventos }\end{array}$ & $\begin{array}{c}\text { № de } \\
\text { Reprovações }\end{array}$ \\
\hline 25 & 10 & $A$ & OK & 7 & 10 & A & OK & 0 \\
\hline 26 & 10 & $A$ & OK & 1 & 10 & A & OK & 0 \\
\hline 27 & 10 & $A$ & OK & 0 & 10 & A & OK & 0 \\
\hline 28 & 10 & $A$ & OK & 6 & 10 & A & OK & 0 \\
\hline 29 & 10 & $\mathrm{R}$ & OK & 3 & 10 & A & OK & 0 \\
\hline 30 & 10 & $\mathrm{R}$ & $\mathrm{OK}$ & 9 & 10 & A & OK & 0 \\
\hline 31 & 10 & $\mathrm{R}$ & OK & 3 & 10 & A & OK & 0 \\
\hline 32 & 10 & $\mathrm{R}$ & OK & 11 & 10 & $A$ & OK & 0 \\
\hline
\end{tabular}

\subsubsection{VTCD COM AMPLITUDES EVOLUTIVAS}

Assim como a série de testes anterior, não houve problemas com as medições das amplitudes dos eventos. Novamente, percebe-se uma dificuldade do ION $7600 \mathrm{em}$ aferir corretamente as grandezas temporais, mas nesse caso, o SEL-734 apresentou pela primeira vez uma leitura com erro maior que 1/2 ciclo de onda. Em sequência, as 
Tabelas 4.14 e 4.15 exibem respectivamente os valores de referência e os resultados dos ensaios de VTCD com amplitudes evolutivas.

Tabela 4.14 - Características dos Ensaios de VTCD com Amplitudes Evolutivas.

\begin{tabular}{|c|c|c|c|c|c|}
\hline \multirow{3}{*}{ Ensaio } & \multicolumn{5}{|c|}{ Características do Ensaio } \\
\hline & \multicolumn{2}{|c|}{ 1을 Evento } & \multicolumn{2}{|c|}{$2^{\circ}$ Evento } & \multirow{2}{*}{$\begin{array}{l}\text { Intervalo Entre os } \\
\text { Eventos [ms] }\end{array}$} \\
\hline & Tensão [\%] & Duração [ms] & Tensão [\%] & Duração [ms] & \\
\hline 33 & 85 & 300 & 70 & 300 & 100 \\
\hline 34 & 85 & 300 & 110 & 300 & 100 \\
\hline 35 & 110 & 300 & 117 & 300 & 100 \\
\hline
\end{tabular}

Tabela 4.15 - Resultados de VTCD com Amplitudes Evolutivas.

\begin{tabular}{|c|c|c|c|c|c|c|}
\hline \multirow{3}{*}{ Ensaio } & \multicolumn{6}{|c|}{ Resultados } \\
\hline & \multirow{2}{*}{ Eq. } & \multicolumn{2}{|c|}{ 1ํㅡㄹento } & \multicolumn{2}{|c|}{ 2ํㅡㄹento } & \multirow{2}{*}{$\begin{array}{l}\text { Intervalo Entre os } \\
\text { Eventos [ms] }\end{array}$} \\
\hline & & Tensão [\%] & Duração [ms] & Tensão [\%] & Duração [ms] & \\
\hline \multirow{2}{*}{33} & ION & 85,0 & 300 & 70,0 & 300 & 100 \\
\hline & SEL & 84,7 & 298 & 69,7 & 303 & 99 \\
\hline \multirow{2}{*}{34} & ION & 85,0 & 291 & 110,2 & 284 & 109 \\
\hline & SEL & 84,6 & 300 & 111,1 & 297 & 103 \\
\hline \multirow{2}{*}{35} & ION & 110,2 & 283 & 116,5 & 300 & 125 \\
\hline & SEL & 111,0 & 283 & 118,1 & 299 & 101 \\
\hline
\end{tabular}

Por conseguinte, as notas e os conceitos de desempenho obtidos para essa seção de ensaios são expostos na Tabela 4.16.

Tabela 4.16 - Notas e Conceitos de VTCD com Amplitudes Evolutivas.

\begin{tabular}{|c|c|c|c|c|c|c|c|c|c|c|}
\hline \multirow{3}{*}{ Ensaio } & \multicolumn{5}{|c|}{ Nota e Avaliação: ION 7600} & \multicolumn{5}{|c|}{ Nota e Avaliação: SEL-734 } \\
\hline & \multicolumn{2}{|c|}{ 10 Evento } & \multicolumn{2}{|c|}{$2^{\circ}$ Evento } & \multirow{2}{*}{$\begin{array}{l}\text { Intervalo } \\
\text { Entre os } \\
\text { Eventos }\end{array}$} & \multicolumn{2}{|c|}{$1 \%$ Evento } & \multicolumn{2}{|c|}{$2^{\circ}$ Evento } & \multirow{2}{*}{$\begin{array}{l}\text { Intervalc } \\
\text { Entre os } \\
\text { Eventos }\end{array}$} \\
\hline & Tensão & Duração & Tensão & Duração & & Tensão & Duração & Tensão & Duração & \\
\hline 33 & 10 & A & 10 & A & A & 10 & A & 10 & A & A \\
\hline 34 & 10 & $\mathrm{R}$ & 10 & $\mathrm{R}$ & $\mathrm{R}$ & 10 & A & 10 & A & A \\
\hline 35 & 10 & $\mathrm{R}$ & 10 & A & $\mathrm{R}$ & 10 & $\mathrm{R}$ & 10 & A & A \\
\hline
\end{tabular}


Obs.: O intervalo entre os eventos foram calculados indiretamente, como é mostrado na expressão 4.1:

$$
\text { Intervalo }=I_{2}-I_{1}-D_{1}
$$

Onde $I_{1}$ e $I_{2}$ representam respectivamente o início do primeiro e do segundo evento e $D_{1}$ representa a duração do primeiro evento.

\subsubsection{Tensões Constantes}

Como pode ser visto na Tabela 4.17, os ensaios de tensões constantes tiveram resultados bem satisfatórios, ambos os medidores foram capazes de aferir as medidas com precisão.

Tabela 4.17 - Resultados de Tensões Constantes.

\begin{tabular}{|c|c|c|c|c|c|}
\hline \multirow{2}{*}{ Ensaio } & Características do Ensaio & \multicolumn{4}{|c|}{ Resultados } \\
\cline { 2 - 7 } & Tensão [V] & Tensão [\%] & Eq. & Tensão [V] & Tensão [\%] \\
\hline 36 & 114,30 & 90 & ION & 114,20 & 90 \\
\hline \multirow{2}{*}{37} & 139,70 & 110 & SEL & 114,35 & 90 \\
\hline & & & ION & 139,60 & 110 \\
\hline
\end{tabular}

Por consequência do bom desempenho, as notas mostradas na Tabela 4.18 não poderiam ser diferentes de 10.

Tabela 4.18 - Notas de Tensões Constantes.

\begin{tabular}{|c|c|c|}
\hline \multirow{2}{*}{ Ensaio } & Nota: ION 7600 & Nota: SEL-734 \\
\cline { 1 - 3 } & Tensão & Tensão \\
\hline 36 & 10 & 10 \\
\hline 37 & 10 & 10 \\
\hline
\end{tabular}

\subsubsection{TENSÃo COM VARIAçÕES SUAVES do VALOR NOMINAL}

Neste último ensaio ambos os modelos se saíram muito bem nos quesitos avaliados, mas ainda assim, ao analisar a Tabela 4.19, percebe-se uma pequena superioridade do ION 7600 em relação ao SEL-734. 
Tabela 4.19 - Resultados de Variações Suaves de Tensão.

\begin{tabular}{|c|c|c|c|c|c|c|c|}
\hline & \multicolumn{3}{|c|}{ Características do Ensaio } & \multicolumn{4}{c|}{ Resultados } \\
Ensaio & $\begin{array}{c}\text { Tensão } \\
\text { Mínima [V] }\end{array}$ & $\begin{array}{c}\text { Tensão } \\
\text { Máxima [V] }\end{array}$ & $\begin{array}{c}\text { Tensão } \\
\text { Média [V] }\end{array}$ & Eq. & $\begin{array}{c}\text { Tensão } \\
\text { Mínima [V] }\end{array}$ & $\begin{array}{c}\text { Tensão } \\
\text { Máxima [V] }\end{array}$ & $\begin{array}{c}\text { Tensão } \\
\text { Média [V] }\end{array}$ \\
\hline 38 & 114,30 & 139,70 & 127,00 & ION & 114,00 & 140 & 126,93 \\
\hline \multirow{2}{*}{38} & & SEL & 116,78 & 139,18 & 127,09 \\
\hline
\end{tabular}

Por fim, as notas obtidas para o ensaio em questão são enquadradas na Tabela 4.20.

Tabela 4.20 - Notas de Variações Suaves de Tensão.

\begin{tabular}{|c|c|c|c|c|c|c|}
\hline & \multicolumn{3}{|c|}{ Nota: ION 7600 } & \multicolumn{3}{c|}{ Nota: SEL-734 } \\
\hline Ensaio & $\begin{array}{c}\text { Tensão } \\
\text { Mínima }\end{array}$ & $\begin{array}{c}\text { Tensão } \\
\text { Máxima }\end{array}$ & $\begin{array}{c}\text { Tensão } \\
\text { Média }\end{array}$ & $\begin{array}{c}\text { Tensão } \\
\text { Mínima }\end{array}$ & $\begin{array}{c}\text { Tensão } \\
\text { Máxima }\end{array}$ & $\begin{array}{c}\text { Tensão } \\
\text { Média }\end{array}$ \\
\hline 38 & 10 & 10 & 10 & 10 & 10 & 10 \\
\hline
\end{tabular}

\subsection{Avaliação Por Divisão em Módulos}

Nesta etapa de avaliação, a análise dos resultados foi feita por meio dos processos metodológicos abordados na seção de mesmo título do capítulo passado. Os resultados obtidos, repartidos por seções de cada módulo, são expostos pelas Tabelas 4.21 a 4.24.

\subsubsection{TENSÕES HARMÔNICAS}

Como pode ser visto na Tabela 4.21, com relação a este módulo de ensaios, ambos os equipamentos se saíram bem, porém, o SEL-734 se mostrou um pouco inferior: obteve nota mais baixa e um erro médio aproximadamente 2,5 vezes maior do que o outro modelo.

Tabela 4.21 - Módulo de Harmônicas.

\begin{tabular}{|c|c|c|}
\hline Modelo & Erro Médio [\%] & Nota Média \\
\hline ION & 0,44 & 9,95 \\
\hline SEL & 1,09 & 9,89 \\
\hline
\end{tabular}




\subsubsection{Flutuações De TENSÃo (FLICKER)}

Com relação ao módulo de ensaios sobre flicker, novamente, os dispositivos obtiveram desempenhos semelhantes. Entretanto desta vez foi o ION 7600 que apresentou resultados um pouco pior, inclusive recebeu uma nota $7 \mathrm{em}$ um dos ensaios. A Tabela 4.22 mostra os valores dos índices calculados.

Tabela 4.22 - Módulo de Flicker.

\begin{tabular}{|c|c|c|}
\hline Modelo & Erro Médio [\%] & Nota Média \\
\hline ION & 1,46 & 9,7 \\
\hline SEL & 1.18 & 10,0 \\
\hline
\end{tabular}

\subsubsection{VARIAÇÕES DE TENSÃo de CURTA DURAÇÃo (VTCD)}

Os ensaios atinentes às variações de tensões de curta duração tem uma quantidade maior de itens para se avaliar. Algumas características intrínsecas ao presente módulo são listadas abaixo e em seguida, complementadas pela Tabela 4.23:

- Erro Médio Percentual: ambos os medidores tiveram bom desempenho, mas o ION 7600 apresentou quase a metade do erro do outro equipamento;

- Erro Médio em Milissegundos: neste quesito, ao contrário do anterior, o SEL-734 obteve um desempenho aproximadamente sete vezes melhor do que o ION 7600;

- Para visualizar os valores relativos aos dois itens acima, porcentagem de eventos captados, aprovações, reprovações e porcentagem das reprovações: ver Tabela 4.23 .

Tabela 4.23 - Módulo de Variações de Tensão de Curta Duração.

\begin{tabular}{|c|c|c|c|c|c|c|c|}
\hline \multirow[b]{2}{*}{ Modelo } & \multirow{2}{*}{$\begin{array}{c}\text { Erro Médio } \\
\text { [\%] }\end{array}$} & \multirow{2}{*}{$\begin{array}{c}\text { Erro Médio } \\
\text { [ms] }\end{array}$} & \multicolumn{4}{|c|}{ Eventos e Intervalos de Duração } & \multirow{2}{*}{$\begin{array}{l}\text { Nota } \\
\text { Média }\end{array}$} \\
\hline & & & $\begin{array}{c}\text { Captados } \\
{[\%]}\end{array}$ & Aprovados & Reprovados & $\begin{array}{c}\text { Índice de } \\
\text { Reprovação }\end{array}$ & \\
\hline ION & 0,38 & 7,91 & 100 & 124 & 45 & $26,63 \%$ & 10,0 \\
\hline SEL & 0,73 & 1,14 & 100 & 168 & 1 & $0,60 \%$ & 10,0 \\
\hline
\end{tabular}




\subsubsection{Variações de Tensão em Regime Permanente}

Como pode ser observado na Tabela 4.24, de todos os módulos de ensaios, este foi o que apresentou o menor erro percentual médio para ambos os equipamentos, mas ainda assim, o valor deste indicador foi quase cinco vezes maior para o SEL-734.

Tabela 4.24 - Módulo de Variações de Tensão em Regime Permanente.

\begin{tabular}{|c|c|c|}
\hline Modelo & Erro Médio [\%] & Nota Média \\
\hline ION & 0,11 & 10,0 \\
\hline SEL & 0,54 & 10,0 \\
\hline
\end{tabular}

\subsection{Avaliação Global}

Utilizando-se a metodologia pormenorizada na seção de mesmo título do capítulo anterior, a presente análise permite fazer um apanhado geral do desempenho dos equipamentos sujeitados aos testes. Dessa forma, se completa a conjuntura de avaliações, visto que os aspectos individuais e por divisão em módulos já foram tratados. Finalmente, por meio da Tabela 4.25 se expõe resultados globais relativos a cada modelo.

Tabela 4.25 - Resultado Final Por Modelo.

\begin{tabular}{|c|c|c|c|c|}
\hline \multirow{2}{*}{ Modelo } & \multirow{2}{*}{$\begin{array}{c}\text { Nota } \\
\text { Final }\end{array}$} & $\begin{array}{c}\text { Erro Médio } \\
{[\%]}\end{array}$ & \multicolumn{2}{|c|}{ Eventos e Intervalos de Duração } \\
\cline { 3 - 5 } & Erro Médio [ms] & Índice de Reprovação [\%] \\
\hline ION & 9,91 & 0,60 & 7,91 & 26,63 \\
\hline SEL & 9,95 & 0,88 & 1,14 & 0,60 \\
\hline
\end{tabular}

Da tabela supracitada se conclui que, em geral, ambos os medidores tiveram desempenhos semelhantes para a parte de erro percentual médio e de nota final. Entretanto, para estes quesitos, o ION 7600 apresentou uma performance pouco melhor apesar de sua nota final ter sido mais baixa, devido principalmente ao resultado atípico do ensaio de número 16.

Os valores relativos à coluna de eventos e intervalos de duração são repetidos da Tabela 4.23, pois os ensaios de variações de tensão de curta duração são os únicos que fazem medidas de grandezas de tempo, portando, a análise para esta parte é a mesma da seção 4.2.3. 


\section{CAPÍTULO 5}

\section{5 - CONCLUSÕES}

\subsection{Conclusões e OBSERVAÇões Gerals}

Este trabalho teve como objetivo principal fazer uma avaliação comparativa entre dois instrumentos capazes de medir grandezas relacionadas à qualidade da energia elétrica. Para dar as condições necessárias ao desenvolvimento do projeto, primeiramente foi tecida toda uma rede de assuntos basilares e conexos.

No Capítulo 1 foi feito um breve apanhado geral da evolução do sistema energético, contrapondo as diferenças dos efeitos causados pela qualidade da energia elétrica no passado e na atualidade.

O mercado nesta área ainda é muito carente a mais investimentos, estudos e pesquisas. Por essas e outras razões, é fundamental que hajam bons equipamentos destinados a monitorar a qualidade da energia, assim como também é importante que os agentes do setor elétrico tenham informações claras a respeito desses produtos.

O Capítulo 2 proporciona uma base de conhecimento necessária para a pessoa que deseja trabalhar com a monitoração da qualidade da energia elétrica. Seus principais indicadores, os quais incluem aqueles ensaiados, foram detalhados com rigor.

Além disso, os aspectos relacionados às normatizações, regulamentações e aos agentes do setor, tanto os nacionais quanto os internacionais foram abordados. Infelizmente um dos motivos que corrobora para a importância do estudo é que no Brasil ainda há uma falta de padronização dos protocolos de medições, assim como também há uma ausência de definições claras para seus limites de aceitação.

Os trabalhos com a aparelhagem iniciaram-se no Capítulo 3. Nesta parte foi estipulada uma metodologia detalhada para a geração dos sinais destinados aos ensaios. Estes por sua vez, foram organizados de forma a oferecer indicadores propícios para os fins pertinentes à avaliação e comparação. Em complemento as abordagens deste capítulo, no apêndice constam as explicações de manuseamento de ambos os medidores e da fonte de distúrbios, oferecendo o domínio requerido para a utilização de toda a aparelhagem empregada.

Por conseguinte, foram propostos os métodos para classificação dos equipamentos, abordando toda a sistemática necessária à obtenção dos indicadores de desempenho, assim como o tratamento estatístico dos dados.

Finalmente, o Capítulo 4 dedica-se exclusivamente a apresentação dos resultados obtidos, os quais foram sintetizados em várias tabelas. A avaliação foi feita de forma imparcial, e dividida em três classes: na análise individual de cada ensaio, por módulos 
condizentes com os índices de qualidade da energia elétrica, e pelo conjunto global de todos os ensaios.

Ainda mantendo a imparcialidade, apenas verbalizando os resultados obtidos, pode-se afirmar que ambos os medidores apresentaram desempenhos muito semelhantes, a exceção dos ensaios de VTCD relativos às leituras de grandezas temporais, neste módulo houve vários conceitos de reprovação (erro maior que 1/2 ciclo de onda sujeita à frequência nominal) atinentes ao modelo ION 7600.

Por outro lado, nos ensaios em que o erro foi medido percentualmente, constata-se uma precisão um pouco inferior para o modelo SEL-734. Porém as notas recebidas por cada um deles foram bastante similares, e raramente receberam conceituações inferiores a 10. Houve casos que apresentaram certa discrepância em relação ao valor de referência, mas muitas vezes os resultados obtidos foram semelhantes pelos dois modelos, indicando possíveis diferenças inerentes ao sinal gerado, e não propriamente a erros na leitura dos dados.

Diante os resultados alcançados assegura-se que os ensaios foram válidos e permitiram que a presente avaliação cumprisse com seus objetivos almejados, trazendo suas contribuições para a área de monitoração da energia elétrica, contribuições tais como:

- Verificar imprecisões;

- Verificar a capacidade dos equipamentos em medir as grandezas;

- Verificar as semelhanças e diferenças entre os produtos;

- Verificar o desempenho individual dos medidores;

- Fazer comparações entre os modelos;

- Legitimar certas características dos produtos;

- Oferecer mais detalhes de modo a corroborar para uma análise de custo/benefício mais precisa.

Apesar de ser bastante completo no sentido de cumprir os objetivos da avaliação comparativa entre os dois instrumentos de medição, o presente estudo ainda deixa algumas brechas para trabalhos futuros, como por exemplo:

- Inserir ensaios sobre desequilíbrios de tensão, e fazer análise do fator k;

- Fazer leituras das correntes, de forma a permitir avaliar o fator de potência;

- E incluir outros modelos de medidores disponíveis no mercado. 


\section{REFERÊNCIAS BIBLIOGRÁFICAS}

Afonso, J. L.; Martins, J. S., (2004) "Qualidade da Energia Elétrictrica" - Departamento de Electrónica Industrial, Universidade do Minho In: Revista o Electricista n. 9 p66-71.

ANEEL - Agência Nacional de Energia Elétrica- Sítio: <http://www.aneel.gov.br/>. Acesso em: 01 de setembro de 2010.

ANSI - American National Standards Institute - Sítio: <http://www.ansi.org/>. Acesso em: 01 de setembro de 2010.

Belchior, F. N.; Bonatto, B. D.; Mertens Jr., E. A.; Suematsu, A. K.; Ahn, S. U.; Bronzeado, H. S.; Soletto, K. T.; J. de Camargo, (2009) "Medição da qualidade da energia elétrica - Protocolo, padronização e certificação" - VIII CBQEE - Conferência Brasileira sobre qualidade de energia elétrica, Blumenau-SC.

Bollen M. H. J., (2000) "Understanding Power Quality Problems - Voltage Sags and Interruptions" - IEEE Press, USA.

CENELEC - European Committee for Electrotechnical Standardization- Sítio: <http://www.cenelec.eu/Cenelec/Homepage.htm>. Acesso em: 01 de setembro de 2010.

Dugan R.C.; McGranaghan M.F.; Santoso S.; Beaty, H.W. (2002) "Electrical Power Systems Quality" - 2ª Edição, McGraw-Hill, USA.

Filho, E. M. L.; Sousa, F. G. G.; Vasconcelos, M. V. L., (2009) "Qualidade da Energia na UnB: Uma Investigação Sobre a Relação Entre Distúrbios na Rede Elétrica e a Falha de Equipamentos" - Trabalho de Conclusão de Curso, Departamento de Engenharia Elétrica, Universidade de Brasília, UnB.

Franco, E., (2009) "Qualidade de Energia - Causas, Efeitos e Soluções" - Engecomp tecnologia em automação e controle LTDA. Disponível em: <http://www.engecomp.com.br/pow_qual.htm>. Acesso em: 25 de janeiro de 2009.

Gbirard, A. D.; Rocha, M. C.; Teixeira, L. A. L. (2002) "Lucratividade e Qualidade na Distribuição de Energia Elétrica" - Nova economia, Belo Horizonte.

IEC 61000-4-15 - International Electrotechnical Commission - Testing and measurement techniques - Flickmeter - functional and design specifications. Electromagnetic Compatibility (EMC) - Part 4, Section 15.

IEC: EMC - International Electrotechnical Commission- Sítio: <http://www.iec.ch/ zone/emc/>. Acesso em: 01 de setembro de 2010. 
IEC: Estrutura - International Electrotechnical Commission - Sítio: <http://www.iec.ch/ zone/emc/baspubs.htm\#str61000 >. Acesso em: 01 de setembro de 2010.

IEC: Missão - International Electrotechnical Commission - Sítio: <http://www.iec.ch/ about/mission-e.htm>. Acesso em: 01 de setembro de 2010.

IEEE - Institute of Electrical and Electronics Engineers - Sítio: <http://www.powerstandards.com/IEEE.htm>. Acesso em: 01 de setembro de 2010.

ISO - International Organization for Standardization - Sítio: <http://www.iso.org/ iso/home.html>. Acesso em: 01 de setembro de 2010.

ITIC - The Information Technology Industry Council - Sítio: <http://www.itic.org/> Acesso em: 01 de setembro de 2010.

Junior, R. A. M.; Prado, T. F., (2006) "Ferramenta Computacional Para Análise de Cintilações Luminosas" - Trabalho de Conclusão de Curso, Departamento de Engenharia Elétrica, Universidade de Brasília, UnB.

Manual do ION 7600 - ION 7500/7600, User's Guide - Power Measurement, Revisado em 09 de maio de 2003.

Manual do SEL-734 - SEL-734 Revenue Metering System, Instruction ManualSchweitzer Engineering Laboratories, INC. (2007).

Manual do Software CIGUI32 - CIGUI32, iX-Series, i-Series, iL-Series, HGA: Software User's Manual - California Instruments, Versão 1.09, Revisado em outubro de 2001.

Matana, G. M., (2008) "Proposta de Equipamento para Medição dos Fenômenos Relativos à Qualidade da Energia Elétrica utilizando Conceitos de Instrumentos Virtuais" Dissertação de Mestrado, Escola de Engenharia de São Carlos, Universidade de São Paulo, USP.

NEMA - National Electrical Manufacturers Association - Sítio: <http://www.nema.org/> Acesso em: 01 de setembro de 2010.

Newman, R., (2009) "Os níveis de desempeno das medições segundo a norma IEC 61000-4-30" - Revista Eletricidade Moderna, No. 419, pag. 90-101, Fevereiro de 2009;

Oliveira, M. A., (2005) "Qualidade da Energia Elétrica" - Departamento de Engenharia Elétrica, Universidade de Brasília, UnB.

ONS - Operador Nacional do Sistema - Sítio: <http://www.ons.org.br/procedimentos/ index.aspx>. Acesso em: 01 de setembro de 2010. 
Pinto, M. G. S., (2006) "Uma Contribuição Para o Estudo do Desequilíbrio de Tensão nos Sistemas Elétricos de Potência" - Trabalho de Conclusão de Curso, Departamento de Engenharia Elétrica, Universidade de Brasília, UnB.

PONTES, M. G. S. R., (2000) "Contribuições à Análise da Propagação das Flutuações de Tensão sob o Enfoque do Fenômeno Flicker" - Dissertação de Mestrado, Departamento de Engenharia Elétrica, Universidade Federal de Uberlândia, UFU.

Relatório Técnico UFU/ONS, (2004) "Testes de Desempenho Funcional em Instrumentos de Medição da Qualidade da Energia Elétrica" - Universidade Federal de Uberlândia, Operador Nacional do Sistema Elétrico, Power Measurement.

Rola D. V.; Júnior T. S. R, (2006) "Ferramenta Computacional Para Análise De Distorções Harmônicas De Tensão" - Trabalho de Conclusão de Curso, Departamento de Engenharia Elétrica, Universidade de Brasília, UnB.

SEL-734 - Especificações - Sítio: <http://www.selinc.com.br/produtos/sel734.htm> Acesso em: 01 de setembro de 2010.

Serni, P. J. A., (2006) "Qualidade da Energia" - Apostila de aula, São Carlos, Universidade de São Paulo, USP, SEL 5749, 146 p.

Xavier, P.A., (2005) "Avaliação das Características Elétricas de Reatores Eletrônicos Utilizados em Lâmpadas Fluorescentes Tubulares" - Dissertação de Mestrado, Departamento de Engenharia Elétrica, Universidade de Brasília, UnB. 


\section{APÊNDICE}

Esta seção tem por objetivo auxiliar e capacitar o leitor em relação aos aspectos práticos para geração dos sinais pela fonte de distúrbios e obtenção dos dados pelos medidores. Não se tem a intenção de entrar em um nível de detalhamento avançado, apenas o necessário para os propósitos dos ensaios deste projeto.

\section{A.1 Software e ManUSEamento da Fonte de Distúrbios}

Depois de feita a instalação do software, ao abrir o aplicativo CIGui32, será apresentada a tela principal mostrada na Figura A.1:

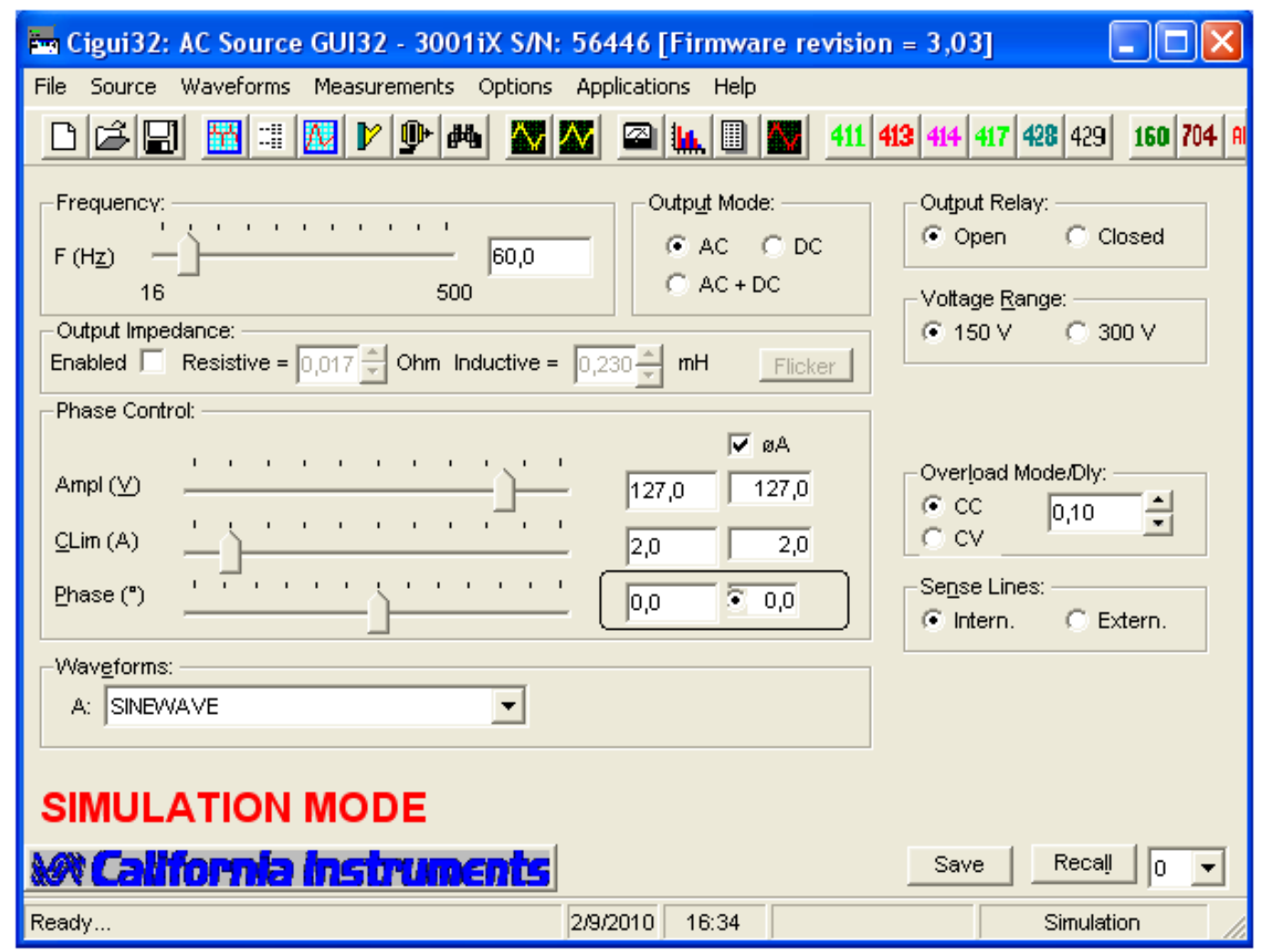

Figura A.1 - Tela Principal do Aplicativo CIGui32.

Observa-se que em vermelho está escrito 'Simulation Mode', isto porque o software ainda não fez a comunicação com a fonte de distúrbios, para tanto, deve-se clicar com o mouse no ícone de comunicação 'Interface Settings - [I+') ou em: ('Source' + 'Interface...').

Em seguida, aparecerá uma janela para escolher o tipo de comunicação (RS232 ou IEEE-488), deve-se escolher aquela condizente com o tipo do cabo que está ligando a fonte ao computador e fazer as configurações de comunicação pertinentes, de acordo como está definido na própria fonte. Ao final, se tudo estiver correto, aparecerá uma 
mensagem dizendo que o dispositivo foi encontrado, então basta pressionar o botão 'Close' e a mensagem de simulação em vermelha desaparecerá.

Já na tela principal, entre outras coisas, o usuário pode:

- Selecionar a forma de onda (formas padrões ou formas programadas pelo usuário);

- Definir a frequência;

- Definir a amplitude eficaz da tensão;

- Definir o limite da corrente;

- Definir o ângulo da respectiva fase;

- Trabalhar com dois níveis máximos de tensão (150 V e 300 V);

- Abrir ou fechar os terminais de saída.

Neste caso, a fonte de tensão é monofásica, caso contrário, haveria a opção de seleção e ajuste das fases restantes (B e C).

Portanto, com o que foi dito até agora, é possível gerar formas de ondas padrões que já vem configuradas na própria fonte, como por exemplo, ondas senoidais ou quadradas. Bastando escolher a sua forma, fazer os ajustes desejados e fechar os terminais de saída.

O próximo passo é fazer as configurações de ondas com componentes harmônicas. Para isso deve-se clicar no ícone 'Create harmonic waveforms - ⿶ㅣㄹ' apresentada (Figura A.2):

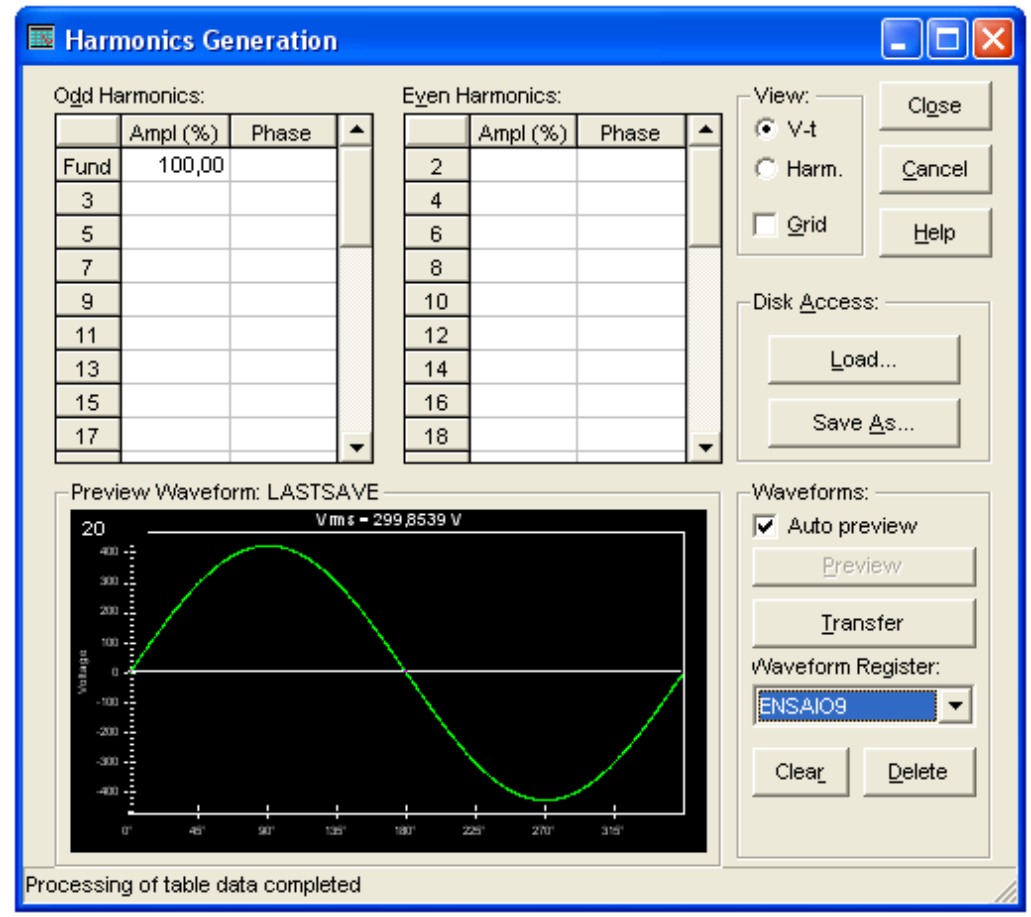

Figura A.2 - Janela Para Configuração de Formas de Onda com Harmônicas. 
A amplitude e fase de cada ordem de harmônica (da fundamental à $50^{\underline{a}}$ ) podem ser ajustadas em 'Ampl (\%)' e 'Phase' respectivamente. Em seguida, para mais tarde poder usar a configuração ajustada, é requerido duas coisas:

1- Salvar as configurações clicando no botão 'Save as' e escolher o local de destino;

2- Fazer a transferência da forma de onda para a memória da fonte pressionando o botão 'Transfer'.

Se os passos descritos acima foram seguidos corretamente, então a forma de onda estará disponível nos Popup Menus 'Waveform(s) (Register)' na janela de harmônicas, na tela principal e na janela de transitórios (vista mais adiante).

Caso se deseje gerar exclusivamente a forma de onda programada, é só proceder como foi explicado anteriormente: fazer os ajustes na tela principal, escolher a opção de 'Waveform' e fechar os terminais de saída da fonte.

Contudo, muitas vezes é preciso realizar a medição de grandezas como: componentes harmônicas individuais, tensão fundamental, frequência e índice de distorção harmônica total. No aplicativo, essas leituras são feitas ao clicar sobre o ícone 'Display harmonic analysis window - 芷', então a janela representada pela Figura A.3 abrirá. Como as funcionalidades relativas à análise das harmônicas são bem simples e intuitivas, o seu detalhamento se encerra por aqui.

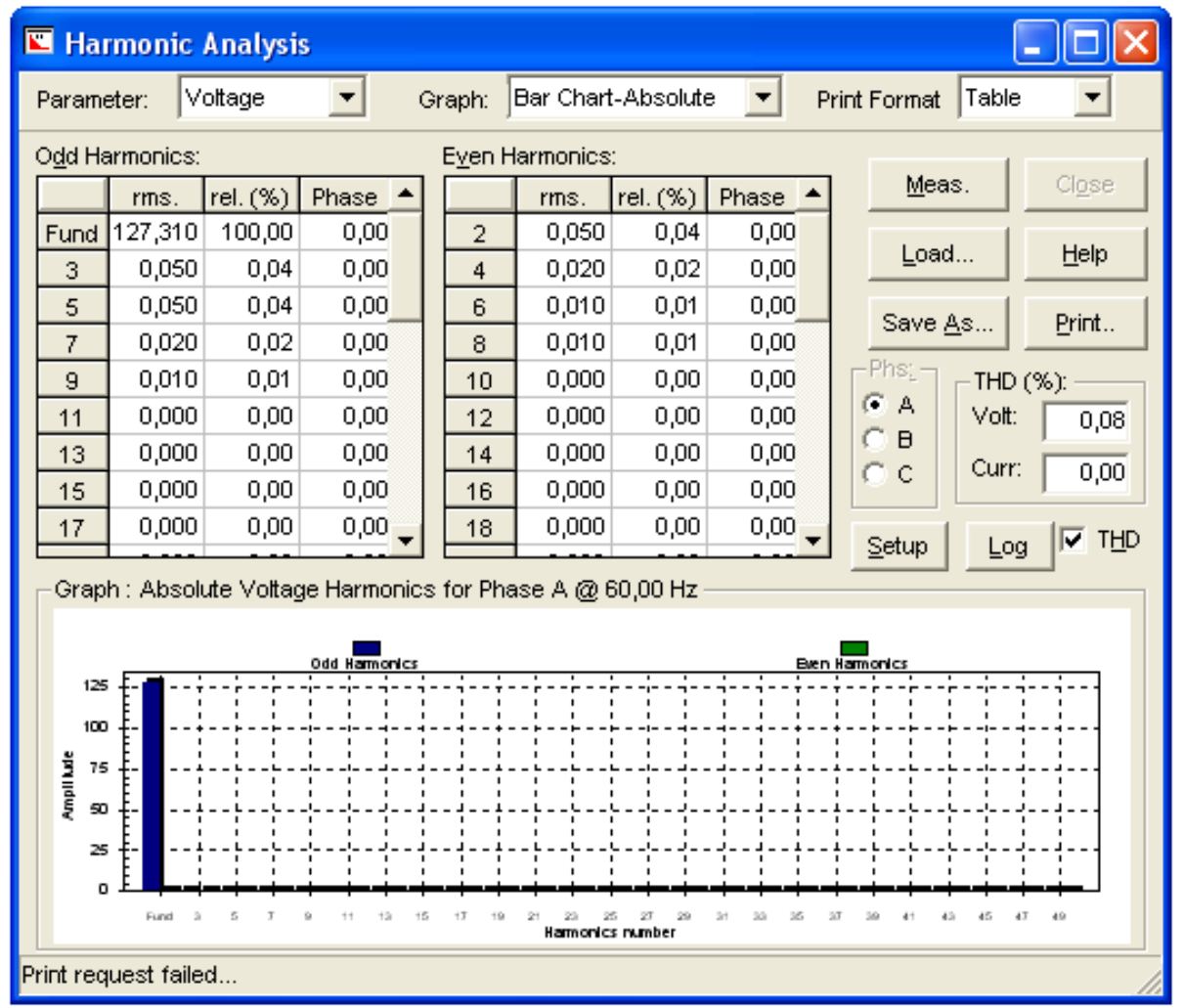

Figura A.3 - Janela do Analisador de Harmônicas. 
Ainda, outra funcionalidade importante, é fazer a captura da onda de tensão ou corrente de forma gráfica. Para isso, deve-se clicar no ícone 'Display waveform capture window ', e uma janela com um intervalo de captura de aproximadamente 900 milissegundos aparecerá, conforme mostra a Figura A. $4^{8}$ :

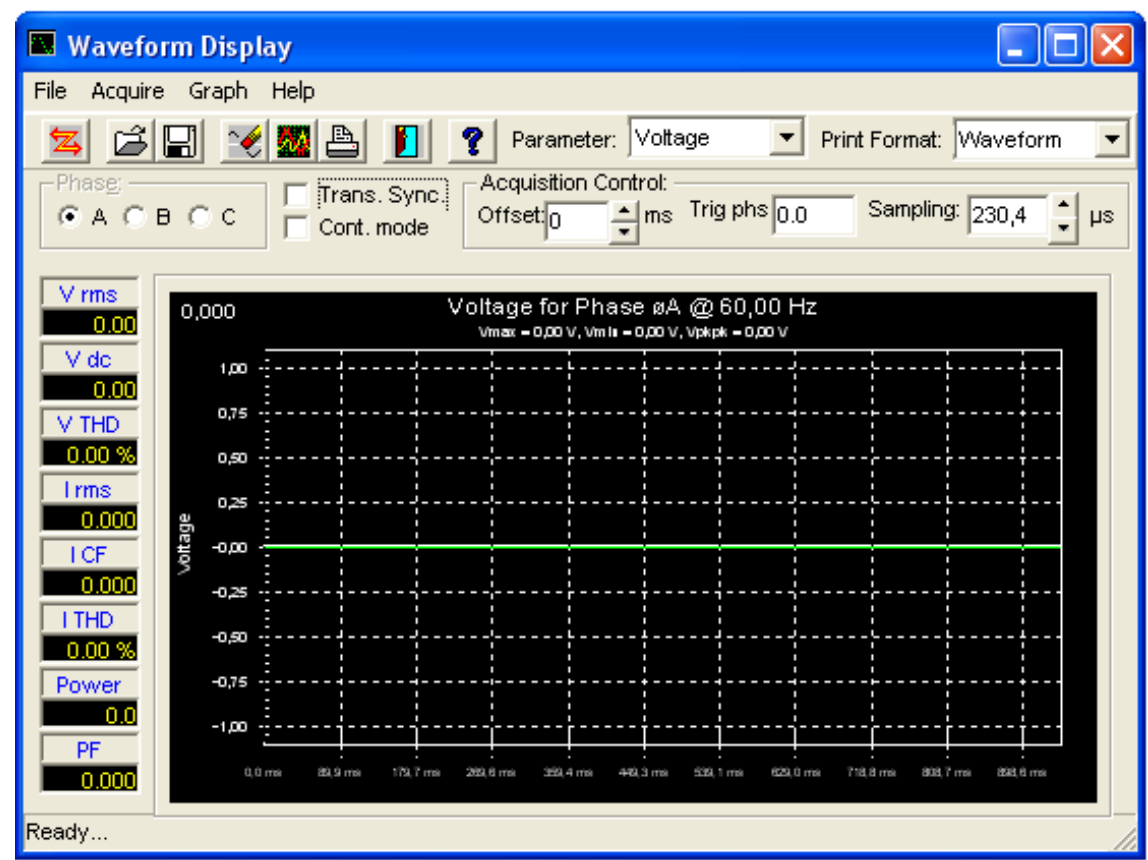

Figura A.4 - Janela de Visualização da Forma de Onda.

Por fim, resta a parte de transitórios, o seu ícone de acesso é o 'Transients - 国', após pressioná-lo, a janela mostrada na Figura A.5 surgirá.

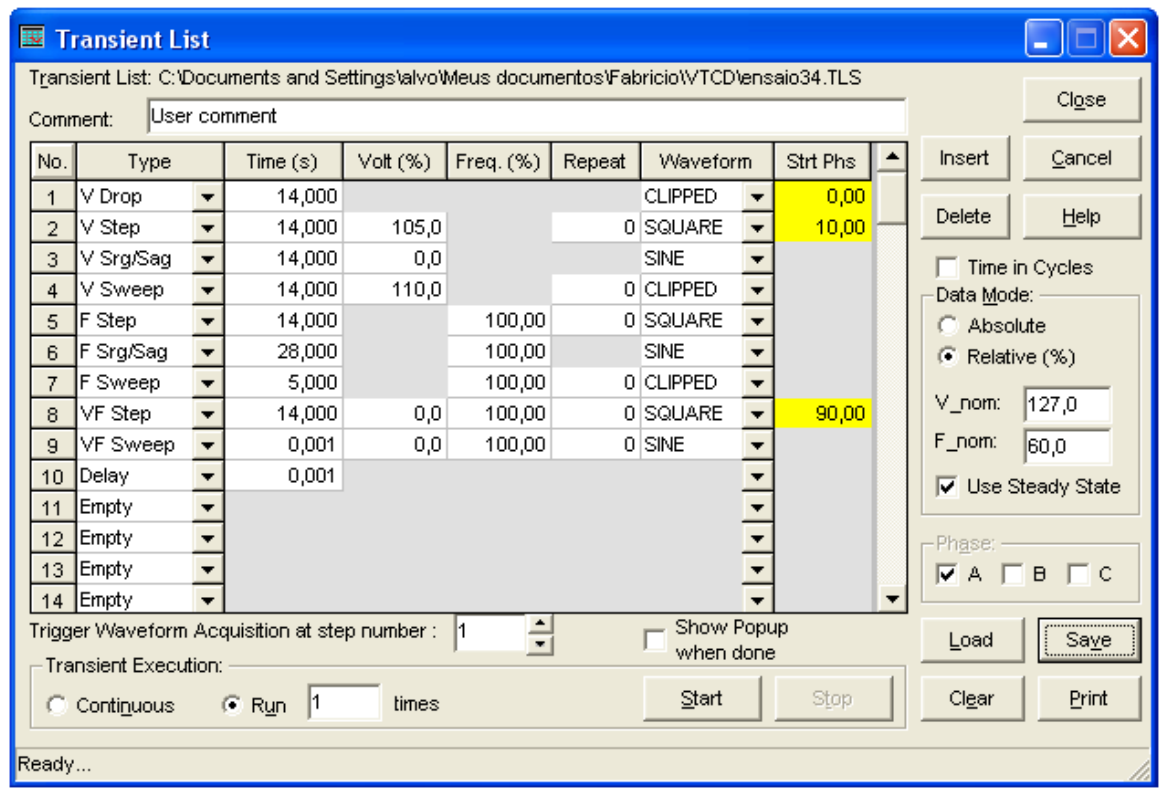

Figura A.5 - Janela Para Geração de Transitórios

\footnotetext{
${ }^{8}$ No momento da captura não estava sendo gerado nenhum sinal, por isso a onda se caracteriza apenas por uma linha de valor nulo na horizontal.
} 
A imagem não permite ver, mas a janela contém uma lista com um total de 100 possíveis transitórios, cada linha oferece a opção de regular o tempo, tensão, frequência, forma de onda, ângulo inicial e o tipo do transiente escolhido. Por sua vez, este último inclui:

- Interrupção de tensão ( $V$ Drop);

- Degrau na tensão ( $V$ Step);

- Afundamento ou elevação de tensão ( $V$ Srg/Sag);

- Variação progressiva na tensão ( $V$ sweep);

- Degrau na frequência ( $F$ Step);

- Afundamento ou elevação de frequência (F Srg/Sag);

- Variação progressiva na frequência ( $F$ sweep);

- Degrau na tensão e na frequência simultâneo (VF Step);

- Variação progressiva na tensão e frequência simultaneamente (VF sweep);

- Atraso (Delay);

- Sem especificação ou vazio (Empty).

Portanto, de acordo com o interesse do usuário programa-se a geração dos transitórios de forma sequencial até que haja uma linha vazia, significando o fim da lista. Se for necessário executar o que foi configurado mais de uma vez, basta selecionar o botão de opção 'Run', e digitar o número total de repetições desejadas (limite de 999). O botão denominado 'Trigger Waveform Acquisition at step number' especifica a linha (transitório) que terá sua forma de onda visualizada quando for aberta a janela destinada a tal finalidade.

Por fim, antes de gerar o sinal pressionando o botão 'start', deve-se certificar que o status dos terminais de saída (localizado na janela principal) está fechado. As demais funcionalidades referentes à programação de transitórios são bem intuitivas, desse modo, não carecem de mais explicações. 


\section{A.2 Programação e Recolhimento dos Dados com o ION 7600}

Quando se trabalha com o ION 7600 o primeiro software que deve ser utilizado é o Management Console, pois ele é o responsável pela comunicação dos dispositivos. Sua tela principal é mostrada na Figura A.6:

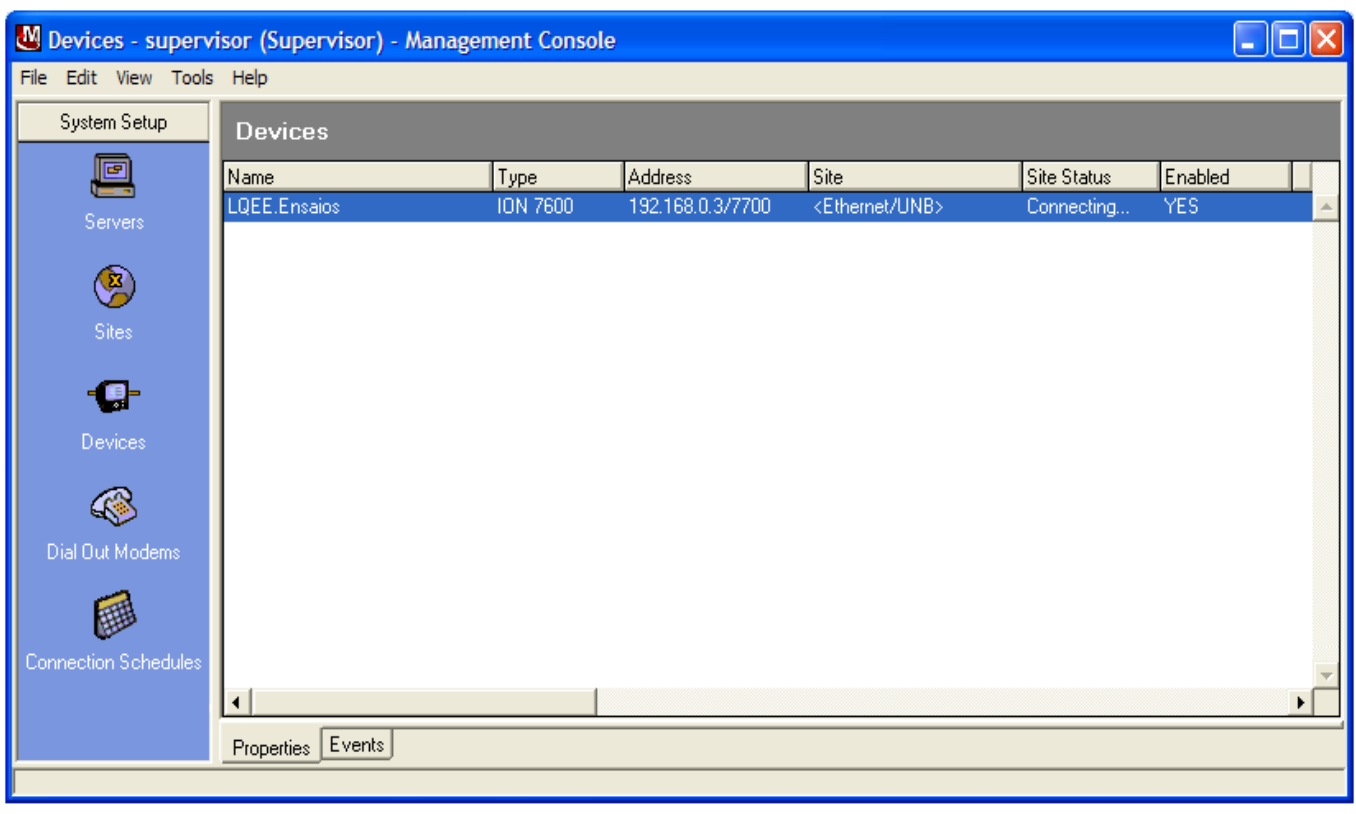

Figura A.6 - Tela principal do Management Console.

Nota-se que existem cinco ícones incluídos no quadro denominado System Setup. Porém, com vistas aos objetivos do projeto, somente serão abordados os três primeiros:

- O ícone 'Servers' (ou servidores) oferece informações sobre os computadores do sistema que tem funções administrativas, os quais controlam os recursos e o acesso à rede, como por exemplo, os dispositivos ION.

- Por sua vez, cada equipamento deve estar conectado a um link de comunicação, dessa forma, aqueles dispositivos que compartilharem o mesmo link pertencerão ao mesmo Site.

- Por último, resta o ícone denominado 'Devices', este faz uma espécie de cadastro dos dispositivos que podem ser conectados a rede.

O que diferencia um equipamento do outro é seu número $\mathrm{IP}^{9}$, portanto as configurações feitas no ícone 'Devices' serão válidas para o IP do dispositivo em questão. Os campos que requerem ser preenchidos para cadastrar os medidores são aqueles mostrados pela Figura A.7. Para poder abrir essa caixa de diálogo deve-se criar um novo dispositivo no ícone 'Devices' (Figura A.6) ou acessar as propriedades de um dispositivo já existente.

\footnotetext{
${ }^{9}$ Existem outras formas de comunicação, mas a principal delas é por ethernet. Para os objetivos requeridos será abordado apenas este tipo de comunicação.
} 


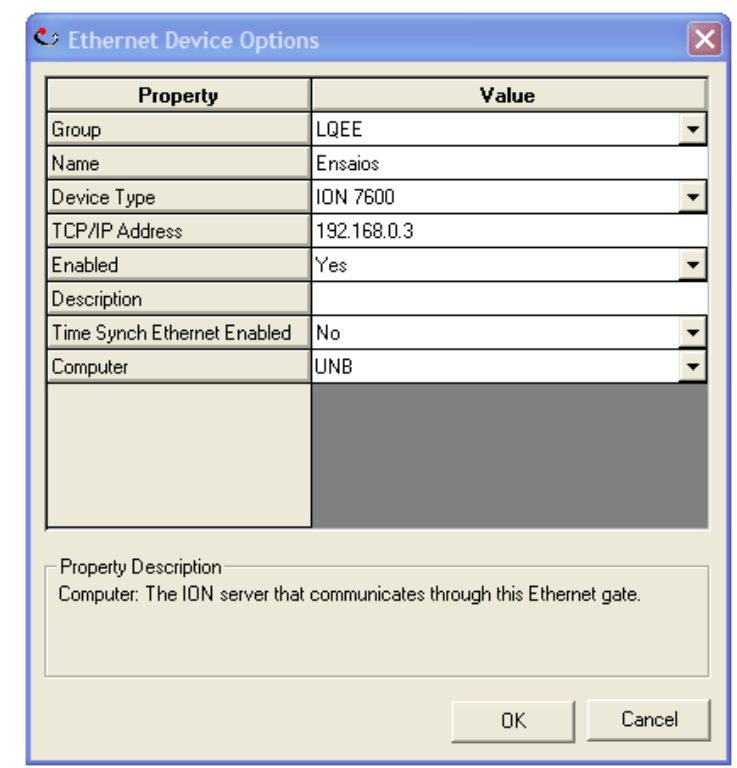

Figura A.7 - Cadastramento de Dispositivos.

Depois de cadastrar o medidor no Management Console, o próximo passo é fazer as configurações para a leitura dos dados. Para tanto, há duas alternativas: utilizar o software ION Designer, ou o ION Setup. Como o presente projeto não requer nenhuma programação avançada, opta-se por trabalhar com o segundo (de uso gratuito).

Após digitar o password (senha: '0' por padrão) e estabelecer a conexão com o dispositivo, ao abrir o ION Setup, aparecerá a janela secundária da Figura A.8:

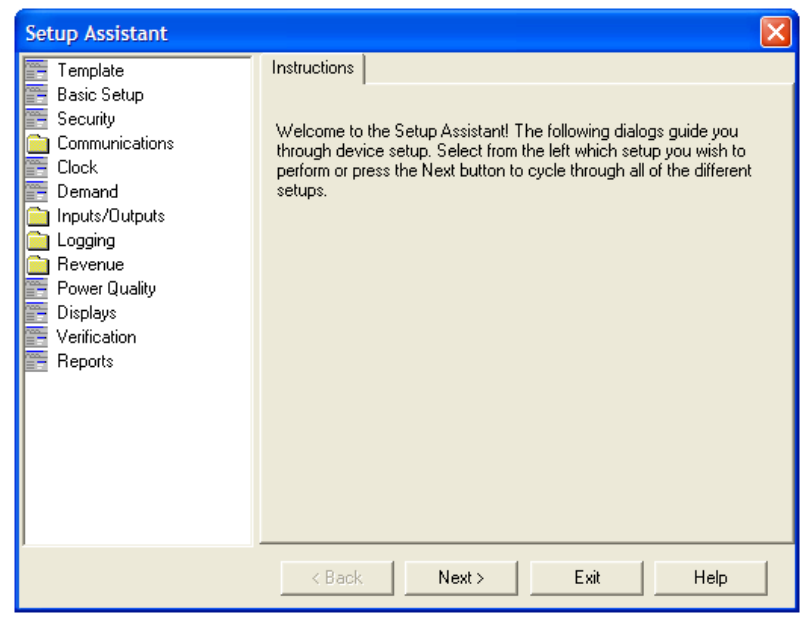

Figura A.8 - Sub-janela Inicial do ION Setup.

Nesta parte deve-se apertar o botão 'Exit' e em seguida dizer 'Não' (Não se deseja conectar a outro dispositivo).

Então, na janela atual, haverá uma árvore de ícones no canto superior esquerdo parecido com o mostrado na Figura A.9: 
System

- 盡 UNB

EthernetSite

固 EthernetDevice

Figura A.9 - Árvore Apresentada na Tela Inicial do ION Setup.

A fim de que a árvore se expanda e abra todos os módulos do medidor, deve-se pressionar a tecla 'Ctrl' e depois clicar com o botão esquerdo do mouse no ícone 'EthernetDevice'. Ao abrir a pasta do módulo 'Data Rec Modules' aparecerão todos os registros do Data Record na parte direita da tela. Portanto, o conteúdo da janela será parecido com o que é mostrado na Figura A.10:

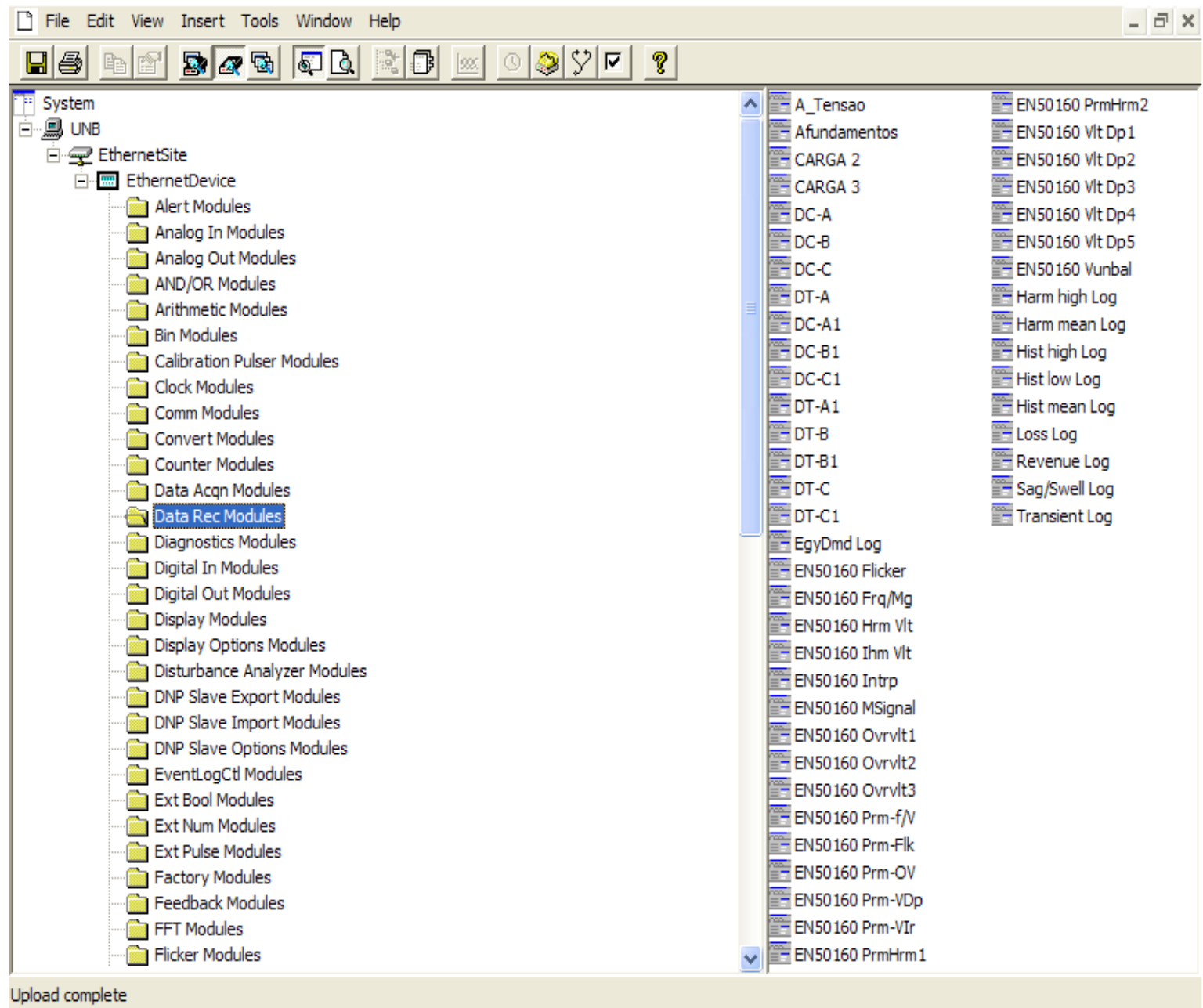

Figura A.10 - Tela Principal do ION Setup.

Esses registros podem ser criados, editados ou excluídos. Ao tentar acessar algum deles, aparecerá um aviso dizendo que os registros internos do medidor serão perdidos. Basta pressionar o botão 'OK, e finalmente uma janela será aberta, permitindo configurar todas as 15 entradas para o registro em questão (Figura A.11): 


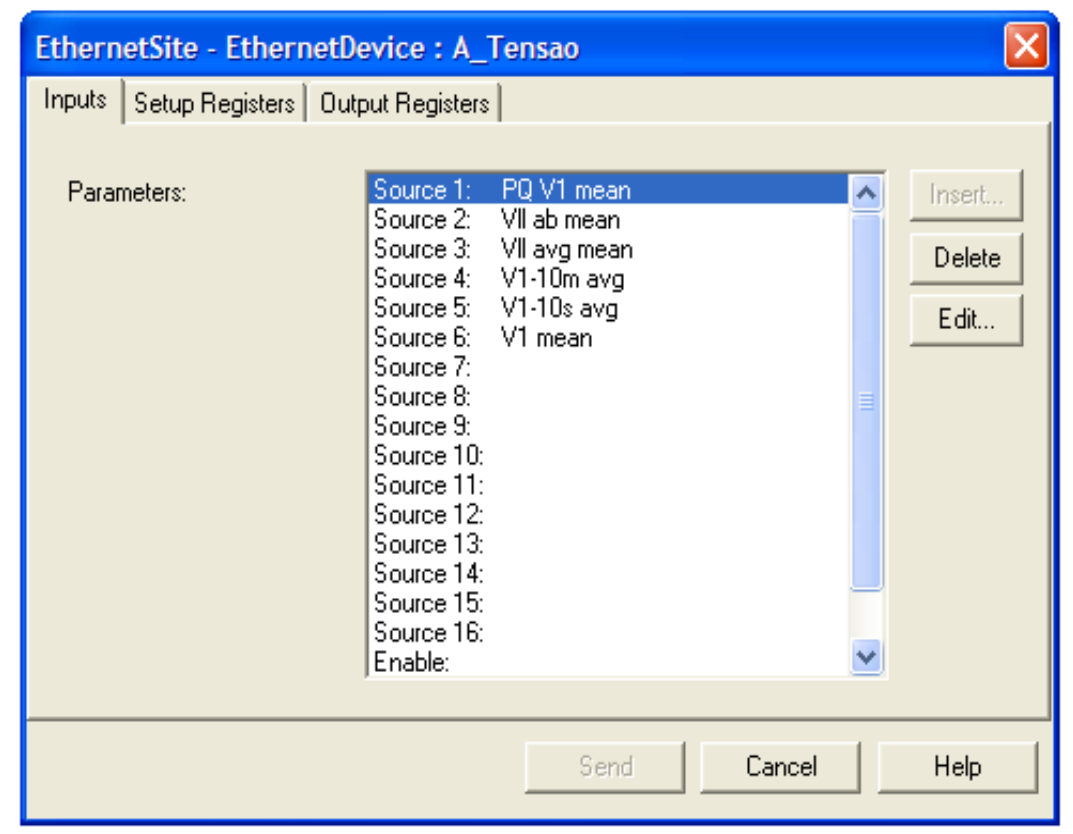

Figura A.11 - Janela Para Configuração dos Registros.

Por sua vez, cada entrada pode ser alterada apertando o botão 'Edit', assim surgirá uma nova janela com a lista de todas as grandezas (Sources) possíveis de serem medidas e incluídas nos relatórios gerados (Figura A.12):

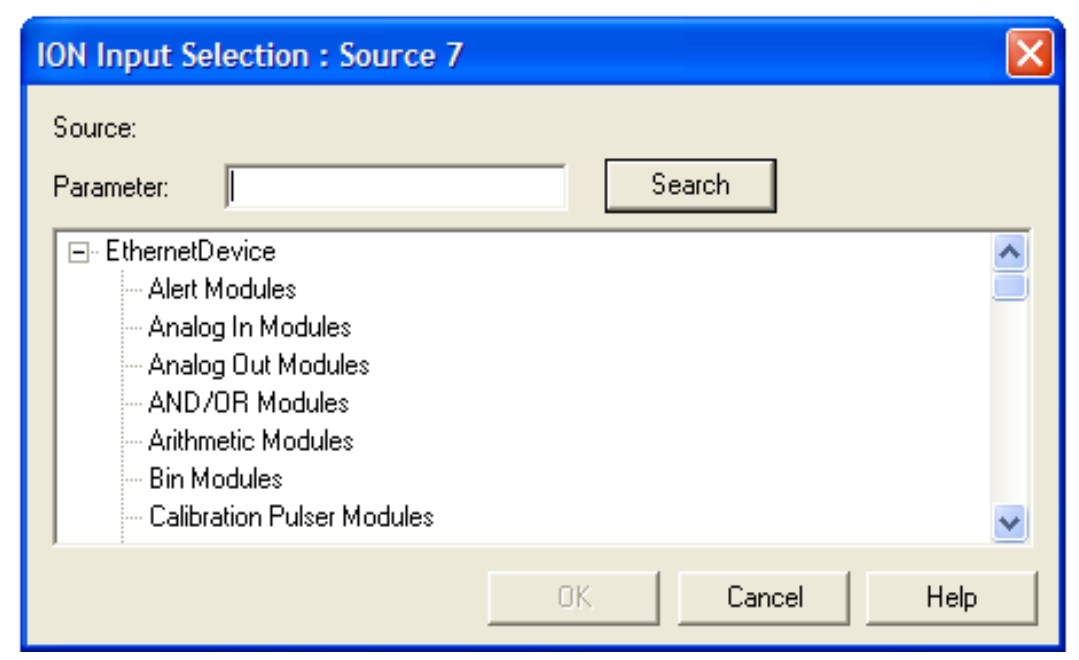

Figura A.12 - Janela Para a Escolha das 'Sources'.

Para que as configurações tenham efeito, elas devem ser descarregadas no medidor ao apertar o botão 'Send' na Figura A.11. Se tudo ocorrer bem, uma mensagem confirmará o êxito da transferência.

Por último, resta fazer a leitura dos dados. Os seus relatórios podem ser obtidos por meio do software ION Reporter (Figura A.13): 


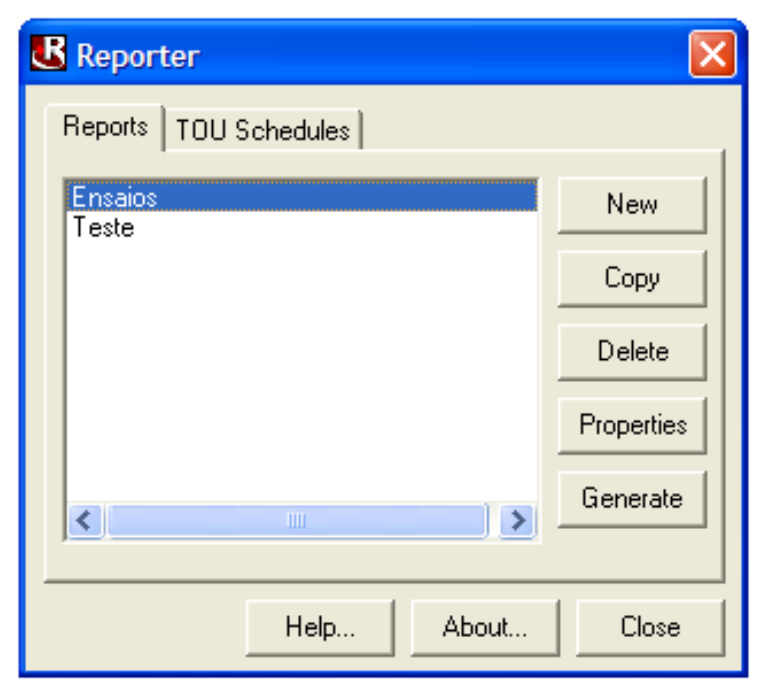

Figura A.13 - Tela Inicial do ION Reporter.

Ao abrir o programa haverá a opção de criar um novo ou utilizar relatórios que já vêm pré-configurados, sugere-se a primeira escolha, pois caso contrário, as configurações de relatórios padrões serão perdidas. Fazendo isso, a janela mostrada na Figura A.14 aparecerá:

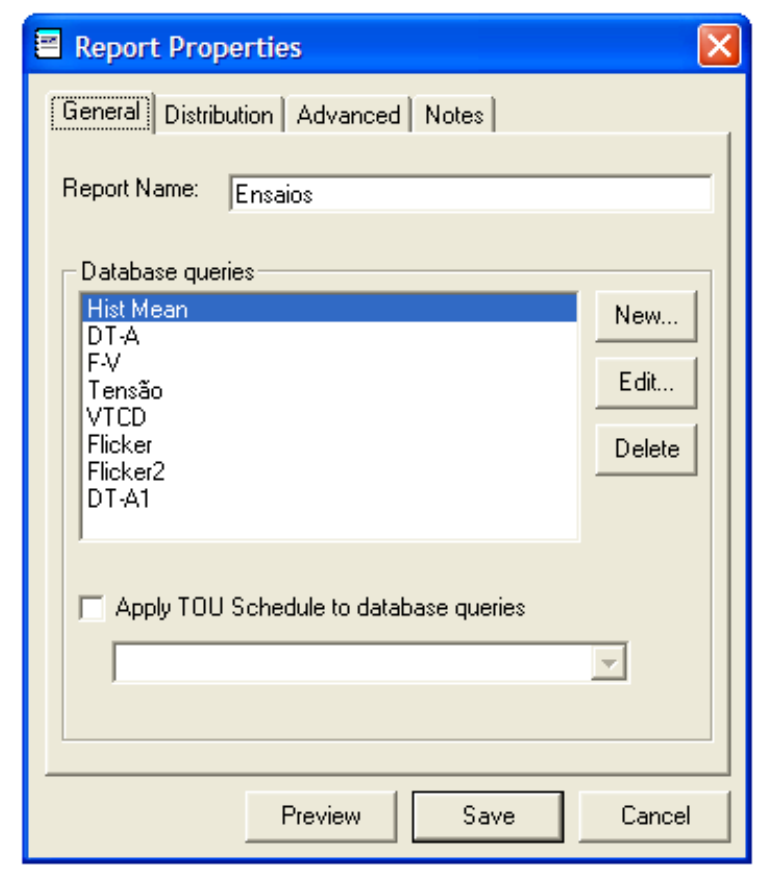

Figura A.14 - Janela Para Edição de Relatórios do ION Reporter.

Nesta etapa, as entradas configuradas no ION Setup $\left(\right.$ Queries $^{10}$ ) já estarão disponíveis. Elas receberão um nome e serão responsáveis por proporcionar as planilhas com os valores lidos (com a mesma ordem em que aparecem no campo 'Database queries').

\footnotetext{
${ }^{10}$ Há a possibilidade de as tabelas virem com colunas extras (de grandezas não configuradas nas 'queries). Isto ocorre pelo fato das 'queries' antigas ficarem registradas no banco de dados.
} 
Em seguida, se for preciso, o restante das abas da janela supracitada permitem fazer as alterações relativas à forma de geração dos relatórios. Para fazer a sua visualização, necessita-se de três passos:

1- Clicar em 'Generate Reports' na tela inicial do ION Reporter (Figura A.13);

2- Especificar o período das leituras (janela da Figura A.15);

3- Apertar o botão escrito 'Close' na janela subsequente.

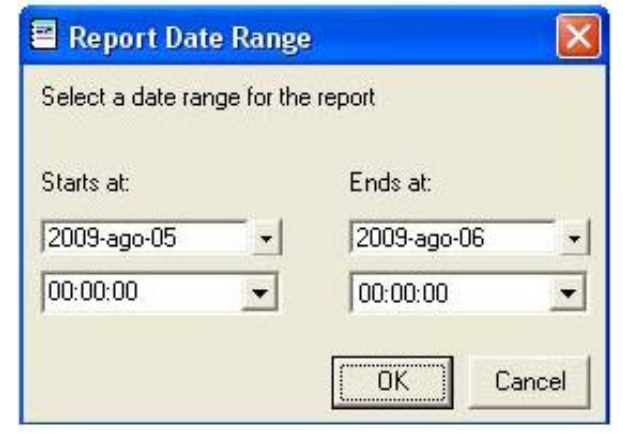

Figura A.15 - Janela Para Escolha de Datas de Geração dos Relatórios.

Seguido esses passos, a planilha contendo os relatórios finalmente será aberta ${ }^{11}$.

${ }^{11}$ Geralmente os dados lidos demoram algumas horas para se atualizarem e serem vistos. Um artifício que às vezes funciona, é incluir módulos que acusam eventos, como por exemplo, VTCD's, e em seguida gerar tais eventos. 


\section{A.3 Programação e Recolhimento dos Dados com o SEL-734}

Diferentemente do ION 7600, o medidor SEL-734 possui um único software para configuração e recolhimento dos dados, o AcSELerator Quick Set. A instalação do programa pode ser feita via internet por meio do software SEL Compass ${ }^{12}$, sendo requerido apenas o preenchimento e envio de um cadastro.

Depois de instalado, ao ser aberto, o AcSELerator Quick Set apresentará a janela da Figura A.16:

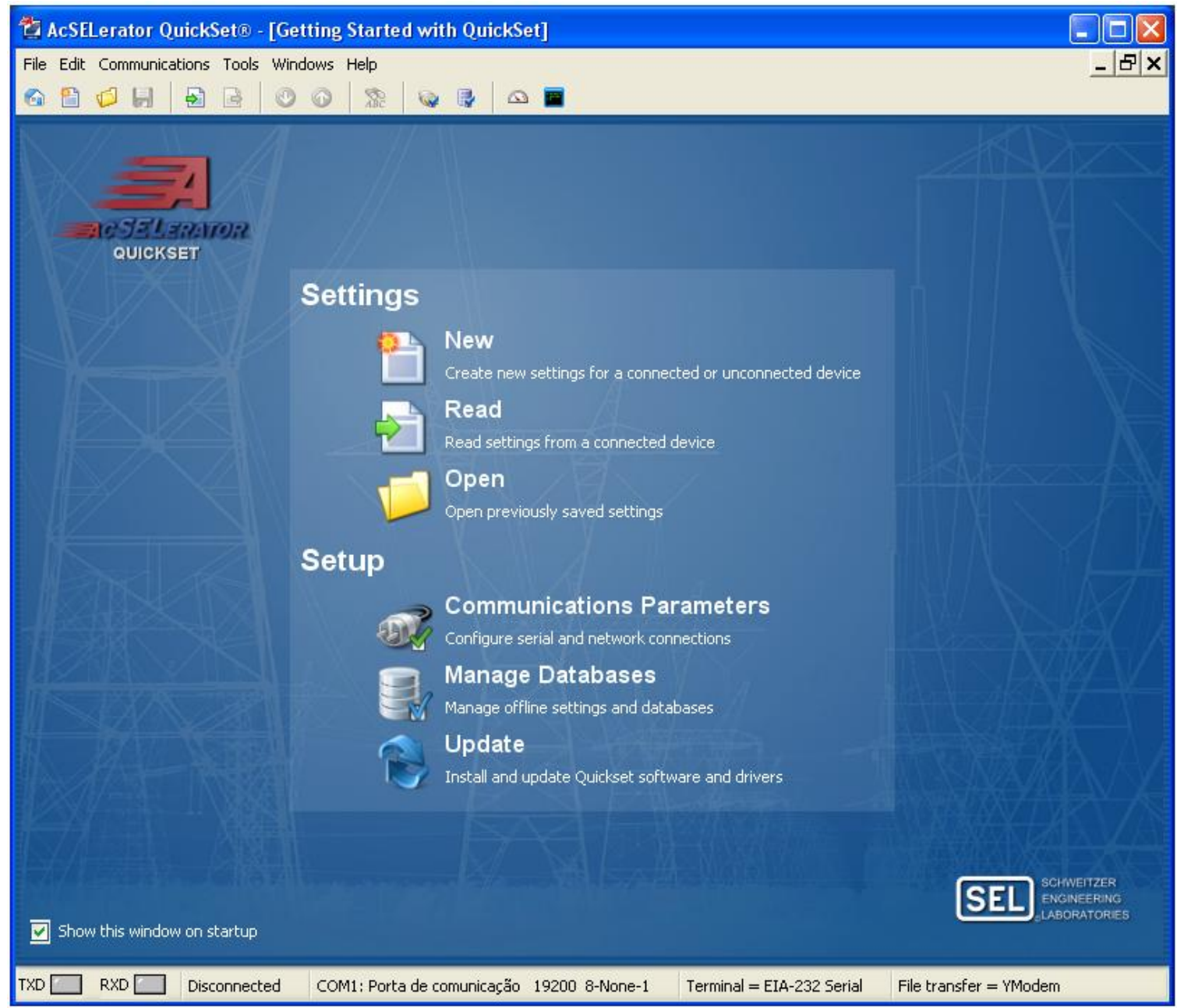

Figura A.16 - Janela Inicial do 'AcSELerator Quick Set'.

Para dar início ao manuseamento com o software, primeiramente, deve-se abrir o ícone denominado 'Communications Parameters' e fazer as configurações pertinentes à comunicação do dispositivo. Em seguida, se os ajustes estiverem corretos, aparecerá uma mensagem dizendo que a comunicação foi estabelecida, e o status no canto inferior esquerdo da tela será de conectado.

Caso a comunicação escolhida seja network (por ethernet), são requeridas duas exigências:

\footnotetext{
12 Explicações sobre uso desse software serão dispensadas, visto que o seu manuseamento é simples, e também foge ao escopo do presente estudo.
} 
- Que o endereço IP seja idêntico àquele atribuído ao dispositivo;

- E que o endereço IP seja da mesma família daquele utilizado na conexão local do computador que acessará os dados. Ou seja, a sequência numérica antes do último sinal de pontuação deve coincidir tanto para a conexão local quanto para o medidor.

Caso a comunicação seja serial, também há dois procedimentos a se realizar:

- Certificar que a "pinagem" do cabo está correta;

- E ajustar os próprios parâmetros de comunicação, como por exemplo, a taxa de transmissão e a paridade dos bis.

Por conseguinte, para fazer as configurações de leitura dos dados e descarregá-las no dispositivo, é necessário abrir a janela denominada 'Settings Editor' (seguir o caminho 'File' + 'Open', ou ir diretamente ao ícone 'Open - D' localizado na tela principal).

A janela do 'Setting Editor' é mostrada pela Figura A.17.

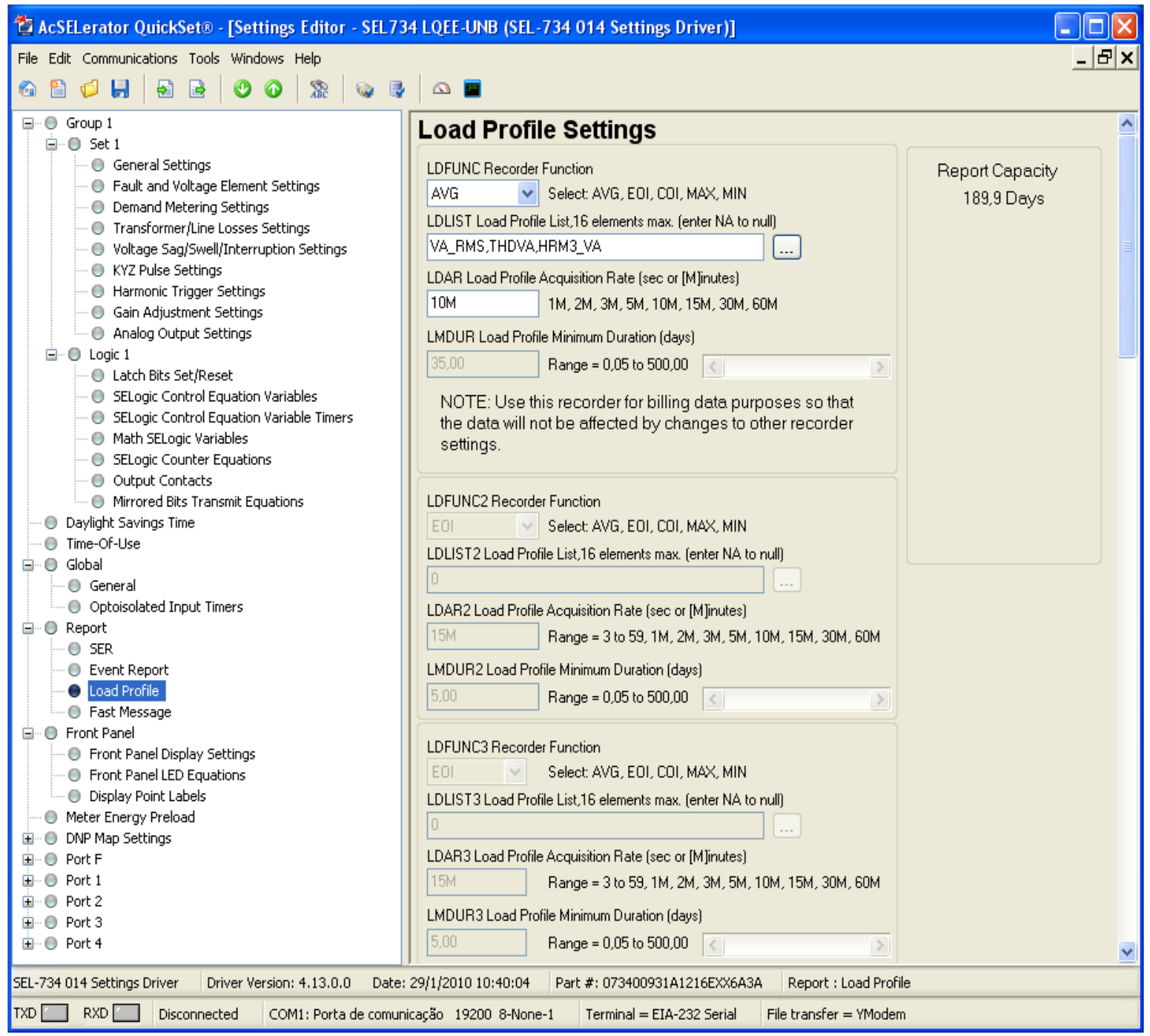

Figura A.17 - Janela de Configurações (Settings Editor). 
Visando os propósitos do projeto, apenas duas entradas da figura supracitada requerem configurações:

1- A entrada 'Load Profile', cujos ajustes são:

- O campo 'LDLIST (botão de reticência - ... ) que contém uma lista das grandezas possíveis de serem medidas pelo 'Load Profile'. No caso da figura serão medidos: a tensão RMS na fase $A$, a distorção harmônica de tensão total na fase $A$, e a componente harmônica de $3^{\underline{a}}$ ordem na fase $A$.

- O campo 'LDAR' que simplesmente define o tempo que as medidas serão integralizadas e disponibilizadas pelo 'Load Profile', neste caso, o tempo será de 10 minutos.

2- A entrada 'Voltage Sag/Swell/Interruption Settings' - define o valor da tensão fundamental e os níveis de interrupção, afundamento e elevação de tensão.

Em seguida, se as configurações desejadas estiverem prontas, elas poderão ser salvas indo no menu 'File' ou diretamente sobre o ícone 'Save Settings - 易'.

Entretanto, provavelmente ainda não será possível descarregar no medidor os ajustes feitos. Para isso, antes é necessário fazer as configurações relativas ao código numérico encontrado na carcaça do medidor. Este código é denominado 'Part Number', sua caixa de diálogo (Figura A.18) é aberta acessando o menu 'Edit' e clicando em 'Part Number'. Os dígitos alfanuméricos que não são caracterizados por asterisco $\left(^{*}\right)$ devem ter os valores iguais aos da etiqueta do aparelho.

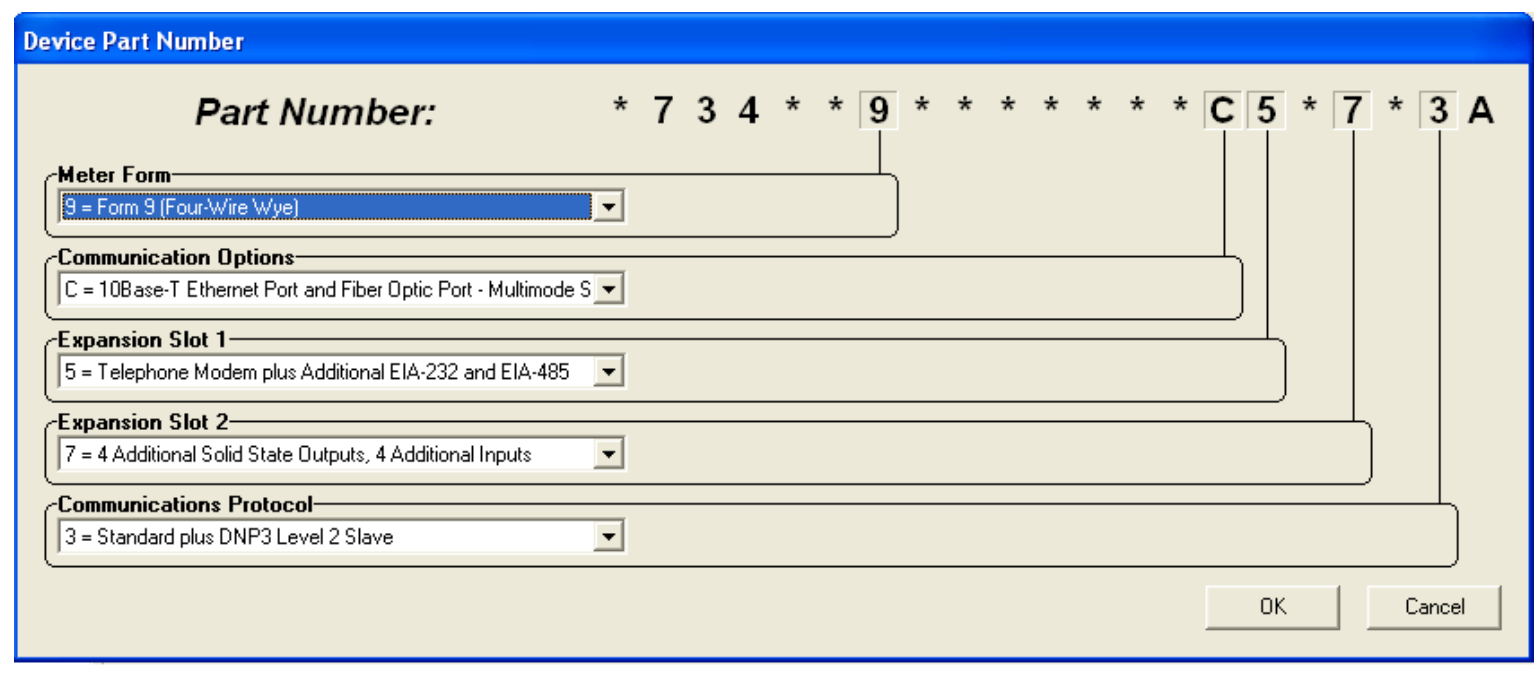

Figura A.18 - Janela Para Configuração do ‘Part Number’.

Finalmente, para enviar as configurações ao dispositivo deve-se clicar no ícone 'Send Active Settings - E', situado ou na tela principal ou no menu 'File'. Dessa maneira, as configurações ativas serão descarregadas no medidor e se tudo ocorrer bem, uma mensagem confirmará o sucesso da transferência. 
A essa altura, os dados programados para leitura já deverão estar armazenado na memória do dispositivo. Para fazer suas visualizações basta clicar no ícone 'Human Machine Interface - $₫$ ' localizado na tela principal e selecionar a entrada 'LDP - Load Profile Data' na árvore de configurações à esquerda. Conforme mostra a Figura A.19:

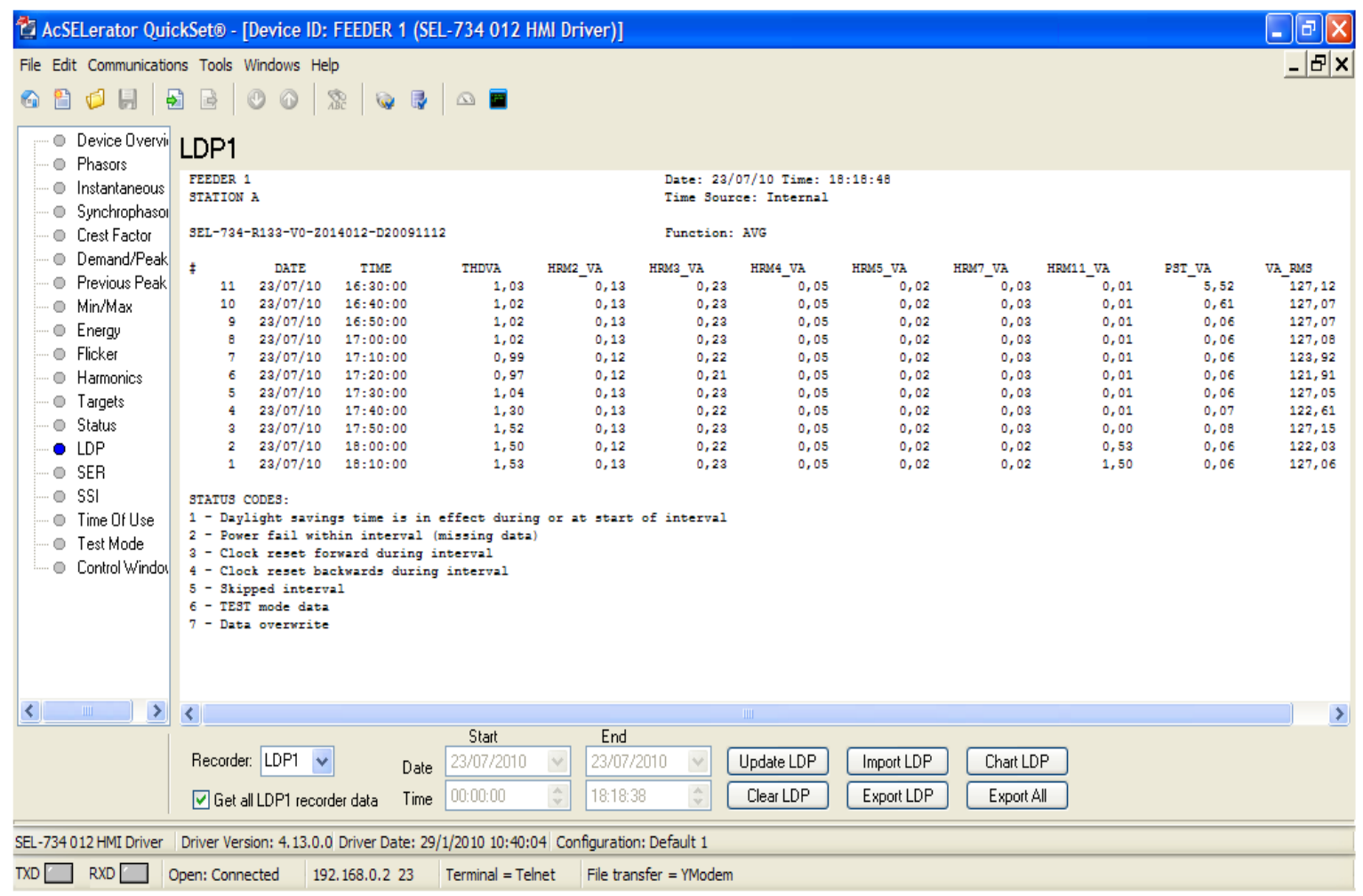

Figura A.19 - Janela do 'Load Profile Data'.

Contudo, o 'Load Profile Data' não permite fazer a leitura das grandezas relativas às variações de tensões e interrupções. Para esse propósito deve-se recorrer à entrada 'SSI - Sag/Swell/Interruption Report', que também se localiza na árvore de configurações da Figura A.19. 